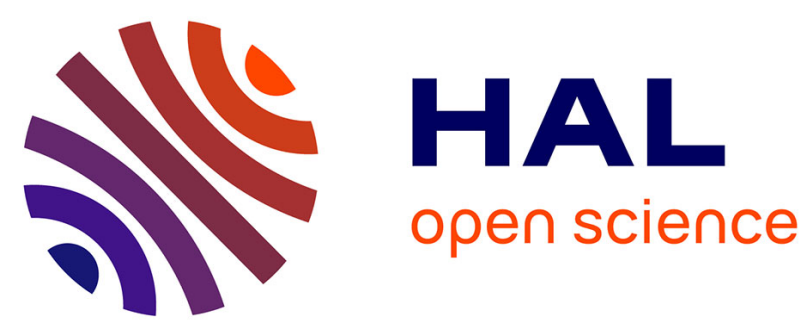

\title{
Multi-dimensional disaggregation of land surface temperature using high-resolution red, near-infrared, shortwave-infrared and microwave-L bands
}

Olivier Merlin, Frédéric Jacob, Jean Pierre Wigneron, Jeffrey P. Walker, Ghani Chehbouni

\section{To cite this version:}

Olivier Merlin, Frédéric Jacob, Jean Pierre Wigneron, Jeffrey P. Walker, Ghani Chehbouni. Multidimensional disaggregation of land surface temperature using high-resolution red, near-infrared, shortwave-infrared and microwave-L bands. IEEE Transactions on Geoscience and Remote Sensing, 2011, 50 (5), pp.1-34. 10.1109/TGRS.2011.2169802 . ird-00658468

\section{HAL Id: ird-00658468 \\ https://hal.ird.fr/ird-00658468}

Submitted on 10 Jan 2012

HAL is a multi-disciplinary open access archive for the deposit and dissemination of scientific research documents, whether they are published or not. The documents may come from teaching and research institutions in France or abroad, or from public or private research centers.
L'archive ouverte pluridisciplinaire HAL, est destinée au dépôt et à la diffusion de documents scientifiques de niveau recherche, publiés ou non, émanant des établissements d'enseignement et de recherche français ou étrangers, des laboratoires publics ou privés. 


\title{
- Multidimensional Disaggregation of Land Surface \\ Temperature Using High-Resolution Red, Near-Infrared, Shortwave-Infrared, and Microwave-L Bands
}

\author{
Olivier Merlin, Frédéric Jacob, Jean-Pierre Wigneron, Jeffrey Walker, and Ghani Chehbouni
}

6 Abstract-Land surface temperature data are rarely available 7 at high temporal and spatial resolutions at the same locations. To 8 fill this gap, the low spatial resolution data can be disaggregated 9 at high temporal frequency using empirical relationships between 10 remotely sensed temperature and fractional green (photosynthet11 ically active) and senescent vegetation covers. In this paper, a 12 new disaggregation methodology is developed by physically link13 ing remotely sensed surface temperature to fractional green and 14 senescent vegetation covers using a radiative transfer equation. 15 Moreover, the methodology is implemented with two additional 16 factors related to the energy budget of irrigated areas, being the 17 fraction of open water and soil evaporative efficiency (ratio of 18 actual to potential soil evaporation). The approach is tested over 19 a $5 \mathbf{~ k m}$ by $32 \mathbf{~ k m}$ irrigated agricultural area in Australia using 20 airborne Polarimetric L-band Multibeam Radiometer brightness 21 temperature and spaceborne Advanced Scanning Thermal 22 Emission and Reflection radiometer (ASTER) multispectral data. 23 Fractional green vegetation cover, fractional senescent vegeta24 tion cover, fractional open water, and soil evaporative efficiency 25 are derived from red, near-infrared, shortwave-infrared, and mi26 crowave-L band data. Low-resolution land surface temperature 27 is simulated by aggregating ASTER land surface temperature to $281-\mathrm{km}$ resolution, and the disaggregated temperature is verified 29 against the high-resolution ASTER temperature data initially used 30 in the aggregation process. The error in disaggregated tempera31 ture is successively reduced from $1.65{ }^{\circ} \mathrm{C}$ to $1.16{ }^{\circ} \mathrm{C}$ by includ32 ing each of the four parameters. The correlation coefficient and 33 slope between the disaggregated and ASTER temperatures are 34 improved from 0.79 to 0.89 and from 0.63 to 0.88 , respectively. 35 Moreover, the radiative transfer equation allows quantification of 36 the impact on disaggregation of the temperature at high resolution 37 for each parameter: fractional green vegetation cover is respon-

Manuscript received December 2, 2010; revised June 28, 2011; accepted September 11, 2011. This work was supported in part by the French program Terre-Océan-Surfaces-Continentales-Atmosphère and in part by the Centre National de la Recherche Scientifique. The National Airborne Field Experiments have been made possible through infrastructure (LE0453434 and LE0560930) and research (DP0557543) funding from the Australian Research Council and the collaboration of a large number of scientists from throughout Australia, U.S., and Europe. Initial setup and maintenance of the study catchments were funded by a research Grant (DP0343778) from the Australian Research Council and by the CRC for Catchment Hydrology.

O. Merlin is with the Centre d'Etudes Spatiales de la Biosphère (CESBIO), 31401 Toulouse, France (e-mail: olivier.merlin@cesbio.cnes.fr).

F. Jacob (e-mail: frederic.jacob@supagro.inra.fr).

J.-P. Wigneron (e-mail: jpwigner@bordeaux.inra.fr).

J. Walker (e-mail: jeff.walker@monash.edu).

G. Chehbouni (e-mail: ghani.chehbouni@cesbio.cnes.fr).

Color versions of one or more of the figures in this paper are available online at http://ieeexplore.ieee.org.

Digital Object Identifier 10.1109/TGRS.2011.2169802 sible for $\mathbf{4 2 \%}$ of the variability in disaggregated temperature, 38 fractional senescent vegetation cover for $\mathbf{1 1 \%}$, fractional open 39 water for $20 \%$, and soil evaporative efficiency for $27 \%$.

Index Terms-Advanced Scanning Thermal Emission and Re- 41 flection radiometer (ASTER), brightness temperature, disaggre- 42 gation, evaporative efficiency, land surface temperature, Moderate 43 Resolution Imaging Spectroradiometer (MODIS), multispectral, 44 open water, soil moisture, vegetation fraction.

\section{INTRODUCTION}

$\mathbf{R}$ EMOTELY sensed land surface temperature is a signature 47 of the thermodynamic equilibrium state of the surface 48 skin. Consequently, it provides the potential to monitor dy- 49 namic information on instantaneous energy and water fluxes 50 at the land-surface-atmosphere interface. Nevertheless, the op- 51 erational use of thermal remote sensing for hydrological and 52 water resource management studies has been limited to regional 53 scale applications (e.g., [1] and [2]) mainly because the spatial 54 resolution (larger than $1 \mathrm{~km}$ ) of current high temporal resolution 55 thermal sensors is too coarse to represent the heterogeneity of 56 man-made landscapes. For example, the Moderate Resolution 57 Imaging Spectroradiometer (MODIS) has a revisit frequency 58 of 1 or 2 times per day but a spatial resolution of only $1 \mathrm{~km}, 59$ while the Advanced Scanning Thermal Emission and Reflection 60 radiometer (ASTER) has a spatial resolution of $90 \mathrm{~m}$ but a 61 revisit time of only 16 days.

The use of remotely sensed land surface temperature over 63 agricultural areas requires data at both high spatial and temporal 64 resolutions [3]. While there is a lack of high spatial resolution 65 thermal data from satellite with high frequency, there is the 66 potential for land surface temperature derived from kilomet- 67 ric resolution sensors having high temporal resolution to be 68 disaggregated using high spatial resolution ancillary data. The 69 first disaggregation approach of remotely sensed temperature 70 was developed by [4] using the fractional green vegetation 71 cover derived from red and near-infrared reflectances. Given 72 the high temperature difference between bare soil and a well- 73 watered crop, this approach has proved to be effective over 74 areas with relatively uniform soil and vegetation hydric status. 75 Recently, [5] has extended the approach of [4] to conditions 76 where vegetation hydric status is heterogeneous. This required 77 developing a methodology to estimate the fraction of senescent 78 vegetation cover from a time series of FORMOSAT-2 images. 79 
80 The accuracy in disaggregated temperature was improved by 81 taking into account fractional senescent vegetation cover in 82 addition to fractional green vegetation cover.

83 Fractional green and senescent vegetation covers, however, 84 are not the only factors explaining the spatial variations of land 85 surface temperature, especially over irrigated areas where crop 86 fields may have different moisture status to the surrounds. In 87 particular, the temperature over a flooded crop field may be 88 drastically different from the temperature over a mature crop 89 field. Therefore, the fraction of open water is an important 90 variable to represent the spatial variations of land surface tem91 perature. Over nonwatered land surfaces, the soil evaporative 92 efficiency (ratio of actual to potential soil evaporation) is a 93 signature of the capacity of the soil to evaporate its water 94 content in the near surface and thus to counter an increase of 95 its thermodynamic temperature. Consequently, soil evaporative 96 efficiency is also an essential variable to describe the spatial 97 variations of land surface temperature. Moreover, knowledge 98 of soil evaporative efficiency is needed to decouple the effects 99 of soil and vegetation hydric status on the surface energy 100 budget and hence to better represent the resultant radiative 101 surface temperature. As an example, the crop water stress index 102 (CWSI) [6], [7] can be used to detect plant stress based on the 103 difference between foliage and air temperature. Nevertheless, 104 the application of the CWSI to partially vegetated areas is 105 subjected to large uncertainties because the soil background 106 may have a different temperature to the plants [7] depending 107 on soil evaporative efficiency. Another example is provided by 108 Moran et al. [8] who proposed the vegetation index/temperature 109 (VIT) trapezoid to estimate a most probable range of plant 110 stress over partially vegetated fields. It is a three-step procedure 111 in which the following steps are performed: 1) the temperatures 112 of the four vertices of the VIT trapezoid are estimated using an 113 energy budget model; 2) the minimum and maximum probable 114 vegetation temperatures are estimated from the measured com115 posite land surface temperature, together with the maximum 116 and minimum simulated soil temperatures; and 3) the minimum 117 and maximum probable CWSIs are computed by normalizing 118 the minimum and maximum probable vegetation temperatures 119 from the vegetation temperature extremes simulated by the 120 energy budget model. The point is that this approach does not 121 allow estimating a single CWSI value because the retrieval 122 problem is underdetermined. In particular, Moran et al. [8] 123 noted that "with knowledge of a second point within the 124 hourglass (perhaps soil temperature), it would be possible to 125 infer [the canopy-air temperature] difference and pinpoint the 126 CWSI value." In the latter case, knowledge of soil temperature 127 is equivalent to knowledge of soil evaporative efficiency, which 128 would remove the underdetermination of the VIT trapezoid.

129 The objective of this paper is to develop a new disaggrega130 tion methodology of kilometric land surface temperature using 131 hectometric multivariable ancillary data. The approach is based 132 on a radiative transfer equation that estimates differences in 133 temperature data at hectometric resolution. Specifically, the use 134 of a radiative transfer equation allows the following: 1) includ135 ing variables other than those used by previous disaggregation 136 approaches and 2) deducing the most pertinent variables. In 137 addition to fractional green and senescent vegetation covers, the new methodology includes the variability at hectometric reso- 138 lution of fractional open water and soil evaporative efficiency. 139 With respect to other disaggregation algorithms in literature 140 [4], [5], the proposed technique differs in the following four 141 main aspects: 1) it relies on a physically based radiative transfer 142 equation rather than empirical linear regressions; 2) it takes 143 into account the fractional open water derived from shortwave- 144 infrared band as required; 3) it takes into account the soil hydric 145 status via microwave-derived soil evaporative efficiency; and 146 4) it allows the relative weight of each parameter used for 147 disaggregating temperature to be quantified.

148

The new disaggregation technique is compared to the ex- 149 isting approaches using data collected during the National 150 Airborne Field Experiment in 2006 (NAFE'06; [9]). The ex- 151 perimental site covers a $5 \mathrm{~km}$ by $32 \mathrm{~km}$ irrigated agricultural 152 area, which included approximately 5\% of flooded rice crops 153 during NAFE'06. Disaggregation algorithms are first tested by 154 aggregating ASTER temperature at $1-\mathrm{km}$ resolution and by 155 comparing the disaggregated temperature to the high-resolution 156 ASTER temperature initially used in the aggregation process. 157 The application to aggregated ASTER data allows evaluating 158 approaches independently of differences between ASTER and 159 MODIS products [5]. Disaggregation algorithms are then ap- 160 plied to MODIS data.

\section{EXPERIMENTAL DATA}

162

The study area is a $5 \mathrm{~km}$ by $32 \mathrm{~km}$ area included in the 163 Coleambally Irrigation Area (CIA) located in the flat west- 164 ern plains of the Murrumbidgee catchment in southeastern 165 Australia $\left(35^{\circ} \mathrm{S}, 146^{\circ} \mathrm{E}\right)$. The principal summer crops grown 166 in the CIA are rice, maize, and soybeans, while winter crops 167 include wheat, barley, oats, and canola. In November, rice crops 168 are flooded under $30 \mathrm{~cm}$ height of irrigation water.

The NAFE'06 was conducted from October 31 to 170 November 20, 2006, over a $40 \mathrm{~km}$ by $60 \mathrm{~km}$ area, with more 171 detailed flights over the $5 \mathrm{~km}$ by $32 \mathrm{~km}$ focus area studied 172 in this paper. While a full description of the NAFE'06 data 173 set is given in [9], a brief overview of the most pertinent 174 details is provided here. The data used in this paper are 175 comprised of airborne L-band brightness temperature; ASTER 176 red, near-infrared, and shortwave-infrared reflectances; ASTER 177 land surface temperature data (resampled at 250-m resolution); 178 MODIS land surface temperature data; and air temperature data 179 collected by a meteorological station in the NAFE'06 area.

\section{A. PLMR}

The Polarimetric L-band Multibeam Radiometer (PLMR) is 182 an airborne instrument that measures both $\mathrm{H}$ and $\mathrm{V}$ polariza- 183 tions using a single receiver with polarization switching at view 184 angles of $\pm 7^{\circ}, \pm 21.5^{\circ}$, and $\pm 38.5^{\circ}$. The accuracy of the PLMR 185 is estimated to be better than $2 \mathrm{~K}$ and $3 \mathrm{~K}$ in the $\mathrm{H}$ and $\mathrm{V} 186$ polarization, respectively [10].

During NAFE'06, the PLMR flew on November 14 to collect 188 L-band brightness temperature at 250-m resolution over the 189 $5 \mathrm{~km}$ by $32 \mathrm{~km}$ area in the CIA. PLMR was mounted in the 190 across-track configuration so that each pixel was observed at a 191 
192 given incidence angle (approximately $7^{\circ}, 21.5^{\circ}$, or $38.5^{\circ}$ ). Data 193 were processed for incidence angle and beam location on the 194 ground by taking into account aircraft position, attitude, and 195 ground topography.

196 As the sensitivity to soil moisture is higher for H-polarized 197 brightness temperature than for V-polarized brightness temper198 ature, only the $\mathrm{H}$-polarized brightness temperature $T B$ is used 199 in this paper. Preprocessing of $T B$ consists of the following: 200 1) resampling H-polarized PLMR data at 250-m resolution 201 on a grid that matches in symmetry to the flight lines over 202 the $5 \mathrm{~km}$ by $32 \mathrm{~km}$ area and 2) converting the resampled $203 T B$ to an equivalent value at $21.5^{\circ}$ incidence angle. The in204 cidence angle $21.5^{\circ}$ is chosen to minimize conversion errors. 205 The angular conversion involves the brightness temperature 206 collected by inner beams at approximately $7^{\circ}$ incidence angle 207 being multiplied by the ratio $\overline{T B_{\mathrm{MB}}} / \overline{T B_{\mathrm{IB}}}$, with $\overline{T B_{\mathrm{MB}}}$ and $208 \overline{T B_{\text {IB }}}$ being the mean brightness temperatures collected by the 209 middle and inner beams, respectively. Similarly, the brightness 210 temperature collected by the outer beams at approximately $21138.5^{\circ}$ incidence angle is multiplied by the ratio $\overline{T B_{\mathrm{MB}}} / \overline{T B_{\mathrm{OB}}}$, 212 with $\overline{T B_{\mathrm{OB}}}$ being the mean brightness temperature collected by 213 the outer beams. Mean brightness temperatures $\overline{T B_{\mathrm{IB}}}, \overline{T B_{\mathrm{MB}}}$, 214 and $\overline{T B_{\mathrm{OB}}}$ are computed as the average (for all flight lines) 215 of the $T B$ collected by the beams pointing at $\pm 7^{\circ}, \pm 21.5^{\circ}$, 216 and $\pm 38.5^{\circ}$, respectively. This technique was already used in 217 [11] to generate $T B$ images by assuming that the impact of 218 soil moisture and biomass on the angular dependance of TB is 219 negligible or small. In this paper, a slightly different approach 220 is adopted to take into account the variations in aircraft attitude 221 during data collection, which made the incidence angle $\theta$ os222 cillate around $7^{\circ}, 21.5^{\circ}$, and $38.5^{\circ}$. The brightness temperature $223 T B(\theta)$ observed at the incidence angle $\theta$ is multiplied by the 224 ratio $\overline{T B_{\mathrm{MB}}} / \overline{T B_{\text {interp }}(\theta)}$, with $\overline{T B_{\text {interp }}(\theta)}$ being the mean 225 brightness temperature linearly interpolated at $\theta$ incidence an226 gle from the mean data collected by the inner, middle, and outer 227 beams.

\section{B. ASTER}

229 The ASTER instrument was launched in 1999 aboard Terra, a 230 sun synchronous platform with 11:00 UTC descending Equator 231 crossing and a 16-day revisit cycle. An ASTER scene covers an 232 area of approximately $60 \mathrm{~km}$ by $60 \mathrm{~km}$ and consists of 14 nadir233 looking bands and one oblique-looking band to create stereo234 based digital elevation models. The three nadir-looking bands 235 in the visible and near infrared have a $15-\mathrm{m}$ resolution. The six 236 bands in the shortwave-infrared have a 30-m resolution. Finally, 237 there are five thermal infrared bands with a 90-m resolution.

238 The ASTER overpass of the NAFE'06 site was on 239 November 16, 2006. Official ASTER products [12] were used 240 here for surface reflectance (AST_07) and radiometric temper241 ature (AST_08) with accuracies of 5\% and $1.5 \mathrm{~K}$, respectively 242 [13]-[19]. They were downloaded from the Earth Observing 243 System Data Gateway (EDG).

244 ASTER 15-m resolution red (B2) and near-infrared (B3) 245 bands were extracted over the $5 \mathrm{~km}$ by $32 \mathrm{~km}$ area and re246 sampled at 250-m resolution to match the spatial resolution 247 and extent of PLMR observations. The ASTER 30-m resolution
B5 band $(1.60-1.70 \mu \mathrm{m})$ was extracted over the $5 \mathrm{~km}$ by 248 $32 \mathrm{~km}$ study area and resampled at 50-m resolution. Fractional 249 open water was estimated using B5 band [20] based on a 250 threshold method. Consequently, B5 data were resampled at 251 a resolution finer than that $(250 \mathrm{~m})$ of PLMR data to classify 252 open water pixels at 50-m resolution and to obtain fractional 253 open water at 250-m resolution from the binary classification. 254 ASTER 90-m resolution radiometric temperature was extracted 255 over the $5 \mathrm{~km}$ by $32 \mathrm{~km}$ area and aggregated at 250-m res- 256 olution to match the spatial resolution and extent of PLMR 257 observations. Aggregation was achieved by linearly averaging 258 high-resolution surface temperatures, i.e., without accounting 259 for the nonlinear relationship between physical temperature and 260 radiance. This choice was motivated by the results of [21], 261 which compared the temperature aggregated using different 262 scaling approaches and obtained very low differences (maxi- 263 mum difference of $0.2^{\circ} \mathrm{C}$ ).

The MODIS/Terra data were collected concurrently with 266 ASTER data. MODIS official products consisted of the 928-m 267 resolution surface skin temperature (MOD11-L2) retrieved by 268 the "generalized split window" algorithm [22]-[24] and reg- 269 istered in the sinusoidal projection. The MODIS Reprojection 270 Tool was used to project MOD11-L2 data in UTM WGS 1984271 $55 \mathrm{~S}$ with a sampling interval of $1 \mathrm{~km}$.

272

In this paper, the disaggregation of 1-km MODIS tempera- 273 ture is evaluated using high-resolution ASTER data. To distin- 274 guish the errors associated with the disaggregation technique 275 and the errors associated with the discrepancy between MODIS 276 and ASTER temperature products, a comparison is made be- 277 tween ASTER and MODIS data at $1-\mathrm{km}$ resolution over the 278 $5 \mathrm{~km}$ by $32 \mathrm{~km}$ study area. The ASTER data are aggregated 279 at the MODIS spatial resolution $(1 \mathrm{~km})$ by linearly averaging 280 high-resolution temperatures. The root-mean-square difference 281 (RMSD), bias, correlation coefficient, and slope of the linear 282 regression between MODIS and aggregated ASTER data are 283 $2.7{ }^{\circ} \mathrm{C},-2.3{ }^{\circ} \mathrm{C}, 0.75$, and 0.52 , respectively. The discrepancy 284 between MODIS and ASTER data, which is mainly explained 285 here by a significant bias and a relatively low slope of the linear 286 regression, is on the same order of magnitude as the mean 287 difference (about $3{ }^{\circ} \mathrm{C}$ ) reported in literature [5], [21], [25].

288

\section{Disaggregation Algorithms}

This paper aims to compare different approaches for dis- 290 aggregating kilometric MODIS land surface temperature data. 291 The study uses aggregated ASTER and real MODIS data 292 and demonstrates the disaggregation at 250-m resolution. The 293 resolution of $250 \mathrm{~m}$ is chosen to match with the lowest reso- 294 lution at which ancillary data composed of red, near-infrared, 295 shortwave-infrared, and microwave-L bands are available. In 296 this case study, the target scale is determined by the resolution 297 $(250 \mathrm{~m})$ of airborne microwave data.

298

As shown in the schematic diagram of Fig. 1, the disaggre- 299 gation algorithms are noted as $D k$, with $k$ being the number 300 of factors taken into account in the disaggregation. The new 301 


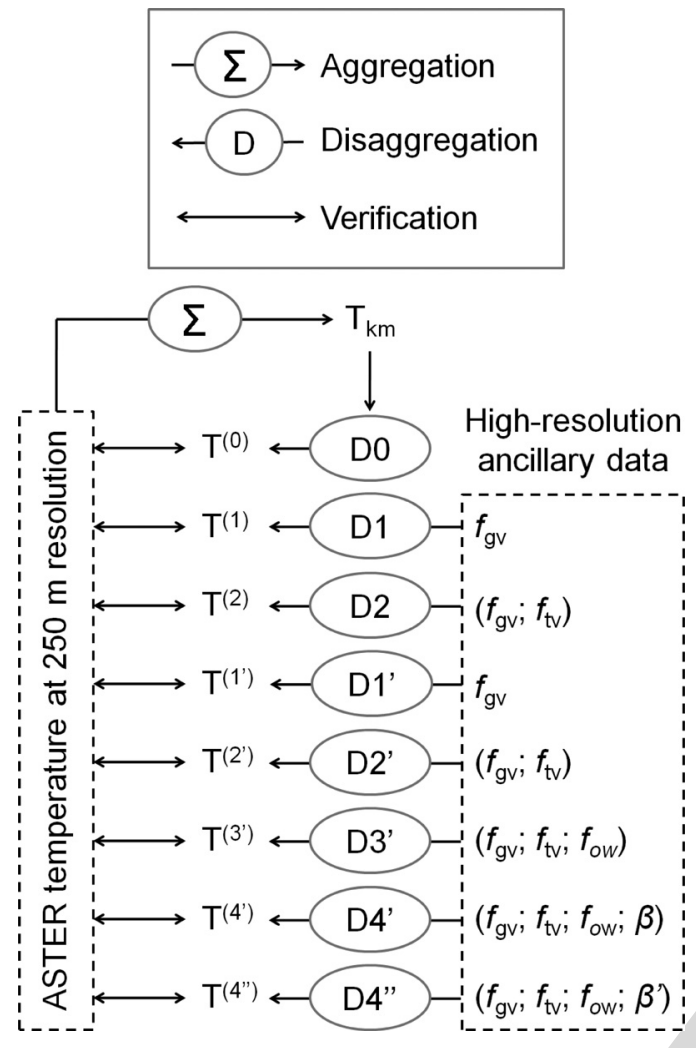

Fig. 1. Schematic diagram presenting the different disaggregation algorithms of kilometric temperature $T_{\mathrm{km}}$ and the verification strategy at high $(250 \mathrm{~m})$ resolution.

302 algorithms are noted as $\mathrm{Dk}^{\prime}$. D0 does not use any ancillary 303 data, while D1 is based on a linear regression between land 304 surface temperature and fractional green (photosynthetically 305 active) vegetation cover. Fractional green vegetation cover $f_{\mathrm{gv}}$ 306 is defined as the surface area of green vegetation per unit area 307 of soil. D1 is the same as in [4]. D2 is based on D1 but 308 takes into account both fractional green and total vegetation 309 covers. Fractional vegetation cover $f_{\mathrm{tv}}$ is defined as the total 310 surface area of (green plus senescent) vegetation per unit area 311 of soil. D2 is the same as in [5]. The new algorithms D1', $312 \mathrm{D} 2^{\prime}, \mathrm{D} 3^{\prime}$, and $\mathrm{D} 4^{\prime}$ (and $\mathrm{D} 4^{\prime \prime}$ ) are all derived from a radiative 313 transfer equation. The four algorithms differ with regard to the 314 number of factors which are explicitly taken into account. D1' 315 includes the variability of $f_{\mathrm{gv}}$ and is thus a substitute for D1 316 based on radiative transfer. D2 $2^{\prime}$ includes the variability of both $317 f_{\mathrm{gv}}$ and $f_{\mathrm{tv}}$ and is thus a substitute for $\mathrm{D} 2$ based on radiative 318 transfer. The other algorithms D ${ }^{\prime}$ and $\mathrm{D} 4^{\prime}$ integrate additional 319 variables. D $3^{\prime}$ includes the variability of $f_{\mathrm{gv}}, f_{\mathrm{tv}}$, and fractional 320 open water $f_{\text {ow }}$. D 4 ' includes the variability of $f_{\mathrm{gv}}, f_{\mathrm{tv}}, f_{\mathrm{ow}}$, 321 and soil evaporative efficiency (ratio of actual to potential soil 322 evaporation) $\beta$. D $4^{\prime \prime}$ is the same as $\mathrm{D} 4^{\prime}$ but with a different 323 formulation for soil evaporative efficiency.

324 D0 sets the disaggregated temperature as

$$
T^{(0)}=T_{\mathrm{km}}
$$

325 with $T_{\mathrm{km}}$ being the land surface temperature observed at kilo326 metric resolution.
Using D1, the disaggregated temperature is computed as

$$
T^{(1)}=T_{\mathrm{km}}+\mathbf{a}_{\mathbf{1}} \times\left(f_{\mathrm{gv}}-\left\langle f_{\mathrm{gv}}\right\rangle_{\mathrm{km}}\right)
$$

with $f_{\mathrm{gv}}$ being the fractional green vegetation cover derived at 328 high resolution, $\left\langle f_{\mathrm{gv}}\right\rangle_{\mathrm{km}}$ being the $f_{\mathrm{gv}}$ aggregated at kilometric 329 resolution, and $\mathbf{a}_{\mathbf{1}}$ being the slope of the linear regression 330 between $T_{\mathrm{km}}$ and $\left\langle f_{\mathrm{gv}}\right\rangle_{\mathrm{km}}$. Note that the variables defined at 331 kilometric resolution are noted with the subscript $\mathrm{km}$.

Using D2, the disaggregated temperature is computed as

$$
T^{(2)}=T_{\mathrm{km}}+\mathbf{a}_{\mathbf{1}}^{\text {proj }} \times\left(f_{\mathrm{gv}}^{\text {proj }}-\left\langle f_{\mathrm{gv}}\right\rangle_{\mathrm{km}}\right)
$$

with $f_{\mathrm{gv}}^{\text {proj }}$ being the projected $f_{\mathrm{gv}}$ and $\mathbf{a}_{1}^{\text {proj }}$ being the slope 334 of the linear regression between $T_{\mathrm{km}}$ and the projected $f_{\mathrm{gv}}$ es- 335 timated at kilometric resolution $f_{\mathrm{gv}, \mathrm{km}}^{\mathrm{proj}}$. Note that the variables 336 defined at the image scale are written in bold. The notion of 337 a "projected variable" was introduced in [26]. It is a robust 338 tool that strenghtens the correlation between two variables by 339 representing the dependence of these variables on other addi- 340 tional variables. In [5], the projection technique was applied 341 to fractional green vegetation cover to artificially improve the 342 spatial correlation between $T$ and $f_{\mathrm{gv}}$ by taking into account 343 the dependence of $T$ on $f_{\mathrm{tv}}$. The projected fractional green 344 vegetation cover is computed as

$$
f_{\mathrm{gv}}^{\mathrm{proj}}=f_{\mathrm{gv}}-\frac{\mathbf{T}_{\mathbf{f c s v}}-\left(\mathbf{T}_{\mathbf{b}, \mathbf{d s}}+\mathbf{T}_{\mathbf{b}, \mathbf{w s}}\right) / 2}{\mathbf{T}_{\mathbf{f c s v}}-\mathbf{T}_{\mathbf{f c g v}}} \times\left(f_{\mathrm{tv}}-\left\langle f_{\mathrm{tv}}\right\rangle_{\mathrm{km}}\right)
$$

with $f_{\mathrm{tv}}$ being the fractional total vegetation cover derived at 346 high resolution, $\left\langle f_{\mathrm{tv}}\right\rangle_{\mathrm{km}}$ being the $f_{\mathrm{tv}}$ aggregated at kilomet- 347 ric resolution, $\mathbf{T}_{\mathbf{b} \text {,ws }}$ being the temperature of wet bare soil, 348 $\mathbf{T}_{\mathbf{b}, \mathbf{d s}}$ being the temperature of dry bare soil, $\mathbf{T}_{\mathbf{f c g v}}$ being the 349 temperature of full-cover green vegetation, and $\mathbf{T}_{\text {fcsv }}$ being 350 the temperature of full-cover senescent vegetation (notations 351 are summarized in Table I). Following the interpretation of 352 the "triangle method" [27], $\mathbf{T}_{\mathbf{b}, \mathbf{w s}}, \mathbf{T}_{\mathbf{b}, \mathbf{d s}}, \mathbf{T}_{\mathbf{f c g v}}$, and $\mathbf{T}_{\mathbf{f c s v}} 353$ correspond to the minimum and maximum soil and vegetation 354 temperatures within the study area, respectively. It is reminded 355 that $f_{\mathrm{tv}}=f_{\mathrm{gv}}+f_{\mathrm{sv}}$, with $f_{\mathrm{gv}}$ and $f_{\mathrm{sv}}$ being the fractional 356 green and senescent vegetation covers, respectively.

In (4), the projected fractional green vegetation cover esti- 358 mated at kilometric resolution is

$$
\begin{aligned}
& f_{\mathrm{gv}, \mathrm{km}}^{\mathrm{proj}}=\left\langle f_{\mathrm{gv}}\right\rangle_{\mathrm{km}}-\frac{\mathbf{T}_{\mathrm{fcsv}}-\left(\mathbf{T}_{\mathbf{b}, \mathrm{ds}}+\right.}{\left.\mathbf{T}_{\mathbf{b}, \mathbf{w s}}\right) / 2} \\
& \mathbf{T}_{\mathbf{f c s v}}- \mathbf{T}_{\mathbf{f c g v}} \\
& \times\left(\left\langle f_{\mathrm{tv}}\right\rangle_{\mathrm{km}}-\mathbf{f}_{\mathbf{t v}}\right)
\end{aligned}
$$

with $\mathbf{f}_{\mathbf{t v}}$ being the mean $f_{\mathrm{tv}}$ over the whole study area.

The new algorithms $\mathrm{D}^{\prime}$ use a radiative transfer equation 361 to model the spatial variability of disaggregated temperature 362 within each 1-km resolution pixel, using ancillary data avail- 363 able at high resolution such as $f_{\mathrm{gv}}, f_{\mathrm{tv}}, f_{\mathrm{ow}}$, and $\beta$. $\mathrm{D} 1^{\prime}$ is 364 a substitute for D1 based on radiative transfer. It expresses 365 disaggregated temperature as

366

$$
T^{\left(1^{\prime}\right)}=T_{\mathrm{km}}+\Delta T^{\left(1^{\prime}\right)}
$$


TABLE I

INTERPRETATION OF THE VERTICES IN THE GENERALIZED "TriANGLE APPROACH"

\begin{tabular}{|c||c|c|c|}
\hline Vertex & Surface type & Near-surface soil hydric status & Abbreviation \\
\hline A & Bare soil & Dry & b,ds \\
B & Bare soil & Wet & b,ws \\
C & Full-cover green vegetation & Wet or dry & fcgv \\
C $^{\prime}$ & Full-cover green vegetation & Wet & fcgv,ws \\
C $^{\prime \prime}$ & Full-cover green vegetation & Dry & fcgv,ds \\
D & Full-cover senescent vegetation & Wet or dry & fcsv \\
D $^{\prime}$ & Full-cover senescent vegetation & Dry & fcsv,ds \\
\hline
\end{tabular}

367 with $\Delta T^{\left(1^{\prime}\right)}$ being the difference between the temperature 368 simulated using high-resolution $f_{\mathrm{gv}}$ and that aggregated within 369 the $1-\mathrm{km}$ resolution pixel

$$
\begin{aligned}
\Delta T^{\left(1^{\prime}\right)}= & T_{\bmod }\left(f_{\mathrm{gv}},\left\langle f_{\mathrm{tv}}\right\rangle_{\mathrm{km}},\left\langle f_{\mathrm{ow}}\right\rangle_{\mathrm{km}},\langle\beta\rangle_{\mathrm{km}}\right) \\
& -\left\langle T_{\bmod }\left(f_{\mathrm{gv}},\left\langle f_{\mathrm{tv}}\right\rangle_{\mathrm{km}},\left\langle f_{\mathrm{ow}}\right\rangle_{\mathrm{km}},\langle\beta\rangle_{\mathrm{km}}\right)\right\rangle_{\mathrm{km}}
\end{aligned}
$$

370 with $T_{\text {mod }}$ being the land surface temperature simulated by 371 a radiative transfer equation. In (7), fractional total vegetation 372 cover, fractional open water, and soil evaporative efficiency 373 are set to their values aggregated at kilometric resolution. 374 Therefore, only the variability of $f_{\mathrm{gv}}$ is taken into account at 375 high resolution.

376 D2 ${ }^{\prime}$ is a substitute for D2 based on radiative transfer. It 377 expresses the disaggregated temperature as in (6), with the 378 simulated temperature difference $\Delta T^{\left(2^{\prime}\right)}$ written as

$$
\begin{aligned}
\Delta T^{\left(2^{\prime}\right)}=T_{\bmod } & \left(f_{\mathrm{gv}}, f_{\mathrm{tv}},\left\langle f_{\mathrm{ow}}\right\rangle_{\mathrm{km}},\langle\beta\rangle_{\mathrm{km}}\right) \\
- & \left\langle T_{\bmod }\left(f_{\mathrm{gv}}, f_{\mathrm{tv}},\left\langle f_{\mathrm{ow}}\right\rangle_{\mathrm{km}},\langle\beta\rangle_{\mathrm{km}}\right)\right\rangle_{\mathrm{km}}
\end{aligned}
$$

379 D3' is derived from the same radiative transfer equation and 380 includes the variability of $f_{\mathrm{gv}}, f_{\mathrm{tv}}$, and $f_{\mathrm{ow}}$ at high resolution. 381 It determines the disaggregated temperature using (6) but with 382 the simulated temperature difference $\Delta T^{\left(3^{\prime}\right)}$ written as

$$
\begin{aligned}
\Delta T^{\left(3^{\prime}\right)}=T_{\mathrm{mod}}\left(f_{\mathrm{gv}}, f_{\mathrm{tv}}, f_{\mathrm{ow}},\langle\beta\rangle_{\mathrm{km}}\right) & \\
& -\left\langle T_{\mathrm{mod}}\left(f_{\mathrm{gv}}, f_{\mathrm{tv}}, f_{\mathrm{ow}},\langle\beta\rangle_{\mathrm{km}}\right)\right\rangle_{\mathrm{km}} .
\end{aligned}
$$

$383 \mathrm{D}^{\prime}$ is derived from the same radiative transfer equation and 384 includes the variability of $f_{\mathrm{gv}}, f_{\mathrm{tv}}, f_{\mathrm{ow}}$, and $\beta$ at high resolu385 tion. It determines the disaggregated temperature using (6) but 386 with the simulated temperature difference $\Delta T^{\left(4^{\prime}\right)}$ written as

$$
\begin{aligned}
\Delta T^{\left(4^{\prime}\right)}=T_{\mathrm{mod}}\left(f_{\mathrm{gv}}, f_{\mathrm{tv}}\right. & \left., f_{\mathrm{ow}}, \beta\right) \\
& -\left\langle T_{\bmod }\left(f_{\mathrm{gv}}, f_{\mathrm{tv}}, f_{\mathrm{ow}}, \beta\right)\right\rangle_{\mathrm{km}} .
\end{aligned}
$$

$387 \mathrm{D} 4^{\prime \prime}$ is an extension of (10) to replace $\beta$ by another formula388 tion of soil evaporative efficiency noted as $\beta^{\prime}$.

389 The high- to low-resolution simulated temperature difference 390 in (7)-(10) is computed using a linearized radiative transfer 391 equation [5], [28], [29]. Modeled land surface temperature $392 T_{\bmod }$ is written as

$$
T_{\text {mod }}=f_{\text {ow }} T_{\text {ow }}+\left(1-f_{\text {ow }}\right) T_{\text {nw }}
$$

393 with $T_{\text {ow }}$ being the surface temperature of a water body and $394 T_{\text {nw }}$ being the skin temperature of a nonwatered land surface.
Nonwatered land surface temperature is expressed as

$$
T_{\mathrm{nw}}=f_{\mathrm{gv}} \mathbf{T}_{\mathrm{fcgv}}+\left(f_{\mathrm{tv}}-f_{\mathrm{gv}}\right) \mathbf{T}_{\mathrm{fcsv}}+\left(1-f_{\mathrm{tv}}\right) T_{\mathrm{bs}}
$$

with $\mathbf{T}_{\mathbf{f c g v}}$ and $\mathbf{T}_{\mathbf{f c s v}}$ being the temperature of full-cover green 396 and senescent vegetations, respectively, and $T_{\mathrm{bs}}$ being the bare 397 soil temperature. With the soil evaporative efficiency defined 398 [30] as

$$
\beta=\frac{\mathbf{T}_{\mathbf{b}, \mathbf{d s}}-T_{\mathrm{bs}}}{\mathbf{T}_{\mathbf{b}, \mathbf{d s}}-\mathbf{T}_{\mathbf{b}, \mathbf{w s}}}
$$

the bare soil temperature can be expressed as

$$
T_{\mathrm{bs}}=\beta \mathbf{T}_{\mathbf{b}, \mathbf{w s}}+(1-\beta) \mathbf{T}_{\mathbf{b}, \mathbf{d s}}
$$

By assuming that water temperature is close to well-watered 401 green vegetation [27], modeled land surface temperature 402 becomes

$$
T_{\text {mod }}=f_{\text {ow }} \mathbf{T}_{\text {fcgv }}+\left(1-f_{\text {ow }}\right) T_{\text {nw }}
$$

with the nonwatered land surface temperature expressed as

$T_{\mathrm{nw}}=f_{\mathrm{gv}} \mathbf{T}_{\mathrm{fcgv}}+\left(f_{\mathrm{tv}}-f_{\mathrm{gv}}\right) \mathbf{T}_{\mathrm{fcsv}}$

$$
+\left(1-f_{\mathrm{tv}}\right)\left[\beta \mathbf{T}_{\mathbf{b}, \mathbf{w s}}+(1-\beta) \mathbf{T}_{\mathbf{b}, \mathbf{d s}}\right] .
$$

The temperature extremes $\mathbf{T}_{\mathbf{b}, \mathbf{d s}}, \mathbf{T}_{\mathbf{b}, \mathbf{w s}}, \mathbf{T}_{\mathbf{f c g v}}$, and $\mathbf{T}_{\mathbf{f c s v}}$ are 405 extrapolated (according to Section V) from low-resolution land 406 surface temperatures using high-resolution ancillary data [5]. 407

\section{DERIVATION OF BIOPHYSICAL VARIABLES}

The four variables used by the disaggregation methodol- 409 ogy are the following: fractional green vegetation cover $f_{\mathrm{gv}}, 410$ fractional total (green plus senescent) vegetation cover $f_{\mathrm{tv}}, 411$ fractional open water $f_{\text {ow }}$, and soil evaporative efficiency $\beta .412$ All of these variables are estimated from ASTER red, near- 413 infrared, and shortwave-infrared reflectance products and from 414 the PLMR H-polarized brightness temperature converted at an 415 incidence angle of $21.5^{\circ}$.

\section{A. Fractional Green Vegetation Cover}

Fractional green vegetation cover can be estimated from the 418 Normalized Difference Vegetation Index (NDVI) as in [31] 419

$$
f_{\mathrm{gv}}=\frac{\mathrm{NDVI}-\mathbf{N D V I}_{\mathbf{b s}}}{\mathbf{N D V I}_{\mathbf{f c g v}}-\mathbf{N D V I}_{\mathbf{b s}}}
$$




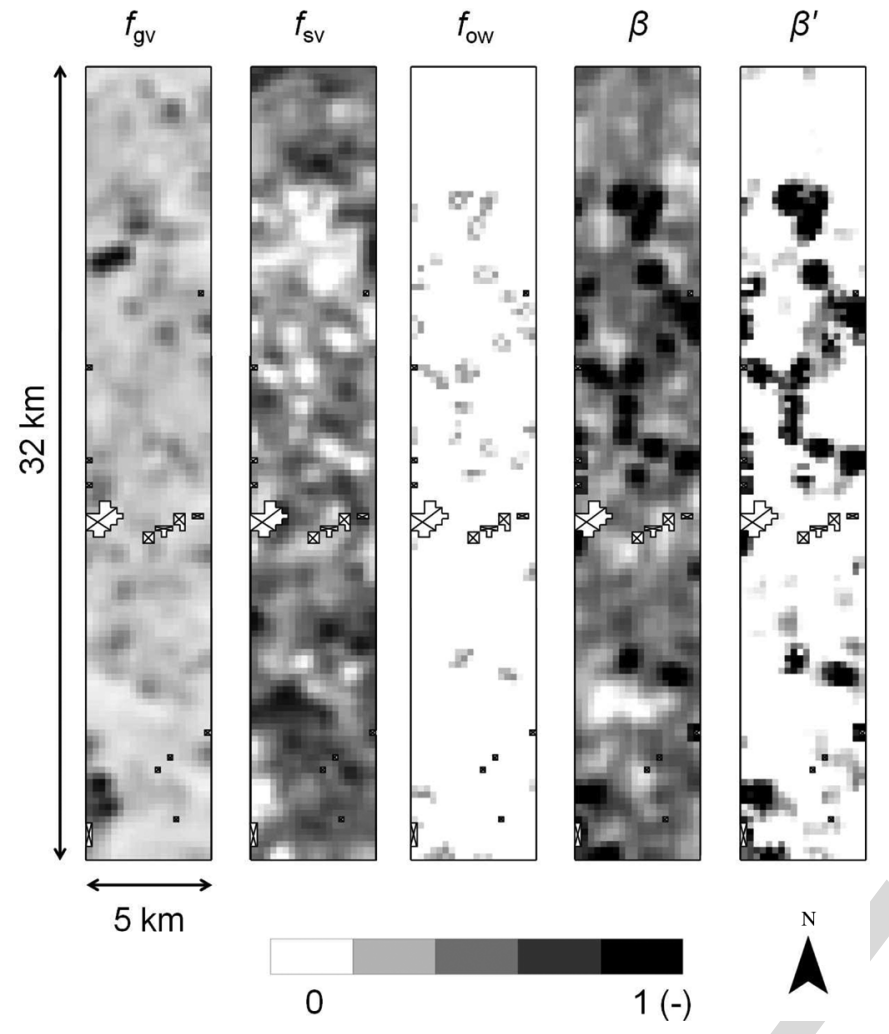

Fig. 2. Images of fractional green vegetation cover $f_{\mathrm{gv}}$, fractional senescent vegetation cover $f_{\mathrm{sv}}=f_{\mathrm{tv}}-f_{\mathrm{gv}}$, fractional open water $f_{\mathrm{ow}}$, soil evaporative efficiency $\beta$, and soil evaporative efficiency $\beta^{\prime}$. Note that $2 \%$ of the $5 \mathrm{~km}$ by $32 \mathrm{~km}$ area is contaminated by clouds and cloud shadow. Contaminated $250-\mathrm{m}$ resolution pixels are represented by crossed-out surfaces.

420 with $\mathbf{N D V I}_{\text {bs }}$ and $\mathbf{N D V I}_{\text {fcgv }}$ being the NDVI over bare 421 soil and full-cover green vegetation, respectively. NDVI is 422 computed as the difference between near-infrared and red bands 423 divided by their sum. The spatial variation of fractional green 424 vegetation cover over the study area is shown in Fig. 2.

\section{B. Fractional Total (Green Plus Senescent) Vegetation Cover}

426 Fractional total vegetation cover is estimated by correlating $427 f_{\mathrm{tv}}$ with surface albedo for green vegetation and by setting $f_{\mathrm{tv}}$ 428 to the maximum $f_{\mathrm{gv}}$ for senescent vegetation. This methodol429 ogy [5] is based on two assumptions, which are generally met in 430 agricultural areas: 1) soil albedo is generally lower than green 431 vegetation albedo, and 2) green vegetation albedo is lower than 432 senescent vegetation albedo. Although a time series of red and 433 near-infrared data would be required to estimate soil albedo 434 and green vegetation albedo on a pixel-by-pixel basis [5], only 435 one ASTER scene is available for this study period. Therefore, 436 an alternate approach is adopted. Surface albedo is modeled 437 as a linear mixing of vegetation and soil components (e.g., 438 [32] and [33])

$$
\alpha=\left(1-f_{\mathrm{tv}}\right) \alpha_{\mathbf{b s}}+f_{\mathrm{gv}} \alpha_{\mathbf{f c g v}}+\left(f_{\mathrm{tv}}-f_{\mathrm{gv}}\right) \alpha_{\mathbf{f c s v}}
$$

439 with $\alpha_{\mathbf{b s}}, \alpha_{\mathbf{f c g v}}$, and $\alpha_{\mathbf{f c s v}}$ being the albedo for bare soil, full440 cover green vegetation, and full-cover senescent vegetation, 441 respectively, and with the end-members $\alpha_{\mathbf{b s}}, \alpha_{\mathbf{f c g v}}$, and $\alpha_{\mathbf{f c s v}}$ 442 estimated in Section V.
By inverting (18), fractional vegetation cover is expressed as 443

$$
f_{\mathrm{tv}}=\frac{\alpha-\alpha_{\mathrm{bs}}+f_{\mathrm{gv}}\left(\alpha_{\mathrm{fcsv}}-\alpha_{\mathbf{f c g v}}\right)}{\alpha_{\mathbf{f c s v}}-\alpha_{\mathbf{b s}}}
$$

with $\alpha$ being the surface albedo estimated as a weighted sum of 444 red and near-infrared reflectances using the coefficients given in 445 [34] and validated in [35]-[38]. As stated previously, our case 446 study does not allow calibrating $\alpha_{\mathbf{b s}}, \alpha_{\mathbf{f c g v}}$, and $\alpha_{\mathbf{f c s v}}$ on a 447 pixel-by-pixel basis. Consequently, the value of $f_{\mathrm{tv}}$ computed 448 from (19) may, on some occasions, be lower than $f_{\mathrm{gv}}$ or larger 449 than 1 . To avoid nonphysical values, $f_{\mathrm{tv}}$ is set to $f_{\mathrm{gv}}$ and 1 in 450 the former and latter case, respectively.

The spatial variation of fractional senescent vegetation cover 452 $\left(f_{\mathrm{sv}}=f_{\mathrm{tv}}-f_{\mathrm{gv}}\right)$ over the study area is shown in Fig. 2 . Note 453 that NAFE'06 was undertaken at the beginning of the summer 454 agricultural season so that all irrigated crops were green and 455 healthy.

\section{Fractional Open Water}

The fraction of open water within each 250 -m resolution 458 pixel is estimated using 50-m resolution resampled ASTER 459 B5 reflectance product. Various studies have indicated that the 460 shortwave-infrared band centered at around $1 \mu \mathrm{m}$ is highly 461 sensitive to the presence of open water [20], [39], [40]. In this 462 paper, a simple threshold method is applied to classify at 50-m 463 resolution the $5 \mathrm{~km}$ by $32 \mathrm{~km}$ area in two classes: water and 464 nonwatered surface. The threshold value is estimated as 0.170465 from one flooded crop field in the south of the study area. The 466 spatial variation of fractional open water over the study area is 467 shown in Fig. 2. Open water represents $5 \%$ of the study area 468 and is attributed to rice cropping.

\section{Soil Evaporative Efficiency}

Soil evaporative efficiency $\beta$ is defined as the ratio of actual 471 to potential soil evaporation. In this paper, $\beta$ is estimated from 472 PLMR brightness temperatures. Two different formulations 473 are used to evaluate the coupling effects of near-surface soil 474 moisture, $f_{\mathrm{gv}}$, and $f_{\mathrm{sv}}$ on microwave-derived soil evaporative 475 efficiency.

By assuming that brightness temperature is mainly sensitive 477 to surface soil moisture [41] and that soil evaporative efficiency 478 is mainly driven by surface soil moisture [42], [43], soil evapo- 479 rative efficiency can be estimated as

$$
\beta=1-\frac{T B-\mathbf{T B}_{\mathbf{b}, \mathbf{w s}}}{\mathbf{T B}_{\mathbf{f c s v}, \mathbf{d s}}-\mathbf{T B}_{\mathbf{b}, \mathbf{w s}}}
$$

with $\mathbf{T B}_{\mathbf{b}, \mathbf{w s}}$ and $\mathbf{T} \mathbf{B}_{\mathbf{f c s v}, \mathbf{d s}}$ being the minimum and max- 481 imum brightness temperatures observed over the study area, 482 respectively. As brightness temperature generally decreases 483 with surface soil moisture and increases with vegetation cover 484 [44], $\mathbf{T} \mathbf{B}_{\mathbf{b}, \mathbf{w s}}$ and $\mathbf{T} \mathbf{B}_{\mathbf{f c s v}, \mathbf{d s}}$ are interpreted as the brightness 485 temperatures over wet bare soil and full-cover senescent vege- 486 tation with dry soil, respectively. The spatial variation of $\beta$ over 487 the study area is shown in Fig. 2.

Since brightness temperature also depends on biomass (e.g., 489 [45]), a second formulation of soil evaporative efficiency $\beta^{\prime}$ is 490 
TABLE II

NDVI AND SURFACE ALBEDo END-MEMBERS

\begin{tabular}{|c||c|c|}
\hline End-member & Value & Unit \\
\hline $\mathbf{N D V I}_{\mathbf{b s}}$ & 0.15 & - \\
$\mathbf{N D V I}_{\mathbf{f c g v}}$ & 0.65 & - \\
$\alpha_{\text {bs }}$ & 0.17 & - \\
$\alpha_{\mathbf{f c g v}}$ & 0.22 & - \\
$\alpha_{\mathbf{f c s v}}$ & 0.31 & - \\
\hline
\end{tabular}

491 derived in order to decouple the effects of soil moisture, $f_{\mathrm{gv}}$, 492 and $f_{\mathrm{sv}}$ on $T B$. As in [46], the assumption is that, for a given 493 vegetated pixel, if vegetation is partially stressed (i.e., $f_{\mathrm{sv}}>0$ 494 or $f_{\mathrm{tv}}>f_{\mathrm{gv}}$ ), then near-surface soil moisture availability is 495 zero (i.e., $\beta^{\prime}=0$ ). Alternatively, if that pixel does not contain 496 senescent vegetation (i.e., $f_{\mathrm{sv}}=0$ or $f_{\mathrm{tv}}=f_{\mathrm{gv}}$ ), then $\beta^{\prime}$ is 497 computed as the ratio of the measured "wet soil" brightness 498 temperature difference to the "dry soil"-"wet soil" brightness 499 temperature difference. Formally, one writes

$$
\begin{aligned}
& \beta^{\prime}=0 \quad \text { if } \quad T B>T B_{\mathbf{d s}} \\
& \beta^{\prime}=1-\frac{T B-T B_{\mathbf{w s}}}{T B_{\mathbf{d s}}-T B_{\mathbf{w s}}} \text { if } T B \leq T B_{\mathbf{d s}}
\end{aligned}
$$

500 with $T B_{\mathrm{ds}}$ and $T B_{\mathrm{ws}}$ being the "dry soil" and "wet soil" 501 brightness temperatures, respectively, both being estimated for $502 f_{\mathrm{sv}}=0$. Since green vegetation is partially transparent to mi503 crowaves, the "dry soil" brightness temperature is computed as 504 a weighted sum of the brightness temperature over dry bare soil 505 (noted as $\mathbf{T} \mathbf{B}_{\mathrm{b}, \mathrm{ds}}$ ) and the brightness temperature over full506 cover green vegetation with dry soil (noted as $\mathbf{T} \mathbf{B}_{\mathrm{fcgv}, \mathrm{ds}}$ )

$$
T B_{\mathrm{ds}}=f_{\mathrm{gv}} \mathbf{T B}_{\mathrm{fcgv}, \mathrm{ds}}+\left(1-f_{\mathrm{gv}}\right) \mathbf{T B}_{\mathbf{b}, \mathbf{d s}} .
$$

507 Similarly, the "wet soil" brightness temperature is computed as 508 a weighted sum of the brightness temperature over wet bare soil 509 (noted as $\mathbf{T B}_{\mathbf{b}, \mathbf{w s}}$ ) and the brightness temperature over full510 cover green vegetation with wet soil (noted as $\mathbf{T} \mathbf{B}_{\mathrm{fcgv}, \mathbf{w s}}$ )

$$
T B_{\mathrm{ws}}=f_{\mathrm{gv}} \mathbf{T B}_{\mathrm{fcgv}, \mathrm{ws}}+\left(1-f_{\mathrm{gv}}\right) \mathbf{T B}_{\mathbf{b}, \mathbf{w s}} .
$$

511 The spatial variation of $\beta^{\prime}$ over the study area is shown in Fig. 2.

\section{2 \\ V. Estimating End-Members}

513 A key step in the disaggregation procedure is estimating 514 the 14 end-members from ASTER and PLMR data. They 515 are composed of the following: $\mathbf{N D V I}_{\mathbf{b s}}, \mathbf{N D V I}_{\mathbf{f c g v}}, \alpha_{\mathbf{b s}}$, $516 \alpha_{\mathrm{fcgv}}, \alpha_{\mathrm{fcsv}}, \mathbf{T}_{\mathbf{b}, \mathrm{ws}}, \mathbf{T}_{\mathrm{b}, \mathrm{ds}}, \mathbf{T}_{\mathrm{fcgv}}, \mathbf{T}_{\mathrm{fcsv}}, \mathbf{T B}_{\mathrm{b}, \mathrm{ws}}, \mathbf{T B}_{\mathrm{b}, \mathrm{ds}}$, $517 \mathbf{T B}_{\mathrm{fcgv}, \mathrm{ws}}, \mathbf{T B}_{\mathrm{fcgv}, \mathrm{ds}}$, and $\mathbf{T B}_{\mathrm{fcsv}, \mathrm{ds}}$. For the convenience 518 of the reader, the unit is degree Celsius for radiometric temper519 ature and kelvin for brightness temperature.

\section{A. NDVI}

521 NDVI end-members are estimated as the minimum and maxi522 mum values of NDVI observed over the $5 \mathrm{~km}$ by $32 \mathrm{~km}$ area for 523 bare soil and full-cover green vegetation, respectively. Values 524 for $\mathbf{N D V I}_{\mathrm{bs}}$ and $\mathbf{N D V I}_{\mathbf{f c g v}}$ are reported in Table II.

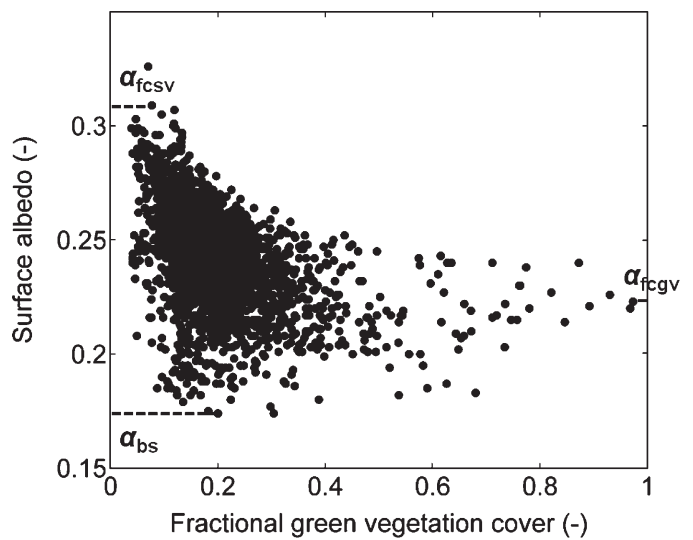

Fig. 3. ASTER surface albedo $\alpha$ plotted against ASTER fractional green vegetation cover $f_{\mathrm{gv}}$. Three particular values of $\alpha$ are identified: the soil albedo $\alpha_{\mathrm{bs}}$ estimated as the minimum surface albedo, the green vegetation albedo $\alpha_{\mathrm{fcgv}}$ estimated as the albedo corresponding to the largest $f_{\mathrm{gv}}$, and the senescent vegetation albedo $\alpha_{\mathrm{fcsv}}$ estimated as the maximum surface albedo.

In this paper, the study domain included extreme conditions 525 in terms of vegetation cover so that NDVI end-members could 526 be estimated from the red and near-infrared reflectances ac- 527 quired over the area on a single date. In the case where extreme 528 conditions are not encountered in the application domain, a 529 different approach should be adopted, such as the use of a time 530 series of NDVI data (instead of a single snapshot image) that 531 would capture the phenological stages of agricultural crops. 532 Also, the determination of reflectance end-members could 533 be further constrained by the use of ancillary spectral data 534 sets [47].

\section{B. Albedo}

Fig. 3 shows the space defined by surface albedo $\alpha$ and 537 fractional green vegetation cover $f_{\mathrm{gv}}$. Pixels including open 538 water are removed from the scatterplot. The soil albedo $\alpha_{\mathbf{b s}} 539$ is defined as the minimum ASTER surface albedo observed 540 within the study area by assuming that the dependence of 541 $\alpha_{\mathrm{bs}}$ on soil moisture is small compared to the dependence of 542 $\alpha$ on vegetation cover. The green vegetation albedo $\alpha_{\mathbf{f c g v}}$ is 543 estimated as the surface albedo corresponding to maximum 544 fractional green vegetation cover. The senescent vegetation 545 albedo $\alpha_{\mathbf{f c s v}}$ is estimated as the maximum surface albedo 546 observed within the study area. Values for $\alpha_{\mathbf{b s}}, \alpha_{\mathbf{f c g v}}$, and 547 $\alpha_{\mathrm{fcsv}}$ are reported in Table II.

\section{Land Surface Temperature}

As the range of surface conditions varies with spatial res- 550 olution, two different procedures are developed to estimate 551 temperature end-members.

552

1) When estimating temperature end-members from 250 -m 553 resolution data, one pixel is identified as fully covered 554 green vegetation, one pixel as fully covered senescent 555 vegetation, one pixel as bare dry soil, and one pixel as 556 bare wet soil. In this case, it is assumed that all extreme 557 conditions are included at high resolution within the study 558 domain. 
TABLE III

LAND SURFACE TEMPERATURE AND L-BAND BRIGHTNESS Temperature End-Members That ARe Estimated From High-Resolution ASTER Temperature Data, Extrapolated From AGgREGATED ASTER TEMPERATURE DATA, AND EXTRAPOLATED From MODIS TEMPERATURE DATA. For THE CONVENIENCE OF THE READER, THE UNIT IS DEgREE CELSIUSFOR RADIOMETRIC TEMPERATURE AND KELVIN FOR BRIGHTNESS TEMPERATURE

\begin{tabular}{|c||c|c|c|c|}
\hline & High-resolution & Aggregated ASTER & MODIS & \\
End-member & $T$ & $T_{\mathrm{km}}$ & $T_{\mathrm{km}}$ & Unit \\
\hline $\mathbf{T}_{\mathbf{b}, \mathbf{d s}}$ & 38 & 40.2 & 38.9 & ${ }^{\circ} \mathrm{C}$ \\
$\mathbf{T}_{\mathbf{b}, \mathbf{w s}}$ & 25 & 27.6 & 26.2 & ${ }^{\circ} \mathrm{C}$ \\
$\mathbf{T}_{\text {fcgv }}$ & 21 & 21.0 & 21.0 & ${ }^{\circ} \mathrm{C}$ \\
$\mathbf{T}_{\text {fcsv }}$ & 34 & 32.0 & 28.7 & ${ }^{\circ} \mathrm{C}$ \\
$\mathbf{T B}_{\mathbf{b}, \mathbf{d s}}$ & 240 & 246 & 241 & $\mathrm{~K}$ \\
$\mathbf{T B}_{\mathbf{b}, \mathbf{w s}}$ & 190 & 193 & 193 & $\mathrm{~K}$ \\
$\mathbf{T B}_{\text {fcgv,ws }}$ & 205 & 205 & 205 & $\mathrm{~K}$ \\
$\mathbf{T B}_{\text {fcgv,ds }}$ & 240 & 240 & 240 & $\mathrm{~K}$ \\
$\mathbf{T B}_{\text {fcsv,ds }}$ & 280 & 280 & 280 & $\mathrm{~K}$ \\
\hline
\end{tabular}

560

561

562

563

564

565

566

567

568 569 mined by analyzing the consistency of the diagrams in Fig. 4. 570 Fig. 4(a) shows the space defined by ASTER land surface 571 temperature and ASTER fractional green vegetation cover. The 572 three edges of the triangle $T-f_{\mathrm{gv}}$ are interpreted [27] as "bare 573 soil" between $\mathbf{A}$ and $\mathbf{B}$, "wet surface" between $\mathbf{B}$ and $\mathbf{C}$, and 574 "dry soil" between C and A. Fig. 4(b) shows the space de575 fined by ASTER land surface temperature and ASTER surface 576 albedo. An interpretation of the polygon $T-\alpha$ is provided 577 in [5], which is consistent with the triangle method. The four 578 edges are interpreted as "bare soil" between $\mathbf{A}$ and B, "wet 579 surface" between B and C, "full cover" between C and D, 580 and "dry surface" between $\mathbf{D}$ and $\mathbf{A}$. The notation system for 581 polygon vertices $\mathbf{A}, \mathbf{B}, \mathbf{C}$, and $\mathbf{D}$ is summarized in Table $\mathrm{I}$, and 582 the corresponding temperature values $\mathbf{T}_{\mathbf{b}, \mathbf{d s}}, \mathbf{T}_{\mathbf{b}, \mathbf{w s}}, \mathbf{T}_{\mathbf{f c g v}}$, 583 and $\mathbf{T}_{\mathbf{f c s v}}$ are reported in Table III.

584 In this paper, high-resolution temperature $T$ is assumed to 585 be unavailable. Consequently, the extreme temperatures $\mathbf{T}_{\mathbf{b}, \mathbf{d s}}$, $586 \mathbf{T}_{\mathbf{b}, \mathbf{w s}}, \mathbf{T}_{\mathbf{f c g v}}$, and $\mathbf{T}_{\mathbf{f c s v}}$ are extrapoled from the spaces $T_{\mathrm{km}}-$ $587\left\langle f_{\mathrm{gv}}\right\rangle_{\mathrm{km}}$ and $T_{\mathrm{km}}-\langle\alpha\rangle_{\mathrm{km}}$ defined at kilometric resolution 588 (see Fig. 4(c) and (d) for aggregated ASTER temperature and 589 Fig. 4(e) and (f) for MODIS temperature). An approach similar 590 to [5] is used as follows.

1) Vertex $\mathbf{C}$ corresponds to full-cover green vegetation and is located at $\left(1, \mathbf{T}_{\text {fcgv }}\right)$ in Fig. 4(c) (Fig. 4(e) for MODIS temperature) and at $\left(\alpha_{\mathbf{f c g v}}, \mathbf{T}_{\mathbf{f c g v}}\right)$ in Fig. $4(\mathrm{~d})$ [Fig. 4(f)]. In this paper, $\mathbf{T}_{\mathbf{f c g v}}$ is set to the air temperature $\mathbf{T}_{\mathbf{a}}$ measured at the time of ASTER overpass. Vertex $\mathbf{C}$ is thus placed at $\left(1, \mathbf{T}_{\mathbf{a}}\right)$ in Fig. 4(c) [Fig. 4(e)] and at $\left(\alpha_{\text {fcgv }}, \mathbf{T}_{\mathbf{a}}\right)$ in Fig. 4(d) [Fig. 4(f)].
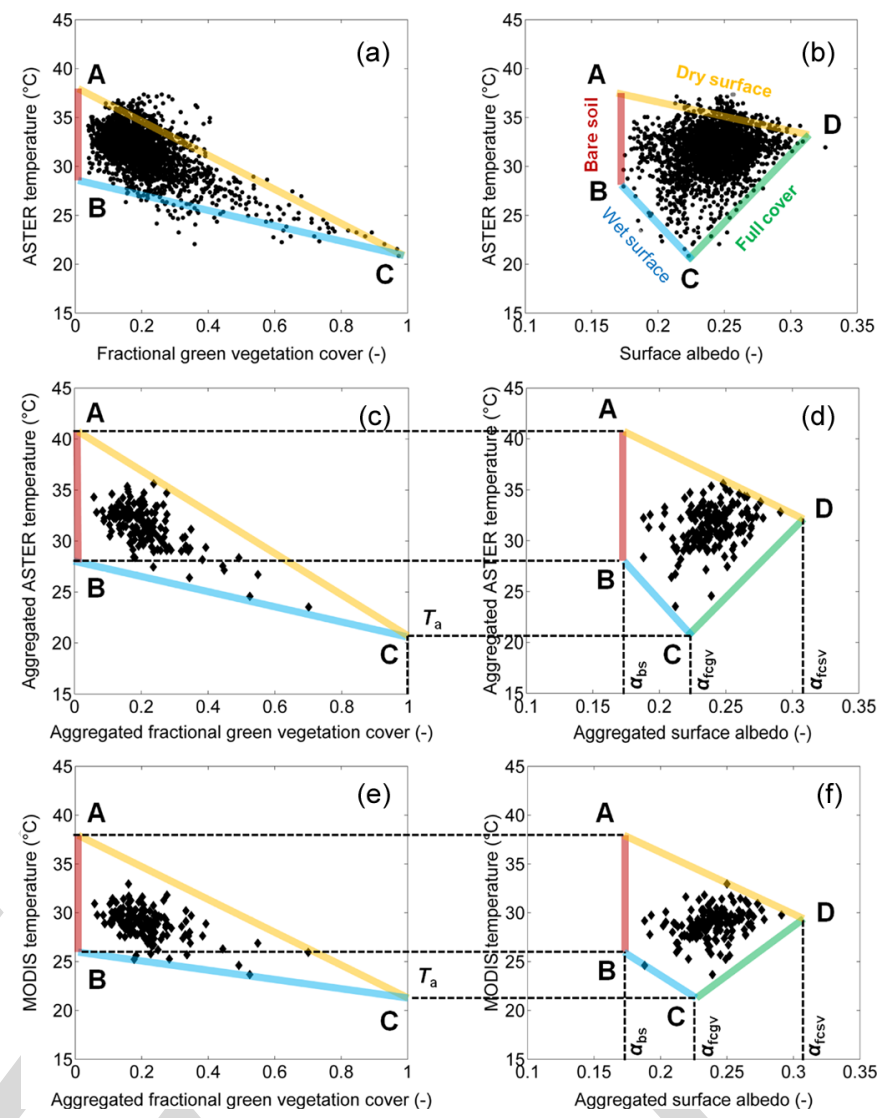

Fig. 4. (a) Scatterplot of ASTER temperature versus fractional green vegetation cover and (b) versus surface albedo, (c) scatterplot of aggregated ASTER temperature versus aggregated fractional green vegetation cover and (d) versus aggregated surface albedo, and (e) scatterplot of MODIS temperature versus aggregated fractional green vegetation cover and (f) versus aggregated surface albedo. The vertices $\mathbf{A}, \mathbf{B}, \mathbf{C}$, and $\mathbf{D}$ obtained using high-resolution data in (a) and (b) are extrapolated using low-resolution data in (c), (d), (e), and (f) from ancillary data composed of air temperature $\mathbf{T}_{\mathbf{a}}$, soil albedo $\alpha_{\mathbf{b s}}$, green vegetation albedo $\alpha_{\mathbf{f c g v}}$, and senescent vegetation albedo $\alpha_{\mathbf{f c s v}}$.

2) Vertex $\mathbf{B}$ corresponds to wet bare soil and is located at 598 $\left(0, \mathbf{T}_{\mathbf{b}, \mathbf{w s}}\right)$ in Fig. 4(c) [Fig. 4(e)] and at $\left(\alpha_{\mathbf{b s}}, \mathbf{T}_{\mathbf{b}, \mathbf{w s}}\right)$ in 599 Fig. 4(d) [Fig. 4(f)]. It is placed in Fig. 4(c) [Fig. 4(e)] 600 at the intersection between (BC) and the vertical line 601 $\left\langle f_{\mathrm{gv}}\right\rangle_{\mathrm{km}}=0$. The slope of $(\mathbf{B C})$ is computed as the slope 602 of the linear regression of the data points corresponding 603 to the "wet surface" edge of the triangle $T_{\mathrm{km}}-\left\langle f_{\mathrm{gv}}\right\rangle_{\mathrm{km}} .604$ The off-set of $(\mathbf{B C})$ is determined from $\mathbf{C}$.

605

3) Vertex $\mathbf{A}$ corresponds to dry bare soil and is located at 606 $\left(0, \mathbf{T}_{\mathbf{b}, \mathbf{d s}}\right)$ in Fig. 4(c) [Fig. 4(e)] and at $\left(\alpha_{\mathbf{b s}}, \mathbf{T}_{\mathbf{b}, \mathbf{d s}}\right)$ in 607 Fig. 4(d) [Fig. 4(f)]. It is placed in Fig. 4(c) [Fig. 4(e)] 608 at the intersection between $(\mathbf{A C})$ and the vertical line 609 $\left\langle f_{\mathrm{gv}}\right\rangle_{\mathrm{km}}=0$. The slope of $(\mathbf{A C})$ is computed as the slope 610 of the linear regression of the data points corresponding 611 to the "dry soil" edge of the triangle $T_{\mathrm{km}}-\left\langle f_{\mathrm{gv}}\right\rangle_{\mathrm{km}}$. The 612 off-set of $(\mathbf{A C})$ is determined from $\mathbf{C}$.

4) Vertex $\mathbf{D}$ corresponds to full-cover senescent vegetation 614 and is located at $\left(\alpha_{\mathbf{f c s v}}, \mathbf{T}_{\mathbf{f c s v}}\right)$ in Fig. $4(\mathrm{~d})$ [Fig. 4(f)]. 615 It is placed in Fig. 4(d) [Fig. 4(f)] at the intersection 616 between $(\mathbf{A D})$ and the vertical line $\langle\alpha\rangle_{\mathrm{km}}=\alpha_{\mathrm{fcsv}}$. The 617 line $(\mathbf{A D})$ is considered as being parallel to (BC)[5]. 618 Consequently, the slope of (AD) is determined from 619 

from $\mathbf{A}$. Note that the lines (AD) and (BC) might not be strictly parallel. This may be due to a lack of representativeness of the surface conditions captured at 250-m resolution within the study area. In that case, one or several data points may be located above (AD). To circumvent this artifact, the slope of (AD) in Fig. 4(d) [Fig. 4(f)] is increased so that all data points will be located below the "dry surface" edge. 630 mated from Fig. 4(a) and (b) using high-resolution ASTER 631 data; 2) extrapolated from Fig. 4(c) and (d) using aggregated 632 ASTER temperature data; and 3) extrapolated from Fig. 4(e) 633 and (f) using MODIS temperature data. The values extrapo634 lated from aggregated ASTER and MODIS temperatures are 635 rather close to those estimated from high-resolution ASTER 636 temperature data, with the maximum difference in extrapolated 637 temperatures being $2.6{ }^{\circ} \mathrm{C}$, except for $\mathbf{T}_{\text {fcsv }}$ using MODIS 638 data. In the latter case, the significant underestimation $\left(5.3{ }^{\circ} \mathrm{C}\right)$ 639 of $\mathbf{T}_{\text {fcsv }}$ can be explained by the following: 1) the negative 640 mean difference $\left(-2.3{ }^{\circ} \mathrm{C}\right)$ between MODIS and ASTER data $641 \mathrm{and} /$ or 2) the smaller range of (spatial dynamics) of 1-km 642 resolution MODIS data in relation to 1-km aggregated ASTER 643 data [please compare Fig. 4(c) with Fig. 4(e), and Fig. 4(d) with 644 Fig. 4(f)].

\section{D. Brightness Temperature}

646 To estimate soil evaporative efficiency $\beta$ in (20) and $\beta^{\prime}$ 647 in (22), five brightness temperature values corresponding to 648 extreme surface conditions are required: $\mathbf{T B}_{\mathbf{b}, \mathbf{d s}}, \mathbf{T} \mathbf{B}_{\mathbf{b}, \mathbf{w s}}$, $649 \mathbf{T B}_{\text {fcgv,ws }}, \mathbf{T B}_{\text {fcgv,ds }}$, and $\mathbf{T B}_{\text {fcsv,ds. In this paper, those }}$ 650 five values are estimated from a generalized version [5], [9] of 651 the classical "triangle method" [27].

652 Fig. 5(a) shows the space defined by PLMR brightness 653 temperature and ASTER land surface temperature. In the fol654 lowing, an original interpretation of the five vertices visible 655 in Fig. 5(a) is provided, which is consistent with both the 656 classical "triangle method" and the state-of-the-art L-band ra657 diative transfer models. Vertices are presented successively in 658 the counterclockwise direction, and the correspondence with 659 vegetation and soil conditions is summarized in Table I.

1) Vertex at minimum brightness temperature: L-band radiative transfer models predict an increase of brightness temperature with biomass and a decrease of brightness temperature with surface soil moisture (e.g., [48] and [49]). Therefore, the point at minimum brightness temperature corresponds to wet bare soil. This vertex is noted as B in Fig. 5(a), which is consistent with Fig. 4.

2) Vertex at maximum land surface temperature: the triangle method predicts a decrease of land surface temperature with both vegetation cover and surface soil moisture. Therefore, the point at maximum land surface temperature corresponds to dry bare soil. This vertex is noted as A in Fig. 5(a), which is consistent with Fig. 4.

3) Vertex at maximum brightness temperature: being consistent with an increase of vegetation emission with biomass and a decrease of soil emission with surface soil moisture, the point at maximum brightness temperature 676 corresponds to full-cover vegetation with dry soil. It 677 could correspond to full-cover green vegetation. How- 678 ever, the associated land surface temperature in Fig. 5(a) 679 is much larger than that over full-cover green vegetation 680 $\left(21{ }^{\circ} \mathrm{C}\right)$ and rather close to the temperature over full- 681 cover senescent vegetation $\left(34^{\circ} \mathrm{C}\right)$. Therefore, the point 682 at maximum brightness temperature corresponds to full- 683 cover senescent vegetation with dry soil. This vertex 684 is noted as $\mathbf{D}^{\prime}$ in Fig. 5(a), which is consistent with 685 Fig. 4. A prime mark indicates that $\mathbf{D}^{\prime}$ corresponds to a 686 dry soil, whereas D does not specify soil hydric status. 687 Note that $\mathbf{D}^{\prime}$ does not necessarily correspond to dry 688 senescent vegetation since wet senescent vegetation can 689 lead to large values of brightness temperature [50]. In 690 our case study, however, no rainfall occurred during the 691 four days preceding the ASTER overpass, which means 692 that senescent vegetation was completely dry. In terms of 693 radiative transfer modeling, the effect of dry biomass on 694 brightness temperature can be represented by large values 695 of roughness parameter [51].

696

4) Vertices at minimum land surface temperature: two more 697 vertices are apparent in the counterclockwise direction. 698 Being consistent with a decrease of land surface tem- 699 perature with green vegetation, both points correspond 700 to full-cover green vegetation. As vegetation is partially 701 transparent to the L-band emission from the soil, each 702 point corresponds to a different soil hydric status. The 703 vertex with a larger $T B$ [noted as $\mathbf{C}^{\prime \prime}$ in Fig. 5(a)] 704 corresponds to full-cover green vegetation with dry soil, 705 and the point with a lower $T B$ [noted as $\mathbf{C}^{\prime}$ in Fig. 5(a)] 706 corresponds to full-cover green vegetation with wet soil. 707

As high-resolution temperature is assumed to be unavailable 708 in this paper, brightness temperature end-members are not 709 estimated from the polygon $T B-T$ in Fig. 5(a) but from 710 the polygon $T B-f_{\mathrm{gv}}$ shown in Fig. 5(b). The following is 711 an interpretation of the polygon in Fig. 5(b), based on the 712 consistency with the polygon in Fig. 5(a). In particular, the five 713 vertices in Fig. 5(a) can be located in Fig. 5(b) as follows.

714

1) Vertex B corresponds to wet bare soil. It is located at 715 the minimum value of brightness temperature such that 716 $f_{\mathrm{gv}}=0$.

2) Vertex $\mathbf{A}$ corresponds to bare dry soil. It is not apparent 718 in Fig. 5(b) because fractional green vegetation is not 719 sufficient information to distinguish between bare soil 720 and senescent vegetation.

3) Vertex $D^{\prime}$ corresponds to full-cover senescent vegetation 722 with dry soil. It is located at the maximum value of 723 brightness temperature.

4) Vertex $\mathbf{C}^{\prime \prime}$ corresponds to full-cover green vegetation 725 with dry soil. It is located at the maximum value of 726 brightness temperature such that $f_{\mathrm{gv}}=1$.

5) Vertex $\mathbf{C}^{\prime}$ corresponds to full-cover green vegetation with 728 wet soil. It is located at the minimum value of brightness 729 temperature such that $f_{\mathrm{gv}}=1$.

Based on the aforementioned interpretation of the polygon 731 $T B-f_{\mathrm{gv}}$ in Fig. 5(b), the methodology used for estimating 732 

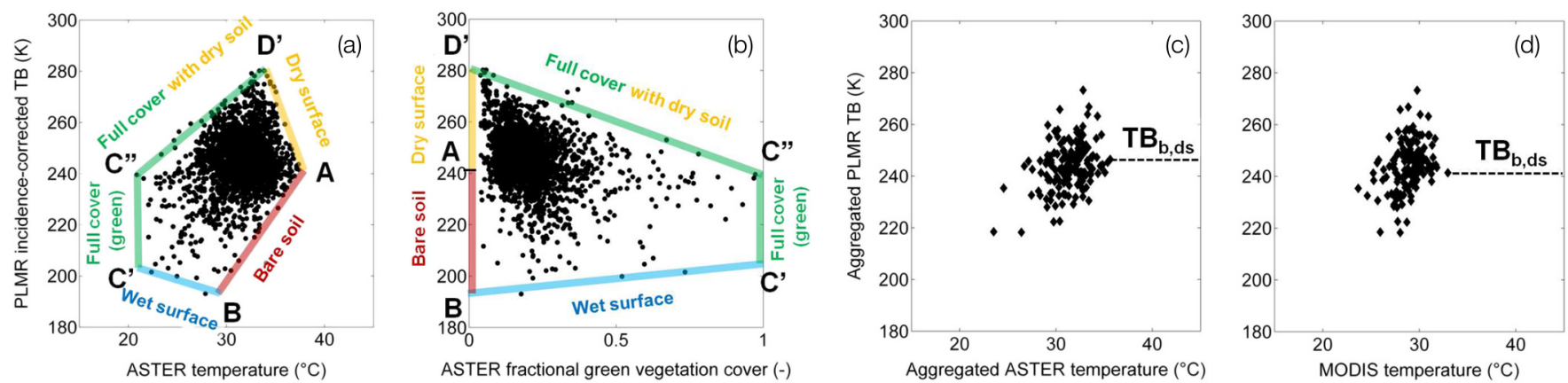

Fig. 5. (a) Scatterplot of PLMR incidence-corrected brightness temperature $T B$ versus ASTER land surface temperature and (b) versus ASTER fractional green vegetation cover, and (c) scatterplot of aggregated $T B$ versus aggregated ASTER temperature and (d) versus MODIS temperature. Extreme brightness temperatures $\mathbf{T} \mathbf{B}_{\mathrm{b}, \mathbf{w s}}, \mathbf{T} \mathbf{B}_{\mathrm{fcgv}, \mathrm{ws}}, \mathbf{T} \mathbf{B}_{\mathrm{fcgv}, \mathrm{ds}}$, and $\mathbf{T} \mathbf{B}_{\mathrm{fcsv}, \mathrm{ds}}$ are estimated by interpreting the bare soil, dry surface, full-cover vegetation, and wet surface edges of the polygon in (b). The estimation of $\mathbf{T} \mathbf{B}_{\mathbf{b}, \mathbf{d s}}$ using low-resolution temperature data is illustrated with aggregated ASTER temperature in (c) and MODIS temperature in $(\mathrm{d})$.

$733 \mathbf{T B}_{\mathrm{b}, \mathrm{ds}}, \mathrm{TB}_{\mathrm{b}, \mathrm{ws}}, \mathrm{TB}_{\mathrm{fcgv}, \mathrm{ws}}, \mathrm{TB}_{\mathrm{fcgv}, \mathrm{ds}}$, and $\mathrm{TB}_{\mathrm{fcsv}, \mathrm{ds}}$ is 734 detailed in the following.

1) The brightness temperature over full-cover dry surface $\left(\mathbf{T B}_{\mathbf{f c s v}, \mathbf{d s}}\right)$ and over wet bare soil $\left(\mathbf{T B}_{\mathbf{b}, \mathbf{w s}}\right)$ are set to the maximum and minimum brightness temperatures observed within the study area, respectively.

2) The brightness temperatures over full-cover green vegetation with wet soil $\left(\mathbf{T B}_{\mathbf{f c g v}, \mathbf{w s}}\right)$ and over full-cover green vegetation with dry soil $\left(\mathbf{T B}_{\mathbf{f c g v}, \mathbf{d s}}\right)$ are estimated as the brightness temperature extrapolated at $f_{\mathrm{gv}}=1$ in Fig. 5(b) along the "wet soil" and the "full-cover dry soil" edge, respectively. The slope of the lines $\left(\mathbf{B C}^{\prime}\right)$ and $\left(\mathbf{D}^{\prime} \mathbf{C}^{\prime \prime}\right)$ are determined so that all of the points with $f_{\mathrm{gv}}>0.5$ be above and below the "wet soil" and "fullcover dry soil" edges, respectively.

3) Vertex $\mathbf{A}$ cannot be identified in the space $T B-f_{\mathrm{gv}}$. Consequently, $\mathbf{T B}_{\mathbf{b}, \mathbf{d s}}$ is set to the brightness temperature corresponding to the maximum $T_{\mathrm{km}}$ (see Fig. 5(c) for aggregated ASTER temperature and Fig. 5(d) for MODIS temperature data).

Table III lists the five brightness temperature end-members: 754 1) estimated from Fig. 5(a) using high-resolution ASTER data; 755 2) estimated from Fig. 5(b) and (c) using high-resolution 756 fractional green vegetation cover and aggregated ASTER tem757 perature data; and 3) estimated from Fig. 5(b) and (d) using 758 high-resolution fractional green vegetation cover and MODIS 759 temperature data. Values estimated from low-resolution tem760 perature are remarkably close to those estimated from high761 resolution ASTER temperature data (Table III), except for $762 \mathbf{T B}_{\mathrm{b}, \mathrm{ds}}$ with a difference of $6 \mathrm{~K}$. This difference is apparently 763 due to the lack of representativeness of kilometric aggregated 764 brightness temperature and the method for estimating $\mathbf{T B}_{\mathbf{b}, \mathbf{d s}}$ 765 at kilometric scale. Note, however, that a 6-K difference is still 766 relatively low compared to the range (190 K-280 K) covered 767 by brightness temperature values.

\section{APPLICATION}

769 The disaggregation algorithms presented here are applied 770 to the NAFE'06 data set. ASTER land surface temperature is 771 aggregated at $1-\mathrm{km}$ resolution, and kilometric temperature is 772 used as input to D0, D1, D1', D2, D2 ', D3', D4', and D4 ${ }^{\prime \prime}$. As shown in Fig. 1, the verification strategy consists in comparing 773 disaggregation results at 250-m resolution with ASTER land 774 surface temperature. An application to MODIS data is also 775 presented.

\section{A. Application to Aggregated ASTER Data}

1) End-Members Derived From High-Resolution Data: The 778 approach is first implemented using the end-members estimated 779 from high-resolution ASTER temperature data. This allows 780 testing the robustness of the model in (15) and (16) inde- 781 pendently of the methodology used for extrapolating the nine 782 end-members $\mathbf{T}_{\mathbf{b}, \mathbf{d s}}, \mathbf{T}_{\mathbf{b}, \mathbf{w s}}, \mathbf{T}_{\mathrm{fcgv}}, \mathbf{T}_{\mathrm{fcsv}}, \mathbf{T} \mathbf{B}_{\mathbf{b}, \mathbf{d s}}, \mathbf{T B}_{\mathbf{b}, \mathbf{w s}}, 783$ $\mathbf{T B}_{\text {fcgv, ws }}, \mathbf{T B}_{\text {fcgv,ds }}$, and $\mathbf{T B}_{\text {fcsv,ds }}$.

Fig. 6 shows the output images of the eight disaggregation 785 algorithms, which are to be compared with the reference image 786 derived from ASTER land surface temperature. One observes 787 that the disaggregated temperature is successively improved 788 by including additional factors in the disaggregation, which 789 indicates that the methodology is able to take into account 790 several independent factors. Although the boxy artifact at 1-km 791 resolution is successively reduced from $T^{(0)}$ to $T^{\left(4^{\prime \prime}\right)}$, it is still 792 apparent for $T^{\left(4^{\prime \prime}\right)}$. This effect may be due to the following: 1) 793 other factors that are not taken into account in the procedure, 794 such as green vegetation water stress, wind speed, surface 795 emissivity, surface albedo, etc.; 2) errors in estimated $f_{\mathrm{gv}}, f_{\mathrm{sv}}, 796$ $f_{\text {ow }}$, and $\beta$; and/or 3) resampling errors at 250-m resolution. 797

Table IV lists the RMSD, correlation coefficient, and slope 798 between the disaggregated and ASTER temperatures for each 799 of the eight disaggregation algorithms. The error is successively 800 decreased from $1.65{ }^{\circ} \mathrm{C}$ to $1.16{ }^{\circ} \mathrm{C}$, while the correlation coef- 801 ficient and slope are successively increased from 0.79 and 0.63802 to 0.89 and 0.88 , respectively. When comparing D1, D2, D1', 803 and D2', no significant differences are observed between all 804 four algorithms in terms of root-mean-square error, correlation 805 coefficient, and slope. Note that, in this paper, $f_{\text {tv }}$ was estimated 806 in a different way than in [5] because only one visible and 807 near-infrared image was available and a FORMOSAT-like time 808 series would be required to derive $f_{\mathrm{tv}}$ more accurately on a 809 pixel-by-pixel basis. Nevertheless, this comparison suggests 810 that $\mathrm{D} 1^{\prime}$ seems to be equivalent to D1 and D2' equivalent to 811 D2, which justifies the use of the $T_{\bmod }$ model. 

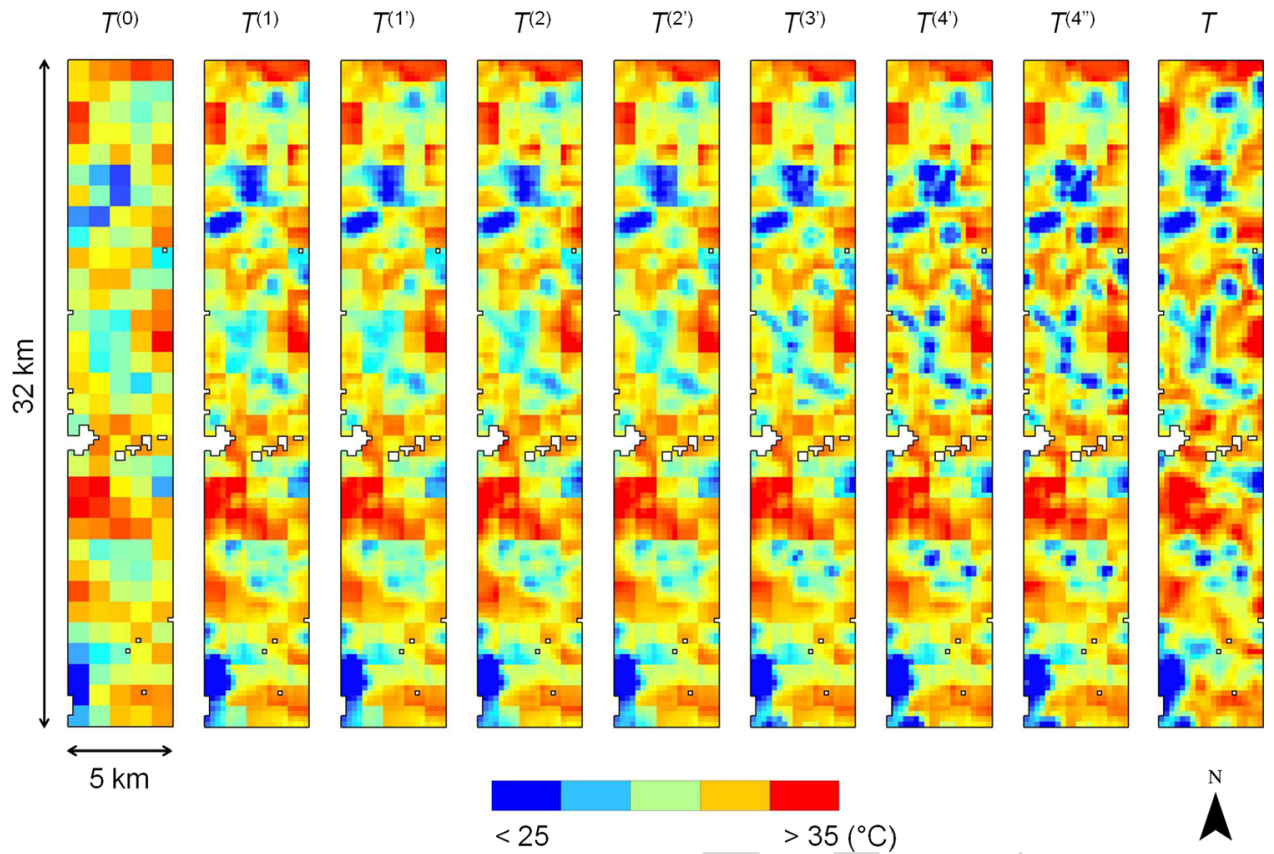

Fig. 6. Maps of the temperature disaggregated by the eight algorithms as compared with the map (right) of high-resolution ASTER temperature.

TABLE IV

RMSD, CorRelation COEFFicient $(R)$, AND SLOPE BETWEen THE DisAGgREGATED AND ASTER TEMPERATURES. THE RESUlTS CORRESPOND TO THE END-MEMBERS ESTIMATED USING High-RESOLUTION ASTER TEMPERATURE DATA (TO THE END-MEMBERS EXTRAPOLATED USING Aggregated ASTER Temperature Data)

\begin{tabular}{|c||c|c|c|}
\hline Algorithm & $\begin{array}{c}\text { RMSD } \\
{ }^{\circ} \mathrm{C}\end{array}$ & $\begin{array}{c}\mathrm{R} \\
-\end{array}$ & $\begin{array}{c}\text { Slope } \\
-\end{array}$ \\
\hline $\mathrm{D} 0$ & 1.65 & 0.79 & 0.63 \\
$\mathrm{D} 1$ & 1.39 & 0.86 & 0.76 \\
$\mathrm{D} 2$ & $1.35(1.35)$ & $0.87(0.87)$ & $0.76(0.76)$ \\
$\mathrm{D}^{\prime}$ & $1.38(1.39)$ & $0.86(0.86)$ & $0.74(0.72)$ \\
$\mathrm{D}^{\prime}$ & $1.30(1.40)$ & $0.88(0.86)$ & $0.75(0.73)$ \\
$\mathrm{D}^{\prime}$ & $1.22(1.27)$ & $0.89(0.88)$ & $0.78(0.76)$ \\
D4 $^{\prime}$ & $1.15(1.15)$ & $0.91(0.91)$ & $0.86(0.84)$ \\
D4 $^{\prime \prime}$ & $1.16(1.24)$ & $0.89(0.80)$ & $0.88(0.86)$ \\
\hline
\end{tabular}

813 The main advantage of the new approach is to take into 814 account a number of additional factors, including fractional 815 open water and soil evaporative efficiency. When comparing the 816 results obtained for $\mathrm{D} 3^{\prime}, \mathrm{D} 4^{\prime}$, and D4 ${ }^{\prime \prime}$ in Table IV, it is observed 817 that the disaggregated temperature is significantly improved 818 against the classical approaches D1 and D2. Moreover, the 819 statistical results are successively improved by including $f_{\mathrm{ow}}$, $820 \beta$, and $\beta^{\prime}$. Fig. 7 shows the improvement, especially in the 821 slope between the disaggregated and ASTER temperatures. The 822 good results obtained for D4" indicate that the performance of 823 disaggregation algorithms is intimately related to the following: 824 1) the capability of separating the independent factors that 825 impact on surface temperature and 2) the ability to integrate 826 them consistently into the procedure.

827 2) End-Members Derived From Aggregated ASTER Data: 828 As disaggregation procedures $\mathrm{D} 1^{\prime}, \mathrm{D} 2^{\prime}, \mathrm{D} 3^{\prime}, \mathrm{D} 4^{\prime}$, and $\mathrm{D} 4^{\prime \prime}$
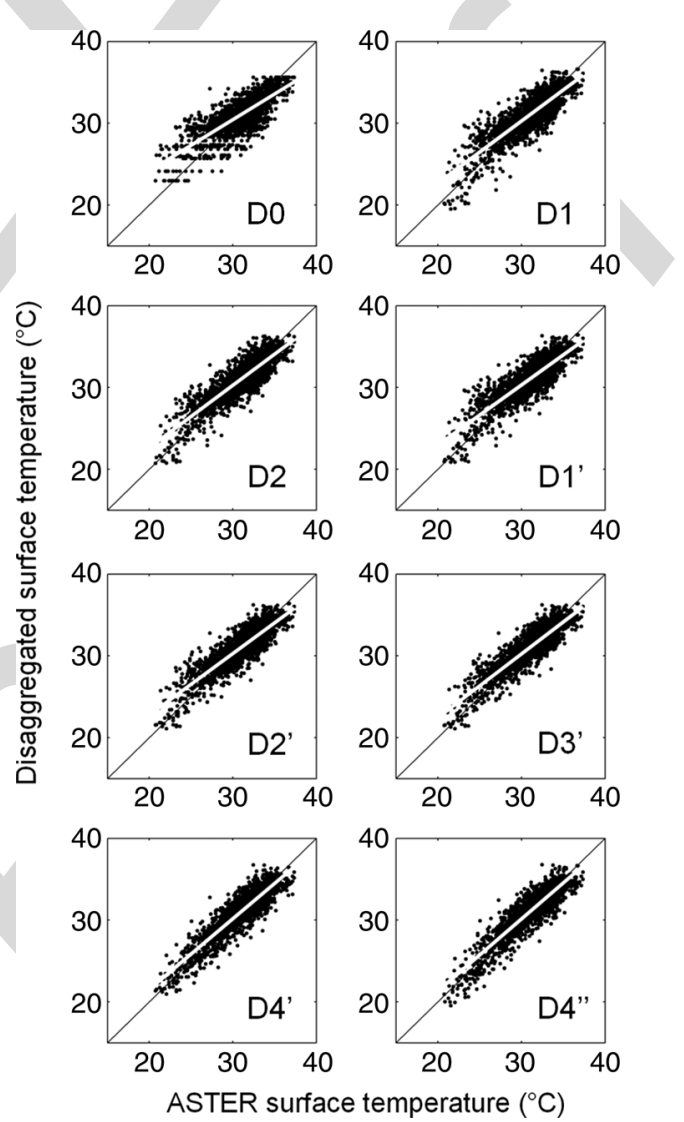

Fig. 7. Aggregated ASTER temperature $(1 \mathrm{~km})$ is disaggregated by each of the eight algorithms and is plotted against high-resolution ASTER temperature.

are subjected to uncertainties in land surface temperature and 829 brightness temperature end-members, the five algorithms are 830 next tested using the end-members estimated from kilomet- 831 ric temperature data, as presented in Section V. Aggregated 832 ASTER (instead of MODIS) data are used to evaluate the 833 

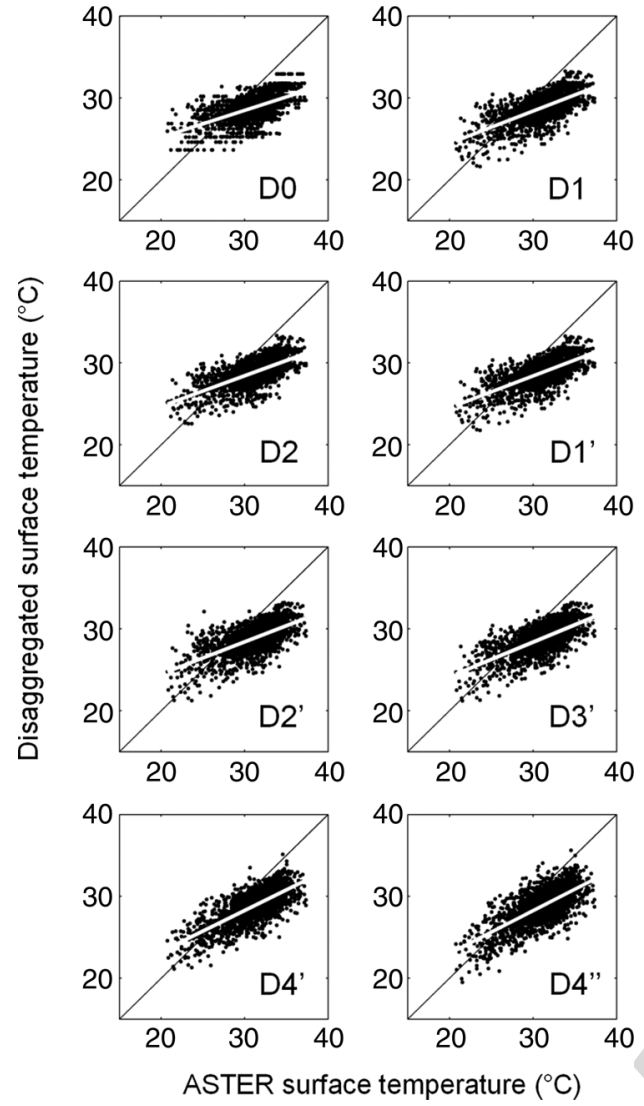

Fig. 8. MODIS temperature $(1 \mathrm{~km})$ is disaggregated by each of the eigh algorithms and is plotted against high-resolution ASTER temperature.

834 impact of end-members regardless of the discrepancy between 835 MODIS and ASTER temperatures.

836 Table IV lists the RMSD, correlation coefficient, and slope 837 between the disaggregated and ASTER temperatures for each 838 of the five algorithms. Results are compared with those ob839 tained using the end-members estimated from high-resolution 840 ASTER temperature. In general, the error is slightly larger, 841 and the correlation coefficient and slope are slightly lower us842 ing extrapolated end-members. Nevertheless, the disaggregated 843 temperature is still much improved by applying D4" instead of $844 \mathrm{D}^{\prime}$, with the correlation coefficient and slope increasing from 8450.74 to 0.88 and from 0.72 to 0.86 , respectively. Consequently, 846 the extrapolation of end-members from kilometric data is not 847 found to be a limiting factor in the methodology.

\section{B. Application to MODIS Data}

849 Disaggregation algorithms D0, D1, D1', D2, D2', D3', D4', 850 and D4" are then applied to MODIS data. In this case, end851 members are derived from MODIS data. Fig. 8 shows the scat852 terplot of disaggregated MODIS versus ASTER temperature for 853 each algorithm separately. One observes that the new methodol854 ogy improves the correlation and slope of the linear regression 855 between the disaggregated and ASTER temperatures. However, 856 a systematic negative bias is apparent in the disaggregated 857 temperature. Table V lists the RMSD, correlation coefficient, 858 and slope between the disaggregated and ASTER temperatures 859 for each of the eight algorithms. The error slightly decreases
TABLE $\mathrm{V}$

RMSD, Correlation CoefFicient $(R)$, AND SLope Between the Dis AGgREgated AND ASTER TEMPERATURES. THE RESUltS CORRESPOND TO THE END-MEMBERS EXTRAPOLATED USING MODIS TEMPERATURE DATA

\begin{tabular}{|c||c|c|c|}
\hline Algorithm & $\begin{array}{c}\text { RMSD } \\
{ }^{\circ} \mathrm{C}\end{array}$ & $\begin{array}{c}\mathrm{R} \\
-\end{array}$ & $\begin{array}{c}\text { Slope } \\
-\end{array}$ \\
\hline D0 & 3.19 & 0.60 & 0.33 \\
D1 & 3.08 & 0.67 & 0.39 \\
D2 & 3.11 & 0.66 & 0.37 \\
D1' & 3.09 & 0.67 & 0.39 \\
D2' $^{\prime}$ & 3.12 & 0.65 & 0.39 \\
D3' $^{\prime}$ & 3.06 & 0.69 & 0.42 \\
D4 $^{\prime}$ & 2.98 & 0.73 & 0.50 \\
D4 $^{\prime \prime}$ & 3.03 & 0.70 & 0.52 \\
\hline
\end{tabular}

from $3.2{ }^{\circ} \mathrm{C}$ to $3.0{ }^{\circ} \mathrm{C}$, while the correlation coefficient and 860 slope increase from 0.6 and 0.3 to 0.7 and 0.5 , respectively. 861 The results obtained for $\mathrm{D} 3^{\prime}$ and $\mathrm{D} 4^{\prime}$ in Table $\mathrm{V}$ indicate that 862 the disaggregated temperature is improved against the classical 863 approaches D1 and D2. As for the application to aggregated 864 ASTER data, the statistical results are successively improved 865 by including $f_{\text {ow }}, \beta$, and $\beta^{\prime}$. However, the improvement with 866 MODIS data is not as visible as with aggregated ASTER 867 data because the difference between MODIS and ASTER data 868 (please refer to Section II-C) has the same order of magnitude 869 as the subpixel variability at 250-m resolution (see RMSD for 870 D0 in Table V). In particular, the mean bias and the relatively 871 low slope of the linear regression between the disaggregrated 872 and ASTER data are associated with the discrepancy at 1-km 873 resolution between the MODIS and ASTER temperature data. 874

\section{SENSITIVITY ANALYSIS}

To further assess the stability of the new $\mathrm{D}^{\prime}$ algorithms based 876 on radiative transfer, two sensitivity analyses are conducted 877 by the following: 1) adding a Gaussian noise on kilometric 878 temperatures and high-resolution brightness temperatures and 879 2) estimating the contribution of each factor on the variability 880 of modeled land surface temperature.

\section{A. Uncertainty in End-Members}

To test the stability of the method for estimating the nine 883 end-members $\left(\mathbf{T}_{\mathbf{b}, \mathbf{d s}}, \mathbf{T}_{\mathbf{b}, \mathbf{w s}}, \mathbf{T}_{\mathbf{f c g v}}, \mathbf{T}_{\mathbf{f c s v}}, \mathbf{T B}_{\mathbf{b}, \mathbf{d s}}, \mathbf{T B}_{\mathbf{b}, \mathbf{w s}}, 884\right.$ $\mathbf{T B}_{\text {fcgv }, \mathbf{w s}}, \mathbf{T B}_{\text {fcgv }, \mathbf{d s}}$, and $\mathbf{T B}_{\text {fcsv }, \mathbf{d s}}$ ) from low-resolution 885 temperature data, a Gaussian noise with a standard deviation 886 of $1{ }^{\circ} \mathrm{C}$ is added to the kilometric (aggregated ASTER) land 887 surface temperature data set, and a Gaussian noise with a stan- 888 dard deviation of $2 \mathrm{~K}$ is added to the high-resolution brightness 889 temperature data set. An ensemble of 100 data sets is generated 890 and used as input to the disaggregation algorithms.

891

Table VI reports the average and standard deviation of ex- 892 trapolated end-members computed within the ensemble of 100893 artificially perturbed data sets. Results indicate that the method 894 for extrapolating end-members is stable for all end-members. 895 
TABLE VI

Mean and Standard Deviation of Land Surface Temperature AND L-BAND BRIGHTNESS TEMPERATURE END-MEMBERS Extrapolated Using Kilometric TEMPerature Data. For the CONVENIENCE OF THE READER, THE UNIT IS DEgREE CELSIUS FOR RADIOMETRIC TEMPERATURE AND KELVIN FOR BRIGHTNESS TEMPERATURE

\begin{tabular}{|c||c|c|c|}
\hline End-member & Mean & St. dev. & Unit \\
\hline $\mathbf{T}_{\mathbf{b}, \mathbf{d s}}$ & 40.8 & 0.8 & ${ }^{\circ} \mathrm{C}$ \\
$\mathbf{T}_{\mathbf{b}, \mathbf{w s}}$ & 25.7 & 1.5 & ${ }^{\circ} \mathrm{C}$ \\
$\mathbf{T}_{\text {fcgv }}$ & 21.0 & 0 & ${ }^{\circ} \mathrm{C}$ \\
$\mathbf{T}_{\text {fcsv }}$ & 33.1 & 1.3 & ${ }^{\circ} \mathrm{C}$ \\
$\mathbf{T B}_{\mathbf{b}, \mathbf{d s}}$ & 246 & 3.2 & $\mathrm{~K}$ \\
$\mathbf{T B}_{\mathbf{b}, \mathbf{w s}}$ & 193 & 1.4 & $\mathrm{~K}$ \\
$\mathbf{T B}_{\text {fcgv,ws }}$ & 204 & 2.3 & $\mathrm{~K}$ \\
$\mathbf{T B}_{\text {fcgv,ds }}$ & 240 & 1.5 & $\mathrm{~K}$ \\
$\mathbf{T B}_{\text {fcsv,ds }}$ & 281 & 1.0 & $\mathrm{~K}$ \\
\hline
\end{tabular}

TABLE VII

RMSD, Correlation CoefFicient $(R)$, ANd Slope Between the DISAGGREGATED AND ASTER TEMPERATURES FOR THE DATA InCLUding All the 100 ARTificially Noised Data SETS

\begin{tabular}{|c||c|c|c|}
\hline Algorithm & $\begin{array}{c}\text { RMSD } \\
{ }^{\circ} \mathrm{C}\end{array}$ & $\begin{array}{c}\mathrm{R} \\
-\end{array}$ & $\begin{array}{c}\text { Slope } \\
-\end{array}$ \\
\hline D0 & 1.81 & 0.75 & 0.63 \\
D1 & 1.58 & 0.82 & 0.76 \\
D2 & 1.54 & 0.83 & 0.76 \\
D1' & 1.57 & 0.82 & 0.73 \\
D2' $^{\prime}$ & 1.54 & 0.83 & 0.74 \\
D3 $^{\prime}$ & 1.44 & 0.85 & 0.78 \\
D4 $^{\prime}$ & 1.39 & 0.87 & 0.87 \\
D4 $^{\prime \prime}$ & 1.48 & 0.86 & 0.89 \\
\hline
\end{tabular}

896 Table VII lists the RMSD, correlation coefficient, and slope 897 between the disaggregated and ASTER temperatures for all 100 898 data sets. Although the results are generally degraded by using 899 noisy input data sets, D4" is still superior to all other algorithms 900 (see Fig. 9). Therefore, the integration of fractional open water 901 and soil evaporative efficiency into the disaggregation is able to 902 improve the representation of land surface temperature variabil903 ity despite the uncertainties in $f_{\text {ow }}$ and $\beta^{\prime}$, and the uncertainties 904 in extrapolated end-members.

\section{B. Weighting Variability Factors}

906 Results with the NAFE'06 data set have indicated that the 907 new $\mathrm{D}^{\prime}$ algorithms based on radiative transfer significantly 908 improve (in relation to D1 and D2 methods) the representation 909 of disaggregated temperature by directly integrating the various 910 input parameters of the radiative transfer equation. Another ad911 vantage of the proposed methodology is to quantify the weight 912 of these input parameters. Here, the relative weights of $f_{\mathrm{gv}}$, $913 f_{\mathrm{sv}}, f_{\mathrm{ow}}$, and $\beta^{\prime}$ are compared, and the relative improvement in 914 disaggregated temperature when including these factors in the 915 disaggregation is assessed. The weight of $f_{\mathrm{gv}}$ on the variability
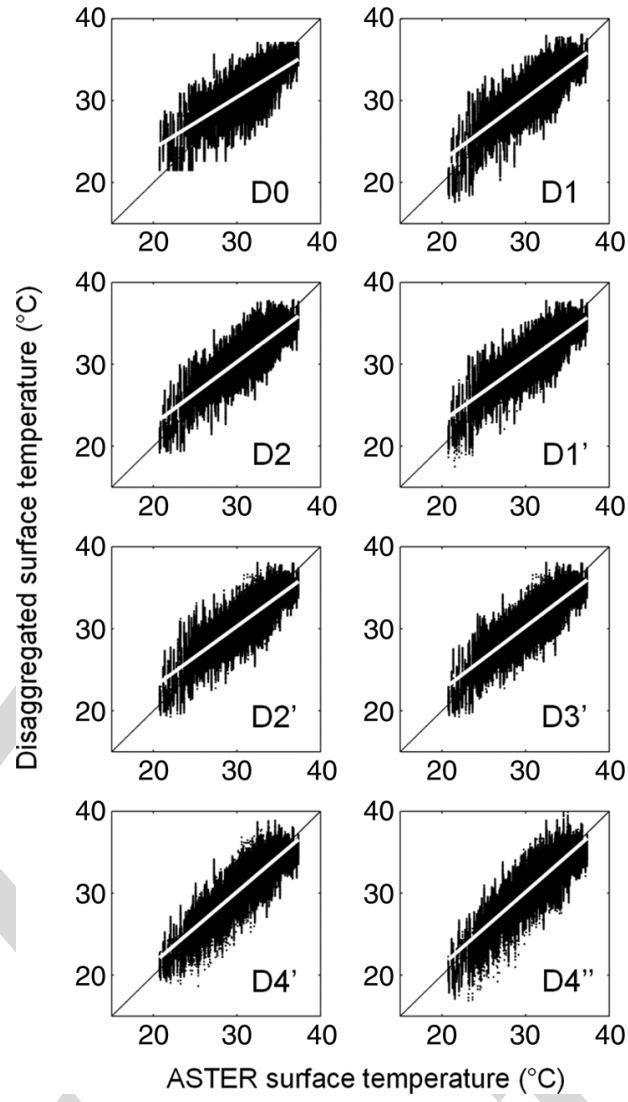

Fig. 9. As for Fig. 7 but using all the 100 artificially noised input data sets.

in land surface temperature is derived by computing the first 916 partial derivative of $T_{\bmod }$ from (15) and (16)

$$
\frac{\partial T_{\text {mod }}}{\partial f_{\mathrm{gv}}}=-\left(1-f_{\mathrm{ow}}\right)\left(\mathbf{T}_{\mathrm{fcsv}}-\mathbf{T}_{\mathrm{fcgv}}\right) .
$$

Similarly, the first partial derivative of $T_{\bmod }$ is computed with 918 respect to $f_{\mathrm{Sv}}$

$$
\frac{\partial T_{\mathrm{mod}}}{\partial f_{\mathrm{sv}}}=-\left(1-f_{\mathrm{ow}}\right)\left[\beta^{\prime} \mathbf{T}_{\mathbf{b}, \mathbf{w s}}+\left(1-\beta^{\prime}\right) \mathbf{T}_{\mathbf{b}, \mathbf{d s}}-\mathbf{T}_{\mathbf{f c s v}}\right]
$$

with respect to $f_{\text {ow }}$

$$
\begin{aligned}
& \frac{\partial T_{\mathrm{mod}}}{\partial f_{\mathrm{ow}}}=-\left[f_{\mathrm{gv}} \mathbf{T}_{\mathbf{f c g v}}+\left(f_{\mathrm{tv}}-f_{\mathrm{gv}}\right) \mathbf{T}_{\mathbf{f c s v}}\right. \\
& \left.\quad+\left(1-f_{\mathrm{tv}}\right)\left(\beta^{\prime} \mathbf{T}_{\mathbf{b}, \mathbf{w s}}+\left(1-\beta^{\prime}\right) \mathbf{T}_{\mathbf{b}, \mathbf{d s}}\right)-\mathbf{T}_{\mathbf{f c g v}}\right]
\end{aligned}
$$

and with respect to $\beta^{\prime}$

$$
\frac{\partial T_{\text {mod }}}{\partial \beta^{\prime}}=-\left(1-f_{\text {ow }}\right)\left(1-f_{\text {tv }}\right)\left(\mathbf{T}_{\mathbf{b}, \mathbf{d s}}-\mathbf{T}_{\mathbf{b}, \mathbf{w s}}\right) .
$$

Table VIII lists the standard deviation of each parameter 922 within the study area, the average of partial derivatives, and the 923 relative weight of each parameter on the variability of modeled 924 land surface temperature. The relative weights of $f_{\mathrm{gv}}, f_{\mathrm{sv}}, f_{\mathrm{ow}}, 925$ and $\beta^{\prime}$ are estimated as the mean partial derivative times the 926 standard deviation. Results indicate that all parameters have a 927 negative impact on $T$. More interestingly, $f_{\mathrm{gv}}$ appears to be 928 the most significant variability factor, with a relative weight 929 of $42 \%$, which is consistent with NDVI-based approaches [4]. 930 
TABLE VIII

Standard Deviation, Mean Partial Derivative, and Impact on High-Resolution Modeled Temperature of Each of the Four Parameters: Fractional Green Vegetation Cover, Fractional Senescent Vegetation Cover, FRACTIONAL OPEN WATER, AND SOIL EVAPORATIVE EFFICIENCY

\begin{tabular}{|c||c|c|c|}
\hline $\begin{array}{c}\text { Factor } \\
-\end{array}$ & $\begin{array}{c}\text { Standard deviation } \\
-\end{array}$ & $\begin{array}{c}\text { Mean partial derivative } \\
{ }^{\circ} \mathrm{C}\end{array}$ & $\begin{array}{c}\text { Impact on } T_{\text {mod }} \text { (percentage of total) } \\
{ }^{\circ} \mathrm{C}(\%)\end{array}$ \\
\hline$f_{\mathrm{gv}}$ & 0.11 & -13 & $0.97(42)$ \\
$f_{\mathrm{sv}}$ & 0.19 & -2.0 & $0.26(11)$ \\
$f_{\text {ow }}$ & 0.06 & -11 & $0.45(20)$ \\
$\beta^{\prime}$ & 0.19 & -4.8 & $0.17(27)$ \\
\hline
\end{tabular}

931 The second and third most significant variability factors are soil 932 evaporative efficiency and fractional open water, with relative 933 weights of $27 \%$ and $20 \%$, respectively. Finally, fractional senes934 cent vegetation cover represents only $11 \%$ of the variability 935 in land surface temperature. The low impact of $f_{\mathrm{Sv}}$ can be 936 associated with the low mean partial derivative. In particular, $937 \partial T_{\bmod } / \partial f_{\mathrm{sv}}$ is low because the temperature difference be938 tween dry bare soil $\left(\mathbf{T}_{\mathbf{b}, \mathbf{d s}}\right)$ and full-cover senescent vegetation $939\left(\mathbf{T}_{\mathbf{f c s v}}\right)$ is also low in our case study.

940 The relative weights in Table VIII are now related with 941 the disaggregation results in Table III. Consequently, the poor 942 improvement of D2 against D1 (and D2' against D1') can be 943 attributed to the relatively low weight of $f_{\mathrm{Sv}}$ in the variability of 944 land surface temperature. Conversely, the significant improve945 ments of D4" against D3', D3' against D2', and D1 (and D1') 946 against D0 are attributed to the large weights of $\beta^{\prime}, f_{\text {ow }}$, and $947 f_{\mathrm{gv}}$, respectively.

948 In summary, the variability of land surface temperature is rea949 sonably represented by model $T_{\bmod }$. Moreover, the approach 950 allows the relative weight of each variability factor to be taken 951 into account in the disaggregation procedure.

\section{SUMmARY AND CONCLUSION}

953 A new disaggregation methodology for land surface tem954 perature has been developed to integrate the main surface 955 parameters involved in the surface energy budget. It is based 956 on a linearized radiative transfer equation, which distinguishes 957 between soil, vegetation, and water temperature, and uses soil 958 evaporative efficiency and fractional senescent vegetation cover 959 to parameterize/estimate soil and vegetation hydric status, re960 spectively. The approach is implemented using four parame961 ters: the fraction of green vegetation cover derived from red 962 and near-infrared bands, the fraction of senescent vegetation 963 cover derived from red and near-infrared bands, the fraction 964 of open water derived from shortwave-infrared band, and the 965 soil evaporative efficiency derived from microwave-L band. 966 It is tested over a $5 \mathrm{~km}$ by $32 \mathrm{~km}$ area of irrigated land in 967 Australia, including flooded rice crops, using ASTER and L968 band airborne data. Low-resolution land surface temperature 969 is simulated by aggregating ASTER land surface tempera970 ture at $1-\mathrm{km}$ resolution, and the disaggregated temperature is 971 compared to high-resolution ASTER temperature. The results 972 indicate that the methodology is able to separate efficiently the 973 independent factors that impact surface temperature and to inte974 grate them consistently into the disaggregation procedure. The error in disaggregated temperature is successively reduced from 975 $1.65{ }^{\circ} \mathrm{C}$ to $1.16{ }^{\circ} \mathrm{C}$ by including each of the four parameters. 976 The correlation coefficient and slope between the disaggregated 977 and ASTER temperatures are improved from 0.79 to 0.89 and 978 from 0.63 to 0.88 , respectively. Moreover, the radiative transfer 979 equation allows quantifying the impact at high resolution of 980 each parameter on land surface temperature. In this case study, 981 fractional green vegetation cover is responsible for $42 \%$ of the 982 variability in disaggregated land surface temperature, fractional 983 senescent vegetation cover for $11 \%$, fractional open water for 984 $20 \%$, and soil evaporative efficiency for $27 \%$.

985

Note that the approach presented in this paper did not take 986 into account the water stress of green vegetation because none 987 of the considered parameters (fractional green vegetation cover, 988 fractional senescent vegetation cover, fractional open water, and 989 soil evaporative efficiency) could describe the hydric status of 990 photosynthetically active (green) vegetation. The analysis was 991 conducted solely in a highly irrigated environment in which 992 vegetation water stress was small. However, in most cases, 993 the vegetation water stress might not be negligible for natural 994 areas. In the presence of water-stressed green vegetation, the 995 scatterplot (temperature versus green vegetation cover) would 996 be transformed into a trapezoidal shape with four vertices 997 rather than a triangle. In such conditions, the disaggregation 998 problem would be partly undetermined since the partitioning 999 between unstressed and stressed green vegetations would not 1000 be represented. Consequently, the approaches shown here are 1001 not expected to be representative of other less extreme environ- 1002 ments than the present irrigated area. Nevertheless, one should 1003 keep in mind that improving the spatial resolution of land 1004 surface temperature data via disaggregation is only relevant in 1005 the conditions where the spatial variability of temperature is 1006 large.

Although the approach was successfully applied to airborne 1008 and satellite data collected during NAFE'06, further research is 1009 needed to test the disaggregation approach on a routine basis. 1010 One may anticipate that fractional green and senescent vege- 1011 tation covers could be derived accurately using FORMOSAT- 1012 like data. The FORMOSAT-2 instrument [52] provides short- 1013 wave data at high spatial resolution $(8 \mathrm{~m})$ and high temporal 1014 frequency (potentially one image per day), which allow a fine 1015 analysis of the seasonality of canopies during the crop cycle 1016 [5], [53], [54]. Fractional open water could be derived from 1017 Landsat-5 data (e.g., [20]). Although the repeat cycle of Landsat 1018 (16 days) is longer than the temporal resolution needed for land 1019 surface temperature, the seasonal variations of water bodies 1020 
1021 such as irrigation canals and flooded fields are expected to 1022 be low. Soil evaporative efficiency could be derived at high 1023 resolution from active microwave sensors, such as the Phased 1024 Array L-band SAR (PALSAR) [55]. Soil evaporative efficiency 1025 formulas express evaporation as a function of normalized sur1026 face soil moisture. Therefore, soil evaporative efficiency is 1027 equivalent to a soil moisture index, which could be replaced 1028 in (20) by the radar-derived soil wetness index computed as 1029 the observed to minimal backscattering coefficient difference 1030 divided by the maximal to minimal backscattering coefficient 1031 difference [56], [57]. Note, however, that the temporal coverage 1032 of the PALSAR fine beam dual polarization mode is relatively 1033 low, with a revisit cycle of 46 days. Consequently, accurate 1034 disaggregation of land surface temperature would still rely on 1035 the availability of high-resolution radar data.

\section{6 \\ ACKNOWLEDGMENT}

1037 The authors would like to thank the NAFE'06 participants 1038 for their participation in collecting this extensive data set.

1039

1040

1041

1042

1043

1044

1045

1046

1047

1048

1049

1050

1051

1052

1053

1054

1055

1056

1057

1058

1059

1060

1061

1062

1063

1064

1065

1066

1067

1068

1069

1070

1071

1072

1073

1074

1075

1076

1077

1078

1079

1080

1081

1082

1083
1084

1085

1086

\section{REFERENCES}

[1] S. Stisen, I. Sandholt, A. Nørgaard, R. Fensholt, and K. H. Jensen, "Combining the triangle method with thermal inertia to estimate regional evapotranspiration-Applied to MSG-SEVERI data in the Senegal River basin," Remote Sens. Environ., vol. 112, no. 3, pp. 1242-1255, Mar. 2008.

2] R. Tang, Z.-L. Li, and B. Tang, "An application of the Ts-VI method with enhanced edges determination for evapotranspiration estimation from MODIS data in arid and semi-arid regions: Implementation and validation," Remote Sens. Environ., vol. 114, no. 3, pp. 540-551, Mar. 2010. doi:DOI:10.1016/j.rse.2009.10.012.

[3] B. Seguin, F. Becker, T. Phulpin, X. F. Gu, G. Guyot, Y. Kerr, C. King, J. P. Lagouarde, C. Ottlé, M. P. Stoll, A. Tabbagh, and A. Vidal, "IRSUTE: A minisatellite project for land surface heat flux estimation from field to regional scale," Remote Sens. Environ., vol. 68, no. 3, pp. 357-369, Jun. 1999.

[4] N. Agam, W. P. Kustas, M. C. Anderson, F. Li, and C. M. U. Neale, "A vegetation index based technique for spatial sharpening of thermal imagery," Remote Sens. Environ., vol. 107, no. 4, pp. 545-558, Apr. 2007.

[5] O. Merlin, B. Duchemin, O. Hagolle, F. Jacob, B. Coudert, G. Chehbouni, G. Dedieu, J. Garatuza, and Y. Kerr, "Disaggregation of MODIS surface temperature over an agricultural area using a time series of FORMOSAT-2 images," Remote Sens. Environ., vol. 114, no. 11, pp. 2500-2512, Nov. 2010. doi:DOI:10.1016/j.rse.2010.05.025.

[6] S. B. Idso, R. D. Jackson, P. J. Pinter, R. J. Reginato, and J. L. Hatfield, "Normalizing the stress-degree-day parameter for environmental variability," Agric. Meteorol., vol. 24, no. 1, pp. 45-55, 1981.

7] R. D. Jackson, S. B. Idso, R. J. Reginato, and P. J. Pinter, "Canopy temperature as a crop water stress indicator," Water Resour. Res., vol. 17, no. 4, pp. 1133-1138, 1981 .

[8] M. S. Moran, T. R. Clarke, Y. Inoue, and A. Vidal, "Estimating crop water deficit using the relation between surface-air temperature and spectral vegetation index," Remote Sens. Environ., vol. 49, no. 3, pp. 246-263, Sep. 1994

[9] O. Merlin, J. P. Walker, J. D. Kalma, E. J. Kim, J. Hacker, R. Panciera, R. Young, G. Summerell, J. Hornbuckle, M. Hafeez, and T. J. Jackson, "The NAFE'06 data set: Towards soil moisture retrieval at intermediate resolution," Adv. Water Resour., vol. 31, no. 11, pp. 1444-1455, Nov. 2008. doi:DOI:10.1016/j.advwatres.2008.01.018.

0] R. Panciera, J. P. Walker, J. D. Kalma, E. J. Kim, J. Hacker, O. Merlin, M. Berger, and N. Skou, "The NAFE'05/CoSMOS data set: Toward SMOS calibration, downscaling and assimilation," IEEE Trans. Geosci. Remote Sens., vol. 46, no. 3, pp. 736-745, Mar. 2008. doi:DOI:10.1109/TGRS.2007.915403.

1] T. Schmugge, T. J. Jackson, W. P. Kustas, R. Roberts, R. Parry, D. C. Goodrich, S. A. Amer, and M. A. Weltz, "Push broom microwave radiometer observations of surface soil moisture in Monsoon '90,' Water Resour. Res., vol. 30, no. 5, pp. 1321-1328, 1994.
[12] M. Abrams, "The Advanced Spaceborne Thermal Emission and 1087 Reflection radiometer (ASTER): Data products for the high spatial res- 1088 olution imager on NASA's Terra platform," Int. J. Remote Sens., vol. 21, 1089 pp. 847-859, 2000.

1090

[13] K. Thome, K. Arai, S. Hook, H. Kieer, H. Lang, T. Matsunaga, A. Ono, 1091 F. Palluconi, H. Sakuma, P. Slater, T. Takashima, H. Tonooka, S. Tsuchida, 1092 R. M. Welch, and E. Zalewski, "ASTER preflight and inflight calibration 1093 and the validation of level 2 products," IEEE Trans. Geosci. Remote Sens., 1094 vol. 36, no. 4, pp. 1161-1172, Jul. 1998.

1095

[14] F. Jacob, F. Petitcolin, T. Schmugge, E. Vermote, A. French, and 1096 K. Ogawa, "Comparison of land surface emissivity and radiometric 1097 temperature derived from MODIS and ASTER sensors," Remote Sens. 1098 Environ., vol. 90, no. 2, pp. 137-152, Mar. 2004.

1099

[15] J. A. Sobrino, J. C. Jiménez-Muñoz, L. Balick, A. R. Gillespie, 1100 D. A. Sabol, and W. T. Gustafson, "Accuracy of ASTER level-2 1101 thermal-infrared standard products of an agricultural area in Spain," 1102 Remote Sens. Environ., vol. 106, no. 2, pp. 146-153, Jan. 2007. 1103 doi:DOI:10.1016/j.rse.2006.08.010.

1104

[16] C. Coll, V. Caselles, E. Valor, R. Niclòs, J. M. Sánchez, J. M. Galve, and 1105 M. Mira, "Temperature and emissivity separation from ASTER data for 1106 low spectral contrast surfaces," Remote Sens. Environ., vol. 110, no. 2, 1107 pp. 162-175, Sep. 2007. doi:DOI:10.1016/j.rse.2007.02.008. 1108

[17] A. French, T. Schmugge, J. Ritchie, A. Hsu, F. Jacob, and K. Ogawa, 1109 "Detecting land cover change at the Jornada Experimental Range, New 1110 Mexico with ASTER emissivities," Remote Sens. Environ., vol. 112, no. 4, 111 pp. 1730-1748, Apr. 2008. doi:DOI:10.1016/j.rse.2007.08.020.

[18] F. Jacob, T. Schmugge, A. Olioso, D. Courault, A. French, K. Ogawa, 1113 F. Petitcolin, G. Chehbouni, A. Pinheiro, and J. Privette, Modeling and 1114 Inversion in Thermal Infrared Remote Sensing Over Vegetated Land Sur- 1115 faces. Advances in Land Remote Sensing, vol. 10, S. Liang, Ed. New 1116 York: Springer-Verlag, 2008.

[19] D. E. Sabol, A. R. Gillespie, E. Abbott, and G. Yamada, "Field val- 1118 idation of the ASTER temperature-emissivity separation algorithm," 1119 Remote Sens. Environ., vol. 113, no. 11, pp. 2328-2344, Nov. 2009. 1120 doi:DOI:10.1016/j.rse.2009.06.008.

[20] T. G. Van Niel, T. R. McVicar, H. Fang, and S. Liang, "Calculating 1122 environmental moisture for per-field discrimination of rice crops," Int. J. 1123 Remote Sens., vol. 24, no. 4, pp. 885-890, 2003.

[21] Y. Liu, T. Hiyama, and Y. Yamaguchi, "Scaling of land surface tempera- 1125 ture using satellite data: A case examination on ASTER and MODIS prod- 1126 ucts over a heterogeneous terrain area," Remote Sens. Environ., vol. 105, 1127 no. 2 , pp. $115-128$, Nov. 2006

[22] Z. Wan and J. Dozier, "A generalized split-window algorithm for retriev- 1129 ing land-surface temperature from space," IEEE Trans. Geosci. Remote 1130 Sens., vol. 34, no. 4, pp. 892-905, Jul. 1996.

[23] G. C. Hulley and S. J. Hook, "Generating consistent land surface tem- 1132 perature and emissivity products between ASTER and MODIS data for 1133 Earth science research," IEEE Trans. Geosci. Remote Sens., vol. 49, no. 9, 1134 pp. 1304-1315, Apr. 2011. doi:DOI:10.1109/TGRS.2010.2063034. 1135

[24] M. Atitar and J. A. Sobrino, "A split-window algorithm for estimating 1136 LST from Meteosat 9 data: Test and comparison with in situ data and 1137 MODIS LSTs," IEEE Geosci. Remote Sens. Lett., vol. 6, no. 1, pp. 122- 1138 126, Jan. 2009. doi:DOI:10.1109/LGRS.2008.2006410.

[25] Y. Liu, Y. Yamaguchi, and C. Ke, "Reducing the discrepancy between 1140 ASTER and MODIS land surface temperature products," Sensors, vol. 7, 1141 pp. 3043-3057, 2007.

[26] O. Merlin, G. Chehbouni, Y. Kerr, E. G. Njoku, and D. Entekhabi, "A 1143 combined modeling and multi-spectral/multi-resolution remote sensing 1144 approach for disaggregation of surface soil moisture: Application to 1145 SMOS configuration," IEEE Trans. Geosci. Remote Sens., vol. 43, no. 9, 1146 pp. 2036-2050, Sep. 2005.

[27] T. Carlson, "An overview of the 'triangle method' for estimating surface 1148 evapotranspiration and soil moisture from satellite imagery," Sensors, 1149 vol. 7, pp. 1612-1629, 2007.

[28] M. C. Anderson, J. M. Norman, G. R. Diak, W. P. Kustas, and J. R. 1151 Mecikalski, "A two-source time-integrated model for estimating surface 1152 fluxes using thermal infrared remote sensing," Remote Sens. Environ., 1153 vol. 60, no. 2, pp. 195-216, May 1997.

[29] O. Merlin and G. Chehbouni, "Different approaches in estimating heat 1155 flux using dual angle observations of radiative surface temperature," 1156 Int. J. Remote Sens., vol. 25, no. 1, pp. 275-289, 2004.

[30] K. Nishida, R. R. Nemani, J. M. Glassy, and S. W. Running, "Develop- 1158 ment of an evapotranspiration index from Aqua/MODIS for monitoring 1159 surface moisture status," IEEE Trans. Geosci. Remote Sens., vol. 41, no. 2, 1160 pp. 493-501, Feb. 2003.

[31] G. Gutman and A. Ignatov, "The derivation of the green vegeta- 1162 tion fraction from NOAA/AVHRR data for use in numerical weather 1163 
prediction models," Int. J. Remote Sens., vol. 19, no. 8, pp. 1533-1543, 1998.

2] J. Noilhan and S. Planton, "A simple parameterization of land surface processes for meteorological models," Monthly Weather Rev., vol. 117, no. 3, pp. 536-549, 1989.

33] D. A. Roberts, M. O. Smith, and J. B. Adams, "Green vegetation, nonphotosynthetic vegetation, and soils in AVIRIS data," Remote Sens. Environ. vol. 44, no. 2/3, pp. 255-269, May 1993.

4] M. Weiss, F. Baret, M. Leroy, A. Begué, O. Hautecoeur, and R. Santer, "Hemispherical reflectance and albedo estimates from the accumulation of across track sun synchronous satellite data," J. Geophys. Res., vol. 104, no. D18, pp. 221-232, 1999.

5] F. Jacob, A. Olioso, M. Weiss, F. Baret, and O. Hautecoeur, "Mapping short-wave albedo of agricultural surfaces using airborne PolDER data," Remote Sens. Environ., vol. 80, no. 1, pp. 36-46, Apr. 2002.

6] F. Jacob, M. Weiss, A. Olioso, and A. French, "Assessing the narrowband to broadband conversion to estimate visible, near infrared and shortwave apparent albedo from airborne PolDER data," Agronomie, vol. 22, no. 6, pp. 537-546, Sep./Oct. 2002.

37] F. Jacob and A. Olioso, "Derivation of diurnal courses of albedo and reflected solar irradiance from airborne PolDER data acquired near solar noon," J. Geophys. Res., vol. 110, no. D10, p. D10 104, May 2005.

38] A. Bsaibes, D. Courault, F. Baret, M. Weiss, A. Olioso, F. Jacob, O. Hagolle, O. Marloie, N. Bertrand, V. Desfond, and F. Kzemipour, "Albedo and LAI estimates from FORMOSAT-2 data for crop monitoring," Remote Sens. Environ., vol. 113, no. 4, pp. 716-729, Apr. 2009. doi:DOI:10.1016/j.rse.2008.11.014.

39] P. M. Barbosa, M. A. Casterad, and J. Herrero, "Performance of several Landsat 5 Thematic Mapper (TM) image classification methods for crop extent estimates in an irrigation district," Int. J. Remote Sens., vol. 17, no. 18, pp. 3665-3674, Dec. 1996.

[40] H. Xu, "Modification of normalized difference water index (NDWI) to enhance open water features in remotely sensed imagery," Int. J. Remote Sens., vol. 27, no. 14, pp. 3025-3033, Jul. 2006.

1] W. P. Kustas, T. J. Schmugge, K. S. Humes, T. J. Jackson, R. Parry, M. A. Weltz, and M. S. Moran, "Relationships between evaporative fraction and remotely sensed vegetation index and microwave brightness temperature for semiarid rangelands," J. Appl. Meteor., vol. 32, no. 12, pp. 1781-1790, Dec. 1993.

42] J. W. Deardorff, "Efficient prediction of ground temperature and moisture with inclusion of a layer of vegetation," J. Geophys. Res., vol. 83, no. C4, pp. 1889-1903, Apr. 1978.

43] P. J. Camillo and R. J. Gurney, "A resistance parameter for bare soil evaporation models," Soil Sci., vol. 141, no. 2, pp. 95-105, Feb. 1986.

4] F. T. Ulaby, R. K. Moore, and A. K. Fung, Microwave Remote Sensing. Active and Passive, vol. 2. Norwood, MA: Artech House, 1982.

5] T. J. Schmugge, "Applications of passive microwave observations of surface soil moisture," J. Hydrol., vol. 212/213, pp. 188-197, Dec. 1998.

6] M. C. Anderson, J. M. Norman, W. P. Kustas, R. Houborg, P. J. Starks, and N. Agam, "A thermal-based remote sensing technique for routine mapping of land-surface carbon, water and energy fluxes from field to regional scales," Remote Sens. Environ., vol. 112, no. 12, pp. 4227-4241, Dec. 2008. doi:DOI:10.1016/j.rse.2008.07.009.

7] L. M. Montandon and E. E. Small, "The impact of soil reflectance on the quantification of the green vegetation fraction from NDVI," Remote Sens. Environ., vol. 112, no. 4, pp. 1835-1845, Apr. 2008. doi:DOI:10.1016/j.rse.2007.09.007.

8] E. G. Njoku and D. Entekhabi, "Passive microwave remote sensing of soil moisture," J. Hydrol., vol. 184, no. 1/2, pp. 101-129, Oct. 1996.

9] J.-P. Wigneron, Y. Kerr, P. Waldteufel, K. Saleh, M.-J. Escorihuela, P. Richaume, P. Ferrazzoli, P. de Rosnay, R. Gurneye, J.-C. Calvet, J. P. Grant, M. Guglielmettih, B. Hornbuckle, C. Matzler, T. Pellarin, and M. Schwank, "L-band Microwave Emission of the Biosphere (L-MEB) model: Description and calibration against experimental data sets over crop fields," Remote Sens. Environ., vol. 107, no. 4, pp. 639-655, Apr. 2007. doi:DOI:10.1016/j.rse.2008.10.014.
[50] K. Saleh, J.-P. Wigneron, P. de Rosnay, J.-C. Calvet, M. J. Escorihuela, 1230 Y. Kerr, and P. Waldteufel, "Impact of rain interception by vegetation and 1231 mulch on the L-band emission of natural grass," Remote Sens. Environ., 1232 vol. 101, no. 1, pp. 127-139, Mar. 2006.

[51] K. Saleh, J.-P. Wigneron, P. Waldteufel, P. deRosnay, M. Schwank, 1234 J.-C. Calvet, and Y. H. Kerr, "Estimates of surface soil moisture under 1235 grass covers using L-band radiometry," Remote Sens. Environ., vol. 109, 1236 no. 1, pp. 42-53, Jul. 2007.

[52] J.-S. Chern, J. Ling, and S.-L. Weng, "Taiwan's second remote sensing 1238 satellite," Acta Astronaut., vol. 63, no. 11/12, pp. 1305-1311, Dec. 2008. 1239 doi:DOI:10.1016/j.actaastro.2008.05.022.

[53] B. Duchemin, O. Hagolle, B. Mougenot, I. Benhadj, R. Hadria, 1241 V. Simonneaux, J. Ezzahar, J. Hoedjes, S. Khabba, M. H. Kharrou, 1242 G. Boulet, G. Dedieu, S. Er-Raki, R. Escadafal, A. Olioso, and 1243 A. G. Chehbouni, "Agrometeorological study of semi-arid areas: An 1244 experiment for analysing the potential of time series of FORMOSAT-2 1245 images (Tensift-Marrakech plain)," Int. J. Remote Sens., vol. 29, no. 17, 1246 pp. 5291-5299, 2008. doi:DOI:10.1080/01431160802036482. 1247

[54] R. Hadria, B. Duchemin, L. Jarlan, G. Dedieu, F. Baup, S. Khabba, 1248 A. Olioso, and T. Le Toan, "Potentiality of optical and radar satellite data 1249 at high spatio-temporal resolutions for the monitoring of irrigated wheat 1250 crops in Morocco," Int. J. Appl. Earth Obs. Geoinf., vol. 12, pp. S32-S37, 1251 Feb. 2010. doi:DOI:10.1016/j.jag.2009.09.003.

[55] A. Rosenqvist, M. Shimada, N. Ito, and M. Watanabe, "ALOS PALSAR: 1253 A pathfinder mission for global-scale monitoring of the environment," 1254 IEEE Trans. Geosci. Remote Sens., vol. 45, no. 11, pp. 3307-3316, 1255 Nov. 2007.

[56] W. Wagner, G. Lemoine, M. Borgeaud, and H. Rott, "A study of vegetation 1257 cover effects on ERS scatterometer data," IEEE Trans. Geosci. Remote 1258 Sens., vol. 37, no. 2, pp. 938-948, Mar. 1999.

[57] R. Fieuzal, B. Duchemin, L. Jarlan, M. Zribi, F. Baup, O. Merlin, 1260 O. Hagolle, and J. Garatuza-Payan, "Combined use of optical and radar 1261 satellite data for the monitoring of irrigation and soil moisture of wheat 1262 crops," Hydrol. Earth Syst. Sci., vol. 15, no. 4, pp. 1117-1129, 2011. 1263 doi:DOI:10.5194/hess-15-117-2011.

Olivier Merlin, photograph and biography not available at the time of 1265 AQ4 publication.

Frédéric Jacob, photograph and biography not available at the time of 1267 publication.

Jean-Pierre Wigneron, photograph and biography not available at the time of 1269 publication.

Jeffrey Walker, photograph and biography not available at the time of 1271 publication.

Ghani Chehbouni, photograph and biography not available at the time of 1273 publication. 


\section{AUTHOR QUERIES}

\section{AUTHOR PLEASE ANSWER ALL QUERIES}

Please be aware that the authors are required to pay overlength page charges ( $\$ 200$ per page) if the paper is longer than 6 pages. If you cannot pay any or all of these charges please let us know.

AQ1 = Please provide the current affiliation (name and specific address of the company) of authors "Frederic Jacob," "Jean-Pierre Wigneron," "Jeffrey Walker," and "Ghani Chehbouni."

AQ2 = The sentence that starts with "It is a three-step procedure..." was modified to properly introduce the list. Please check if the thought is preserved, and correct if necessary.

AQ3 = The caption for Table III was modified. Please check if the thought is preserved, and correct if necessary.

AQ4 = Please provide photo and biography of all authors.

END OF ALL QUERIES 


\title{
- Multidimensional Disaggregation of Land Surface \\ Temperature Using High-Resolution Red, Near-Infrared, Shortwave-Infrared, and Microwave-L Bands
}

\author{
Olivier Merlin, Frédéric Jacob, Jean-Pierre Wigneron, Jeffrey Walker, and Ghani Chehbouni
}

6 Abstract-Land surface temperature data are rarely available 7 at high temporal and spatial resolutions at the same locations. To 8 fill this gap, the low spatial resolution data can be disaggregated 9 at high temporal frequency using empirical relationships between 10 remotely sensed temperature and fractional green (photosynthet11 ically active) and senescent vegetation covers. In this paper, a 12 new disaggregation methodology is developed by physically link13 ing remotely sensed surface temperature to fractional green and 14 senescent vegetation covers using a radiative transfer equation. 15 Moreover, the methodology is implemented with two additional 16 factors related to the energy budget of irrigated areas, being the 17 fraction of open water and soil evaporative efficiency (ratio of 18 actual to potential soil evaporation). The approach is tested over 19 a $5 \mathbf{~ k m}$ by $32 \mathbf{~ k m}$ irrigated agricultural area in Australia using 20 airborne Polarimetric L-band Multibeam Radiometer brightness 21 temperature and spaceborne Advanced Scanning Thermal 22 Emission and Reflection radiometer (ASTER) multispectral data. 23 Fractional green vegetation cover, fractional senescent vegeta24 tion cover, fractional open water, and soil evaporative efficiency 25 are derived from red, near-infrared, shortwave-infrared, and mi26 crowave-L band data. Low-resolution land surface temperature 27 is simulated by aggregating ASTER land surface temperature to $281-\mathrm{km}$ resolution, and the disaggregated temperature is verified 29 against the high-resolution ASTER temperature data initially used 30 in the aggregation process. The error in disaggregated tempera31 ture is successively reduced from $1.65{ }^{\circ} \mathrm{C}$ to $1.16{ }^{\circ} \mathrm{C}$ by includ32 ing each of the four parameters. The correlation coefficient and 33 slope between the disaggregated and ASTER temperatures are 34 improved from 0.79 to 0.89 and from 0.63 to 0.88 , respectively. 35 Moreover, the radiative transfer equation allows quantification of 36 the impact on disaggregation of the temperature at high resolution 37 for each parameter: fractional green vegetation cover is respon-

Manuscript received December 2, 2010; revised June 28, 2011; accepted September 11, 2011. This work was supported in part by the French program Terre-Océan-Surfaces-Continentales-Atmosphère and in part by the Centre National de la Recherche Scientifique. The National Airborne Field Experiments have been made possible through infrastructure (LE0453434 and LE0560930) and research (DP0557543) funding from the Australian Research Council and the collaboration of a large number of scientists from throughout Australia, U.S., and Europe. Initial setup and maintenance of the study catchments were funded by a research Grant (DP0343778) from the Australian Research Council and by the CRC for Catchment Hydrology.

O. Merlin is with the Centre d'Etudes Spatiales de la Biosphère (CESBIO), 31401 Toulouse, France (e-mail: olivier.merlin@cesbio.cnes.fr).

F. Jacob (e-mail: frederic.jacob@supagro.inra.fr).

J.-P. Wigneron (e-mail: jpwigner@bordeaux.inra.fr).

J. Walker (e-mail: jeff.walker@monash.edu).

G. Chehbouni (e-mail: ghani.chehbouni@cesbio.cnes.fr).

Color versions of one or more of the figures in this paper are available online at http://ieeexplore.ieee.org.

Digital Object Identifier 10.1109/TGRS.2011.2169802 sible for $\mathbf{4 2 \%}$ of the variability in disaggregated temperature, 38 fractional senescent vegetation cover for $\mathbf{1 1 \%}$, fractional open 39 water for $20 \%$, and soil evaporative efficiency for $27 \%$.

Index Terms-Advanced Scanning Thermal Emission and Re- 41 flection radiometer (ASTER), brightness temperature, disaggre- 42 gation, evaporative efficiency, land surface temperature, Moderate 43 Resolution Imaging Spectroradiometer (MODIS), multispectral, 44 open water, soil moisture, vegetation fraction.

\section{INTRODUCTION}

$\mathbf{R}$ EMOTELY sensed land surface temperature is a signature 47 of the thermodynamic equilibrium state of the surface 48 skin. Consequently, it provides the potential to monitor dy- 49 namic information on instantaneous energy and water fluxes 50 at the land-surface-atmosphere interface. Nevertheless, the op- 51 erational use of thermal remote sensing for hydrological and 52 water resource management studies has been limited to regional 53 scale applications (e.g., [1] and [2]) mainly because the spatial 54 resolution (larger than $1 \mathrm{~km}$ ) of current high temporal resolution 55 thermal sensors is too coarse to represent the heterogeneity of 56 man-made landscapes. For example, the Moderate Resolution 57 Imaging Spectroradiometer (MODIS) has a revisit frequency 58 of 1 or 2 times per day but a spatial resolution of only $1 \mathrm{~km}, 59$ while the Advanced Scanning Thermal Emission and Reflection 60 radiometer (ASTER) has a spatial resolution of $90 \mathrm{~m}$ but a 61 revisit time of only 16 days.

The use of remotely sensed land surface temperature over 63 agricultural areas requires data at both high spatial and temporal 64 resolutions [3]. While there is a lack of high spatial resolution 65 thermal data from satellite with high frequency, there is the 66 potential for land surface temperature derived from kilomet- 67 ric resolution sensors having high temporal resolution to be 68 disaggregated using high spatial resolution ancillary data. The 69 first disaggregation approach of remotely sensed temperature 70 was developed by [4] using the fractional green vegetation 71 cover derived from red and near-infrared reflectances. Given 72 the high temperature difference between bare soil and a well- 73 watered crop, this approach has proved to be effective over 74 areas with relatively uniform soil and vegetation hydric status. 75 Recently, [5] has extended the approach of [4] to conditions 76 where vegetation hydric status is heterogeneous. This required 77 developing a methodology to estimate the fraction of senescent 78 vegetation cover from a time series of FORMOSAT-2 images. 79 
80 The accuracy in disaggregated temperature was improved by 81 taking into account fractional senescent vegetation cover in 82 addition to fractional green vegetation cover.

83 Fractional green and senescent vegetation covers, however, 84 are not the only factors explaining the spatial variations of land 85 surface temperature, especially over irrigated areas where crop 86 fields may have different moisture status to the surrounds. In 87 particular, the temperature over a flooded crop field may be 88 drastically different from the temperature over a mature crop 89 field. Therefore, the fraction of open water is an important 90 variable to represent the spatial variations of land surface tem91 perature. Over nonwatered land surfaces, the soil evaporative 92 efficiency (ratio of actual to potential soil evaporation) is a 93 signature of the capacity of the soil to evaporate its water 94 content in the near surface and thus to counter an increase of 95 its thermodynamic temperature. Consequently, soil evaporative 96 efficiency is also an essential variable to describe the spatial 97 variations of land surface temperature. Moreover, knowledge 98 of soil evaporative efficiency is needed to decouple the effects 99 of soil and vegetation hydric status on the surface energy 100 budget and hence to better represent the resultant radiative 101 surface temperature. As an example, the crop water stress index 102 (CWSI) [6], [7] can be used to detect plant stress based on the 103 difference between foliage and air temperature. Nevertheless, 104 the application of the CWSI to partially vegetated areas is 105 subjected to large uncertainties because the soil background 106 may have a different temperature to the plants [7] depending 107 on soil evaporative efficiency. Another example is provided by 108 Moran et al. [8] who proposed the vegetation index/temperature 109 (VIT) trapezoid to estimate a most probable range of plant 110 stress over partially vegetated fields. It is a three-step procedure 111 in which the following steps are performed: 1) the temperatures 112 of the four vertices of the VIT trapezoid are estimated using an 113 energy budget model; 2) the minimum and maximum probable 114 vegetation temperatures are estimated from the measured com115 posite land surface temperature, together with the maximum 116 and minimum simulated soil temperatures; and 3) the minimum 117 and maximum probable CWSIs are computed by normalizing 118 the minimum and maximum probable vegetation temperatures 119 from the vegetation temperature extremes simulated by the 120 energy budget model. The point is that this approach does not 121 allow estimating a single CWSI value because the retrieval 122 problem is underdetermined. In particular, Moran et al. [8] 123 noted that "with knowledge of a second point within the 124 hourglass (perhaps soil temperature), it would be possible to 125 infer [the canopy-air temperature] difference and pinpoint the 126 CWSI value." In the latter case, knowledge of soil temperature 127 is equivalent to knowledge of soil evaporative efficiency, which 128 would remove the underdetermination of the VIT trapezoid.

129 The objective of this paper is to develop a new disaggrega130 tion methodology of kilometric land surface temperature using 131 hectometric multivariable ancillary data. The approach is based 132 on a radiative transfer equation that estimates differences in 133 temperature data at hectometric resolution. Specifically, the use 134 of a radiative transfer equation allows the following: 1) includ135 ing variables other than those used by previous disaggregation 136 approaches and 2) deducing the most pertinent variables. In 137 addition to fractional green and senescent vegetation covers, the new methodology includes the variability at hectometric reso- 138 lution of fractional open water and soil evaporative efficiency. 139 With respect to other disaggregation algorithms in literature 140 [4], [5], the proposed technique differs in the following four 141 main aspects: 1) it relies on a physically based radiative transfer 142 equation rather than empirical linear regressions; 2) it takes 143 into account the fractional open water derived from shortwave- 144 infrared band as required; 3) it takes into account the soil hydric 145 status via microwave-derived soil evaporative efficiency; and 146 4) it allows the relative weight of each parameter used for 147 disaggregating temperature to be quantified.

148

The new disaggregation technique is compared to the ex- 149 isting approaches using data collected during the National 150 Airborne Field Experiment in 2006 (NAFE'06; [9]). The ex- 151 perimental site covers a $5 \mathrm{~km}$ by $32 \mathrm{~km}$ irrigated agricultural 152 area, which included approximately 5\% of flooded rice crops 153 during NAFE'06. Disaggregation algorithms are first tested by 154 aggregating ASTER temperature at $1-\mathrm{km}$ resolution and by 155 comparing the disaggregated temperature to the high-resolution 156 ASTER temperature initially used in the aggregation process. 157 The application to aggregated ASTER data allows evaluating 158 approaches independently of differences between ASTER and 159 MODIS products [5]. Disaggregation algorithms are then ap- 160 plied to MODIS data.

\section{EXPERIMENTAL DATA}

162

The study area is a $5 \mathrm{~km}$ by $32 \mathrm{~km}$ area included in the 163 Coleambally Irrigation Area (CIA) located in the flat west- 164 ern plains of the Murrumbidgee catchment in southeastern 165 Australia $\left(35^{\circ} \mathrm{S}, 146^{\circ} \mathrm{E}\right)$. The principal summer crops grown 166 in the CIA are rice, maize, and soybeans, while winter crops 167 include wheat, barley, oats, and canola. In November, rice crops 168 are flooded under $30 \mathrm{~cm}$ height of irrigation water.

The NAFE'06 was conducted from October 31 to 170 November 20, 2006, over a $40 \mathrm{~km}$ by $60 \mathrm{~km}$ area, with more 171 detailed flights over the $5 \mathrm{~km}$ by $32 \mathrm{~km}$ focus area studied 172 in this paper. While a full description of the NAFE'06 data 173 set is given in [9], a brief overview of the most pertinent 174 details is provided here. The data used in this paper are 175 comprised of airborne L-band brightness temperature; ASTER 176 red, near-infrared, and shortwave-infrared reflectances; ASTER 177 land surface temperature data (resampled at 250-m resolution); 178 MODIS land surface temperature data; and air temperature data 179 collected by a meteorological station in the NAFE'06 area.

\section{A. PLMR}

The Polarimetric L-band Multibeam Radiometer (PLMR) is 182 an airborne instrument that measures both $\mathrm{H}$ and $\mathrm{V}$ polariza- 183 tions using a single receiver with polarization switching at view 184 angles of $\pm 7^{\circ}, \pm 21.5^{\circ}$, and $\pm 38.5^{\circ}$. The accuracy of the PLMR 185 is estimated to be better than $2 \mathrm{~K}$ and $3 \mathrm{~K}$ in the $\mathrm{H}$ and $\mathrm{V} 186$ polarization, respectively [10].

During NAFE'06, the PLMR flew on November 14 to collect 188 L-band brightness temperature at 250-m resolution over the 189 $5 \mathrm{~km}$ by $32 \mathrm{~km}$ area in the CIA. PLMR was mounted in the 190 across-track configuration so that each pixel was observed at a 191 
192 given incidence angle (approximately $7^{\circ}, 21.5^{\circ}$, or $38.5^{\circ}$ ). Data 193 were processed for incidence angle and beam location on the 194 ground by taking into account aircraft position, attitude, and 195 ground topography.

196 As the sensitivity to soil moisture is higher for H-polarized 197 brightness temperature than for V-polarized brightness temper198 ature, only the $\mathrm{H}$-polarized brightness temperature $T B$ is used 199 in this paper. Preprocessing of $T B$ consists of the following: 200 1) resampling H-polarized PLMR data at 250-m resolution 201 on a grid that matches in symmetry to the flight lines over 202 the $5 \mathrm{~km}$ by $32 \mathrm{~km}$ area and 2) converting the resampled $203 T B$ to an equivalent value at $21.5^{\circ}$ incidence angle. The in204 cidence angle $21.5^{\circ}$ is chosen to minimize conversion errors. 205 The angular conversion involves the brightness temperature 206 collected by inner beams at approximately $7^{\circ}$ incidence angle 207 being multiplied by the ratio $\overline{T B_{\mathrm{MB}}} / \overline{T B_{\mathrm{IB}}}$, with $\overline{T B_{\mathrm{MB}}}$ and $208 \overline{T B_{\text {IB }}}$ being the mean brightness temperatures collected by the 209 middle and inner beams, respectively. Similarly, the brightness 210 temperature collected by the outer beams at approximately $21138.5^{\circ}$ incidence angle is multiplied by the ratio $\overline{T B_{\mathrm{MB}}} / \overline{T B_{\mathrm{OB}}}$, 212 with $\overline{T B_{\mathrm{OB}}}$ being the mean brightness temperature collected by 213 the outer beams. Mean brightness temperatures $\overline{T B_{\mathrm{IB}}}, \overline{T B_{\mathrm{MB}}}$, 214 and $\overline{T B_{\mathrm{OB}}}$ are computed as the average (for all flight lines) 215 of the $T B$ collected by the beams pointing at $\pm 7^{\circ}, \pm 21.5^{\circ}$, 216 and $\pm 38.5^{\circ}$, respectively. This technique was already used in 217 [11] to generate $T B$ images by assuming that the impact of 218 soil moisture and biomass on the angular dependance of TB is 219 negligible or small. In this paper, a slightly different approach 220 is adopted to take into account the variations in aircraft attitude 221 during data collection, which made the incidence angle $\theta$ os222 cillate around $7^{\circ}, 21.5^{\circ}$, and $38.5^{\circ}$. The brightness temperature $223 T B(\theta)$ observed at the incidence angle $\theta$ is multiplied by the 224 ratio $\overline{T B_{\mathrm{MB}}} / \overline{T B_{\text {interp }}(\theta)}$, with $\overline{T B_{\text {interp }}(\theta)}$ being the mean 225 brightness temperature linearly interpolated at $\theta$ incidence an226 gle from the mean data collected by the inner, middle, and outer 227 beams.

\section{B. ASTER}

229 The ASTER instrument was launched in 1999 aboard Terra, a 230 sun synchronous platform with 11:00 UTC descending Equator 231 crossing and a 16-day revisit cycle. An ASTER scene covers an 232 area of approximately $60 \mathrm{~km}$ by $60 \mathrm{~km}$ and consists of 14 nadir233 looking bands and one oblique-looking band to create stereo234 based digital elevation models. The three nadir-looking bands 235 in the visible and near infrared have a $15-\mathrm{m}$ resolution. The six 236 bands in the shortwave-infrared have a 30-m resolution. Finally, 237 there are five thermal infrared bands with a 90-m resolution.

238 The ASTER overpass of the NAFE'06 site was on 239 November 16, 2006. Official ASTER products [12] were used 240 here for surface reflectance (AST_07) and radiometric temper241 ature (AST_08) with accuracies of 5\% and $1.5 \mathrm{~K}$, respectively 242 [13]-[19]. They were downloaded from the Earth Observing 243 System Data Gateway (EDG).

244 ASTER 15-m resolution red (B2) and near-infrared (B3) 245 bands were extracted over the $5 \mathrm{~km}$ by $32 \mathrm{~km}$ area and re246 sampled at 250-m resolution to match the spatial resolution 247 and extent of PLMR observations. The ASTER 30-m resolution
B5 band $(1.60-1.70 \mu \mathrm{m})$ was extracted over the $5 \mathrm{~km}$ by 248 $32 \mathrm{~km}$ study area and resampled at 50-m resolution. Fractional 249 open water was estimated using B5 band [20] based on a 250 threshold method. Consequently, B5 data were resampled at 251 a resolution finer than that $(250 \mathrm{~m})$ of PLMR data to classify 252 open water pixels at 50-m resolution and to obtain fractional 253 open water at 250-m resolution from the binary classification. 254 ASTER 90-m resolution radiometric temperature was extracted 255 over the $5 \mathrm{~km}$ by $32 \mathrm{~km}$ area and aggregated at 250-m res- 256 olution to match the spatial resolution and extent of PLMR 257 observations. Aggregation was achieved by linearly averaging 258 high-resolution surface temperatures, i.e., without accounting 259 for the nonlinear relationship between physical temperature and 260 radiance. This choice was motivated by the results of [21], 261 which compared the temperature aggregated using different 262 scaling approaches and obtained very low differences (maxi- 263 mum difference of $0.2^{\circ} \mathrm{C}$ ).

The MODIS/Terra data were collected concurrently with 266 ASTER data. MODIS official products consisted of the 928-m 267 resolution surface skin temperature (MOD11-L2) retrieved by 268 the "generalized split window" algorithm [22]-[24] and reg- 269 istered in the sinusoidal projection. The MODIS Reprojection 270 Tool was used to project MOD11-L2 data in UTM WGS 1984271 $55 \mathrm{~S}$ with a sampling interval of $1 \mathrm{~km}$.

272

In this paper, the disaggregation of 1-km MODIS tempera- 273 ture is evaluated using high-resolution ASTER data. To distin- 274 guish the errors associated with the disaggregation technique 275 and the errors associated with the discrepancy between MODIS 276 and ASTER temperature products, a comparison is made be- 277 tween ASTER and MODIS data at $1-\mathrm{km}$ resolution over the 278 $5 \mathrm{~km}$ by $32 \mathrm{~km}$ study area. The ASTER data are aggregated 279 at the MODIS spatial resolution $(1 \mathrm{~km})$ by linearly averaging 280 high-resolution temperatures. The root-mean-square difference 281 (RMSD), bias, correlation coefficient, and slope of the linear 282 regression between MODIS and aggregated ASTER data are 283 $2.7{ }^{\circ} \mathrm{C},-2.3{ }^{\circ} \mathrm{C}, 0.75$, and 0.52 , respectively. The discrepancy 284 between MODIS and ASTER data, which is mainly explained 285 here by a significant bias and a relatively low slope of the linear 286 regression, is on the same order of magnitude as the mean 287 difference (about $3{ }^{\circ} \mathrm{C}$ ) reported in literature [5], [21], [25].

288

\section{Disaggregation Algorithms}

This paper aims to compare different approaches for dis- 290 aggregating kilometric MODIS land surface temperature data. 291 The study uses aggregated ASTER and real MODIS data 292 and demonstrates the disaggregation at 250-m resolution. The 293 resolution of $250 \mathrm{~m}$ is chosen to match with the lowest reso- 294 lution at which ancillary data composed of red, near-infrared, 295 shortwave-infrared, and microwave-L bands are available. In 296 this case study, the target scale is determined by the resolution 297 $(250 \mathrm{~m})$ of airborne microwave data.

298

As shown in the schematic diagram of Fig. 1, the disaggre- 299 gation algorithms are noted as $D k$, with $k$ being the number 300 of factors taken into account in the disaggregation. The new 301 


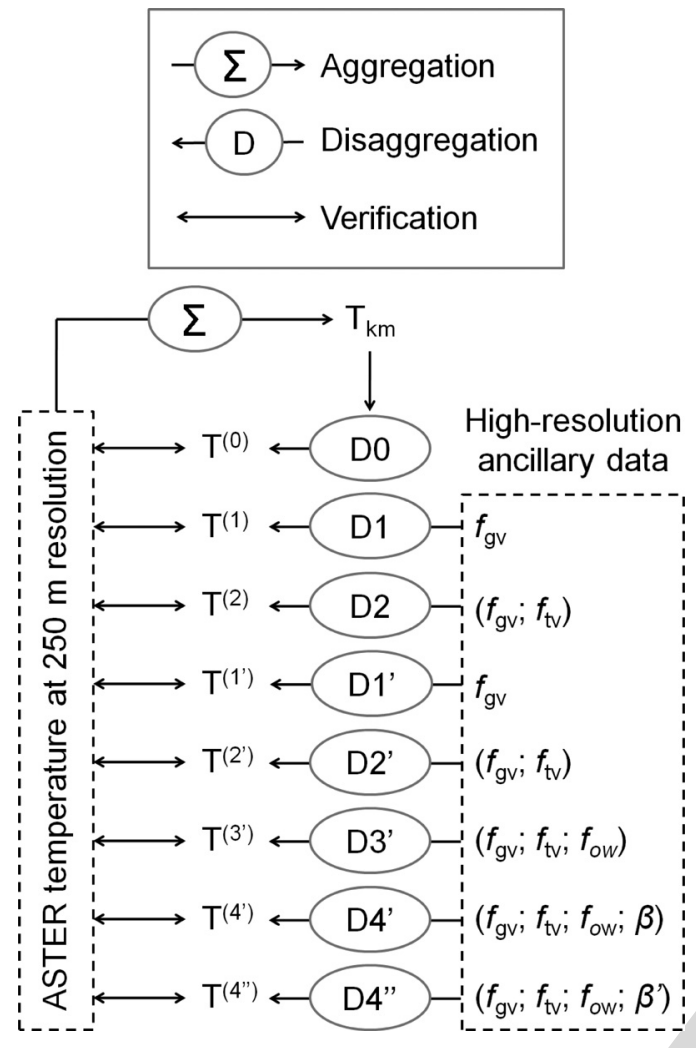

Fig. 1. Schematic diagram presenting the different disaggregation algorithms of kilometric temperature $T_{\mathrm{km}}$ and the verification strategy at high $(250 \mathrm{~m})$ resolution.

302 algorithms are noted as $\mathrm{Dk}^{\prime}$. D0 does not use any ancillary 303 data, while D1 is based on a linear regression between land 304 surface temperature and fractional green (photosynthetically 305 active) vegetation cover. Fractional green vegetation cover $f_{\mathrm{gv}}$ 306 is defined as the surface area of green vegetation per unit area 307 of soil. D1 is the same as in [4]. D2 is based on D1 but 308 takes into account both fractional green and total vegetation 309 covers. Fractional vegetation cover $f_{\mathrm{tv}}$ is defined as the total 310 surface area of (green plus senescent) vegetation per unit area 311 of soil. D2 is the same as in [5]. The new algorithms D1', $312 \mathrm{D} 2^{\prime}, \mathrm{D} 3^{\prime}$, and $\mathrm{D} 4^{\prime}$ (and $\mathrm{D} 4^{\prime \prime}$ ) are all derived from a radiative 313 transfer equation. The four algorithms differ with regard to the 314 number of factors which are explicitly taken into account. D1' 315 includes the variability of $f_{\mathrm{gv}}$ and is thus a substitute for D1 316 based on radiative transfer. D2 $2^{\prime}$ includes the variability of both $317 f_{\mathrm{gv}}$ and $f_{\mathrm{tv}}$ and is thus a substitute for $\mathrm{D} 2$ based on radiative 318 transfer. The other algorithms D ${ }^{\prime}$ and $\mathrm{D} 4^{\prime}$ integrate additional 319 variables. D $3^{\prime}$ includes the variability of $f_{\mathrm{gv}}, f_{\mathrm{tv}}$, and fractional 320 open water $f_{\text {ow }}$. D 4 ' includes the variability of $f_{\mathrm{gv}}, f_{\mathrm{tv}}, f_{\mathrm{ow}}$, 321 and soil evaporative efficiency (ratio of actual to potential soil 322 evaporation) $\beta$. D $4^{\prime \prime}$ is the same as $\mathrm{D} 4^{\prime}$ but with a different 323 formulation for soil evaporative efficiency.

324 D0 sets the disaggregated temperature as

$$
T^{(0)}=T_{\mathrm{km}}
$$

325 with $T_{\mathrm{km}}$ being the land surface temperature observed at kilo326 metric resolution.
Using D1, the disaggregated temperature is computed as

$$
T^{(1)}=T_{\mathrm{km}}+\mathbf{a}_{\mathbf{1}} \times\left(f_{\mathrm{gv}}-\left\langle f_{\mathrm{gv}}\right\rangle_{\mathrm{km}}\right)
$$

with $f_{\mathrm{gv}}$ being the fractional green vegetation cover derived at 328 high resolution, $\left\langle f_{\mathrm{gv}}\right\rangle_{\mathrm{km}}$ being the $f_{\mathrm{gv}}$ aggregated at kilometric 329 resolution, and $\mathbf{a}_{\mathbf{1}}$ being the slope of the linear regression 330 between $T_{\mathrm{km}}$ and $\left\langle f_{\mathrm{gv}}\right\rangle_{\mathrm{km}}$. Note that the variables defined at 331 kilometric resolution are noted with the subscript $\mathrm{km}$.

Using D2, the disaggregated temperature is computed as

$$
T^{(2)}=T_{\mathrm{km}}+\mathbf{a}_{\mathbf{1}}^{\text {proj }} \times\left(f_{\mathrm{gv}}^{\text {proj }}-\left\langle f_{\mathrm{gv}}\right\rangle_{\mathrm{km}}\right)
$$

with $f_{\mathrm{gv}}^{\text {proj }}$ being the projected $f_{\mathrm{gv}}$ and $\mathbf{a}_{1}^{\text {proj }}$ being the slope 334 of the linear regression between $T_{\mathrm{km}}$ and the projected $f_{\mathrm{gv}}$ es- 335 timated at kilometric resolution $f_{\mathrm{gv}, \mathrm{km}}^{\mathrm{proj}}$. Note that the variables 336 defined at the image scale are written in bold. The notion of 337 a "projected variable" was introduced in [26]. It is a robust 338 tool that strenghtens the correlation between two variables by 339 representing the dependence of these variables on other addi- 340 tional variables. In [5], the projection technique was applied 341 to fractional green vegetation cover to artificially improve the 342 spatial correlation between $T$ and $f_{\mathrm{gv}}$ by taking into account 343 the dependence of $T$ on $f_{\mathrm{tv}}$. The projected fractional green 344 vegetation cover is computed as

$$
f_{\mathrm{gv}}^{\mathrm{proj}}=f_{\mathrm{gv}}-\frac{\mathbf{T}_{\mathbf{f c s v}}-\left(\mathbf{T}_{\mathbf{b}, \mathbf{d s}}+\mathbf{T}_{\mathbf{b}, \mathbf{w s}}\right) / 2}{\mathbf{T}_{\mathbf{f c s v}}-\mathbf{T}_{\mathbf{f c g v}}} \times\left(f_{\mathrm{tv}}-\left\langle f_{\mathrm{tv}}\right\rangle_{\mathrm{km}}\right)
$$

with $f_{\mathrm{tv}}$ being the fractional total vegetation cover derived at 346 high resolution, $\left\langle f_{\mathrm{tv}}\right\rangle_{\mathrm{km}}$ being the $f_{\mathrm{tv}}$ aggregated at kilomet- 347 ric resolution, $\mathbf{T}_{\mathbf{b} \text {,ws }}$ being the temperature of wet bare soil, 348 $\mathbf{T}_{\mathbf{b}, \mathbf{d s}}$ being the temperature of dry bare soil, $\mathbf{T}_{\mathbf{f c g v}}$ being the 349 temperature of full-cover green vegetation, and $\mathbf{T}_{\text {fcsv }}$ being 350 the temperature of full-cover senescent vegetation (notations 351 are summarized in Table I). Following the interpretation of 352 the "triangle method" [27], $\mathbf{T}_{\mathbf{b}, \mathbf{w s}}, \mathbf{T}_{\mathbf{b}, \mathbf{d s}}, \mathbf{T}_{\mathbf{f c g v}}$, and $\mathbf{T}_{\mathbf{f c s v}} 353$ correspond to the minimum and maximum soil and vegetation 354 temperatures within the study area, respectively. It is reminded 355 that $f_{\mathrm{tv}}=f_{\mathrm{gv}}+f_{\mathrm{sv}}$, with $f_{\mathrm{gv}}$ and $f_{\mathrm{sv}}$ being the fractional 356 green and senescent vegetation covers, respectively.

In (4), the projected fractional green vegetation cover esti- 358 mated at kilometric resolution is

$$
\begin{aligned}
& f_{\mathrm{gv}, \mathrm{km}}^{\mathrm{proj}}=\left\langle f_{\mathrm{gv}}\right\rangle_{\mathrm{km}}-\frac{\mathbf{T}_{\mathrm{fcsv}}-\left(\mathbf{T}_{\mathbf{b}, \mathrm{ds}}+\right.}{\left.\mathbf{T}_{\mathbf{b}, \mathbf{w s}}\right) / 2} \\
& \mathbf{T}_{\mathbf{f c s v}}- \mathbf{T}_{\mathbf{f c g v}} \\
& \times\left(\left\langle f_{\mathrm{tv}}\right\rangle_{\mathrm{km}}-\mathbf{f}_{\mathbf{t v}}\right)
\end{aligned}
$$

with $\mathbf{f}_{\mathbf{t v}}$ being the mean $f_{\mathrm{tv}}$ over the whole study area.

The new algorithms $\mathrm{D}^{\prime}$ use a radiative transfer equation 361 to model the spatial variability of disaggregated temperature 362 within each 1-km resolution pixel, using ancillary data avail- 363 able at high resolution such as $f_{\mathrm{gv}}, f_{\mathrm{tv}}, f_{\mathrm{ow}}$, and $\beta$. $\mathrm{D} 1^{\prime}$ is 364 a substitute for D1 based on radiative transfer. It expresses 365 disaggregated temperature as

366

$$
T^{\left(1^{\prime}\right)}=T_{\mathrm{km}}+\Delta T^{\left(1^{\prime}\right)}
$$


TABLE I

INTERPRETATION OF THE VERTICES IN THE GENERALIZED "TriANGLE APPROACH"

\begin{tabular}{|c||c|c|c|}
\hline Vertex & Surface type & Near-surface soil hydric status & Abbreviation \\
\hline A & Bare soil & Dry & b,ds \\
B & Bare soil & Wet & b,ws \\
C & Full-cover green vegetation & Wet or dry & fcgv \\
C $^{\prime}$ & Full-cover green vegetation & Wet & fcgv,ws \\
C $^{\prime \prime}$ & Full-cover green vegetation & Dry & fcgv,ds \\
D & Full-cover senescent vegetation & Wet or dry & fcsv \\
D $^{\prime}$ & Full-cover senescent vegetation & Dry & fcsv,ds \\
\hline
\end{tabular}

367 with $\Delta T^{\left(1^{\prime}\right)}$ being the difference between the temperature 368 simulated using high-resolution $f_{\mathrm{gv}}$ and that aggregated within 369 the $1-\mathrm{km}$ resolution pixel

$$
\begin{aligned}
\Delta T^{\left(1^{\prime}\right)}= & T_{\bmod }\left(f_{\mathrm{gv}},\left\langle f_{\mathrm{tv}}\right\rangle_{\mathrm{km}},\left\langle f_{\mathrm{ow}}\right\rangle_{\mathrm{km}},\langle\beta\rangle_{\mathrm{km}}\right) \\
& -\left\langle T_{\bmod }\left(f_{\mathrm{gv}},\left\langle f_{\mathrm{tv}}\right\rangle_{\mathrm{km}},\left\langle f_{\mathrm{ow}}\right\rangle_{\mathrm{km}},\langle\beta\rangle_{\mathrm{km}}\right)\right\rangle_{\mathrm{km}}
\end{aligned}
$$

370 with $T_{\text {mod }}$ being the land surface temperature simulated by 371 a radiative transfer equation. In (7), fractional total vegetation 372 cover, fractional open water, and soil evaporative efficiency 373 are set to their values aggregated at kilometric resolution. 374 Therefore, only the variability of $f_{\mathrm{gv}}$ is taken into account at 375 high resolution.

376 D2 ${ }^{\prime}$ is a substitute for D2 based on radiative transfer. It 377 expresses the disaggregated temperature as in (6), with the 378 simulated temperature difference $\Delta T^{\left(2^{\prime}\right)}$ written as

$$
\begin{aligned}
\Delta T^{\left(2^{\prime}\right)}=T_{\bmod } & \left(f_{\mathrm{gv}}, f_{\mathrm{tv}},\left\langle f_{\mathrm{ow}}\right\rangle_{\mathrm{km}},\langle\beta\rangle_{\mathrm{km}}\right) \\
- & \left\langle T_{\bmod }\left(f_{\mathrm{gv}}, f_{\mathrm{tv}},\left\langle f_{\mathrm{ow}}\right\rangle_{\mathrm{km}},\langle\beta\rangle_{\mathrm{km}}\right)\right\rangle_{\mathrm{km}}
\end{aligned}
$$

379 D3' is derived from the same radiative transfer equation and 380 includes the variability of $f_{\mathrm{gv}}, f_{\mathrm{tv}}$, and $f_{\mathrm{ow}}$ at high resolution. 381 It determines the disaggregated temperature using (6) but with 382 the simulated temperature difference $\Delta T^{\left(3^{\prime}\right)}$ written as

$$
\begin{aligned}
\Delta T^{\left(3^{\prime}\right)}=T_{\mathrm{mod}}\left(f_{\mathrm{gv}}, f_{\mathrm{tv}}, f_{\mathrm{ow}},\langle\beta\rangle_{\mathrm{km}}\right) & \\
& -\left\langle T_{\mathrm{mod}}\left(f_{\mathrm{gv}}, f_{\mathrm{tv}}, f_{\mathrm{ow}},\langle\beta\rangle_{\mathrm{km}}\right)\right\rangle_{\mathrm{km}} .
\end{aligned}
$$

$383 \mathrm{D}^{\prime}$ is derived from the same radiative transfer equation and 384 includes the variability of $f_{\mathrm{gv}}, f_{\mathrm{tv}}, f_{\mathrm{ow}}$, and $\beta$ at high resolu385 tion. It determines the disaggregated temperature using (6) but 386 with the simulated temperature difference $\Delta T^{\left(4^{\prime}\right)}$ written as

$$
\begin{aligned}
\Delta T^{\left(4^{\prime}\right)}=T_{\mathrm{mod}}\left(f_{\mathrm{gv}}, f_{\mathrm{tv}}\right. & \left., f_{\mathrm{ow}}, \beta\right) \\
& -\left\langle T_{\bmod }\left(f_{\mathrm{gv}}, f_{\mathrm{tv}}, f_{\mathrm{ow}}, \beta\right)\right\rangle_{\mathrm{km}} .
\end{aligned}
$$

$387 \mathrm{D} 4^{\prime \prime}$ is an extension of (10) to replace $\beta$ by another formula388 tion of soil evaporative efficiency noted as $\beta^{\prime}$.

389 The high- to low-resolution simulated temperature difference 390 in (7)-(10) is computed using a linearized radiative transfer 391 equation [5], [28], [29]. Modeled land surface temperature $392 T_{\bmod }$ is written as

$$
T_{\text {mod }}=f_{\text {ow }} T_{\text {ow }}+\left(1-f_{\text {ow }}\right) T_{\text {nw }}
$$

393 with $T_{\text {ow }}$ being the surface temperature of a water body and $394 T_{\text {nw }}$ being the skin temperature of a nonwatered land surface.
Nonwatered land surface temperature is expressed as

$$
T_{\mathrm{nw}}=f_{\mathrm{gv}} \mathbf{T}_{\mathrm{fcgv}}+\left(f_{\mathrm{tv}}-f_{\mathrm{gv}}\right) \mathbf{T}_{\mathrm{fcsv}}+\left(1-f_{\mathrm{tv}}\right) T_{\mathrm{bs}}
$$

with $\mathbf{T}_{\mathbf{f c g v}}$ and $\mathbf{T}_{\mathbf{f c s v}}$ being the temperature of full-cover green 396 and senescent vegetations, respectively, and $T_{\mathrm{bs}}$ being the bare 397 soil temperature. With the soil evaporative efficiency defined 398 [30] as

$$
\beta=\frac{\mathbf{T}_{\mathbf{b}, \mathbf{d s}}-T_{\mathrm{bs}}}{\mathbf{T}_{\mathbf{b}, \mathbf{d s}}-\mathbf{T}_{\mathbf{b}, \mathbf{w s}}}
$$

the bare soil temperature can be expressed as

$$
T_{\mathrm{bs}}=\beta \mathbf{T}_{\mathbf{b}, \mathbf{w s}}+(1-\beta) \mathbf{T}_{\mathbf{b}, \mathbf{d s}}
$$

By assuming that water temperature is close to well-watered 401 green vegetation [27], modeled land surface temperature 402 becomes

$$
T_{\text {mod }}=f_{\text {ow }} \mathbf{T}_{\text {fcgv }}+\left(1-f_{\text {ow }}\right) T_{\text {nw }}
$$

with the nonwatered land surface temperature expressed as

$T_{\mathrm{nw}}=f_{\mathrm{gv}} \mathbf{T}_{\mathrm{fcgv}}+\left(f_{\mathrm{tv}}-f_{\mathrm{gv}}\right) \mathbf{T}_{\mathrm{fcsv}}$

$$
+\left(1-f_{\mathrm{tv}}\right)\left[\beta \mathbf{T}_{\mathbf{b}, \mathbf{w s}}+(1-\beta) \mathbf{T}_{\mathbf{b}, \mathbf{d s}}\right] .
$$

The temperature extremes $\mathbf{T}_{\mathbf{b}, \mathbf{d s}}, \mathbf{T}_{\mathbf{b}, \mathbf{w s}}, \mathbf{T}_{\mathbf{f c g v}}$, and $\mathbf{T}_{\mathbf{f c s v}}$ are 405 extrapolated (according to Section V) from low-resolution land 406 surface temperatures using high-resolution ancillary data [5]. 407

\section{DERIVATION OF BIOPHYSICAL VARIABLES}

The four variables used by the disaggregation methodol- 409 ogy are the following: fractional green vegetation cover $f_{\mathrm{gv}}, 410$ fractional total (green plus senescent) vegetation cover $f_{\mathrm{tv}}, 411$ fractional open water $f_{\text {ow }}$, and soil evaporative efficiency $\beta .412$ All of these variables are estimated from ASTER red, near- 413 infrared, and shortwave-infrared reflectance products and from 414 the PLMR H-polarized brightness temperature converted at an 415 incidence angle of $21.5^{\circ}$.

\section{A. Fractional Green Vegetation Cover}

Fractional green vegetation cover can be estimated from the 418 Normalized Difference Vegetation Index (NDVI) as in [31] 419

$$
f_{\mathrm{gv}}=\frac{\mathrm{NDVI}-\mathbf{N D V I}_{\mathbf{b s}}}{\mathbf{N D V I}_{\mathbf{f c g v}}-\mathbf{N D V I}_{\mathbf{b s}}}
$$




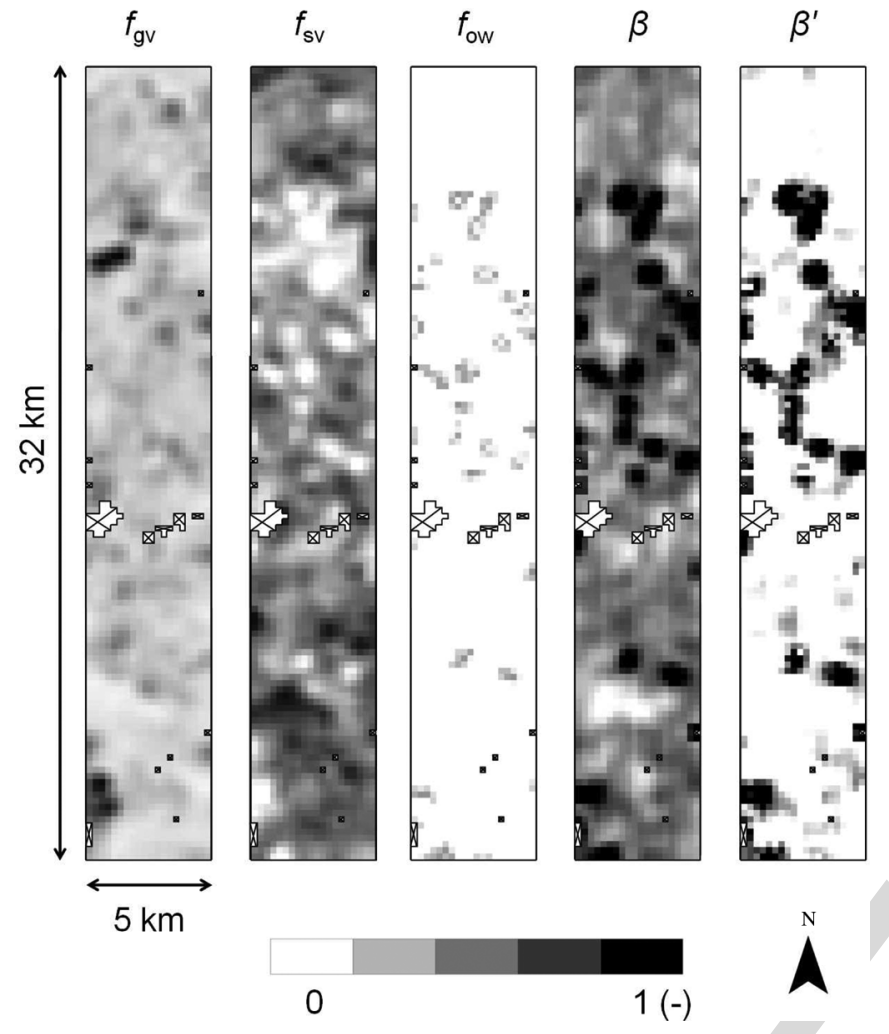

Fig. 2. Images of fractional green vegetation cover $f_{\mathrm{gv}}$, fractional senescent vegetation cover $f_{\mathrm{sv}}=f_{\mathrm{tv}}-f_{\mathrm{gv}}$, fractional open water $f_{\mathrm{ow}}$, soil evaporative efficiency $\beta$, and soil evaporative efficiency $\beta^{\prime}$. Note that $2 \%$ of the $5 \mathrm{~km}$ by $32 \mathrm{~km}$ area is contaminated by clouds and cloud shadow. Contaminated $250-\mathrm{m}$ resolution pixels are represented by crossed-out surfaces.

420 with $\mathbf{N D V I}_{\text {bs }}$ and $\mathbf{N D V I}_{\text {fcgv }}$ being the NDVI over bare 421 soil and full-cover green vegetation, respectively. NDVI is 422 computed as the difference between near-infrared and red bands 423 divided by their sum. The spatial variation of fractional green 424 vegetation cover over the study area is shown in Fig. 2.

\section{B. Fractional Total (Green Plus Senescent) Vegetation Cover}

426 Fractional total vegetation cover is estimated by correlating $427 f_{\mathrm{tv}}$ with surface albedo for green vegetation and by setting $f_{\mathrm{tv}}$ 428 to the maximum $f_{\mathrm{gv}}$ for senescent vegetation. This methodol429 ogy [5] is based on two assumptions, which are generally met in 430 agricultural areas: 1) soil albedo is generally lower than green 431 vegetation albedo, and 2) green vegetation albedo is lower than 432 senescent vegetation albedo. Although a time series of red and 433 near-infrared data would be required to estimate soil albedo 434 and green vegetation albedo on a pixel-by-pixel basis [5], only 435 one ASTER scene is available for this study period. Therefore, 436 an alternate approach is adopted. Surface albedo is modeled 437 as a linear mixing of vegetation and soil components (e.g., 438 [32] and [33])

$$
\alpha=\left(1-f_{\mathrm{tv}}\right) \alpha_{\mathbf{b s}}+f_{\mathrm{gv}} \alpha_{\mathbf{f c g v}}+\left(f_{\mathrm{tv}}-f_{\mathrm{gv}}\right) \alpha_{\mathbf{f c s v}}
$$

439 with $\alpha_{\mathbf{b s}}, \alpha_{\mathbf{f c g v}}$, and $\alpha_{\mathbf{f c s v}}$ being the albedo for bare soil, full440 cover green vegetation, and full-cover senescent vegetation, 441 respectively, and with the end-members $\alpha_{\mathbf{b s}}, \alpha_{\mathbf{f c g v}}$, and $\alpha_{\mathbf{f c s v}}$ 442 estimated in Section V.
By inverting (18), fractional vegetation cover is expressed as 443

$$
f_{\mathrm{tv}}=\frac{\alpha-\alpha_{\mathrm{bs}}+f_{\mathrm{gv}}\left(\alpha_{\mathrm{fcsv}}-\alpha_{\mathbf{f c g v}}\right)}{\alpha_{\mathbf{f c s v}}-\alpha_{\mathbf{b s}}}
$$

with $\alpha$ being the surface albedo estimated as a weighted sum of 444 red and near-infrared reflectances using the coefficients given in 445 [34] and validated in [35]-[38]. As stated previously, our case 446 study does not allow calibrating $\alpha_{\mathbf{b s}}, \alpha_{\mathbf{f c g v}}$, and $\alpha_{\mathbf{f c s v}}$ on a 447 pixel-by-pixel basis. Consequently, the value of $f_{\mathrm{tv}}$ computed 448 from (19) may, on some occasions, be lower than $f_{\mathrm{gv}}$ or larger 449 than 1 . To avoid nonphysical values, $f_{\mathrm{tv}}$ is set to $f_{\mathrm{gv}}$ and 1 in 450 the former and latter case, respectively.

The spatial variation of fractional senescent vegetation cover 452 $\left(f_{\mathrm{sv}}=f_{\mathrm{tv}}-f_{\mathrm{gv}}\right)$ over the study area is shown in Fig. 2 . Note 453 that NAFE'06 was undertaken at the beginning of the summer 454 agricultural season so that all irrigated crops were green and 455 healthy.

\section{Fractional Open Water}

The fraction of open water within each 250 -m resolution 458 pixel is estimated using 50-m resolution resampled ASTER 459 B5 reflectance product. Various studies have indicated that the 460 shortwave-infrared band centered at around $1 \mu \mathrm{m}$ is highly 461 sensitive to the presence of open water [20], [39], [40]. In this 462 paper, a simple threshold method is applied to classify at 50-m 463 resolution the $5 \mathrm{~km}$ by $32 \mathrm{~km}$ area in two classes: water and 464 nonwatered surface. The threshold value is estimated as 0.170465 from one flooded crop field in the south of the study area. The 466 spatial variation of fractional open water over the study area is 467 shown in Fig. 2. Open water represents $5 \%$ of the study area 468 and is attributed to rice cropping.

\section{Soil Evaporative Efficiency}

Soil evaporative efficiency $\beta$ is defined as the ratio of actual 471 to potential soil evaporation. In this paper, $\beta$ is estimated from 472 PLMR brightness temperatures. Two different formulations 473 are used to evaluate the coupling effects of near-surface soil 474 moisture, $f_{\mathrm{gv}}$, and $f_{\mathrm{sv}}$ on microwave-derived soil evaporative 475 efficiency.

By assuming that brightness temperature is mainly sensitive 477 to surface soil moisture [41] and that soil evaporative efficiency 478 is mainly driven by surface soil moisture [42], [43], soil evapo- 479 rative efficiency can be estimated as

$$
\beta=1-\frac{T B-\mathbf{T B}_{\mathbf{b}, \mathbf{w s}}}{\mathbf{T B}_{\mathbf{f c s v}, \mathbf{d s}}-\mathbf{T B}_{\mathbf{b}, \mathbf{w s}}}
$$

with $\mathbf{T B}_{\mathbf{b}, \mathbf{w s}}$ and $\mathbf{T} \mathbf{B}_{\mathbf{f c s v}, \mathbf{d s}}$ being the minimum and max- 481 imum brightness temperatures observed over the study area, 482 respectively. As brightness temperature generally decreases 483 with surface soil moisture and increases with vegetation cover 484 [44], $\mathbf{T} \mathbf{B}_{\mathbf{b}, \mathbf{w s}}$ and $\mathbf{T} \mathbf{B}_{\mathbf{f c s v}, \mathbf{d s}}$ are interpreted as the brightness 485 temperatures over wet bare soil and full-cover senescent vege- 486 tation with dry soil, respectively. The spatial variation of $\beta$ over 487 the study area is shown in Fig. 2.

Since brightness temperature also depends on biomass (e.g., 489 [45]), a second formulation of soil evaporative efficiency $\beta^{\prime}$ is 490 
TABLE II

NDVI AND SURFACE ALBEDo END-MEMBERS

\begin{tabular}{|c||c|c|}
\hline End-member & Value & Unit \\
\hline $\mathbf{N D V I}_{\mathbf{b s}}$ & 0.15 & - \\
$\mathbf{N D V I}_{\mathbf{f c g v}}$ & 0.65 & - \\
$\alpha_{\text {bs }}$ & 0.17 & - \\
$\alpha_{\mathbf{f c g v}}$ & 0.22 & - \\
$\alpha_{\mathbf{f c s v}}$ & 0.31 & - \\
\hline
\end{tabular}

491 derived in order to decouple the effects of soil moisture, $f_{\mathrm{gv}}$, 492 and $f_{\mathrm{sv}}$ on $T B$. As in [46], the assumption is that, for a given 493 vegetated pixel, if vegetation is partially stressed (i.e., $f_{\mathrm{sv}}>0$ 494 or $f_{\mathrm{tv}}>f_{\mathrm{gv}}$ ), then near-surface soil moisture availability is 495 zero (i.e., $\beta^{\prime}=0$ ). Alternatively, if that pixel does not contain 496 senescent vegetation (i.e., $f_{\mathrm{sv}}=0$ or $f_{\mathrm{tv}}=f_{\mathrm{gv}}$ ), then $\beta^{\prime}$ is 497 computed as the ratio of the measured "wet soil" brightness 498 temperature difference to the "dry soil"-"wet soil" brightness 499 temperature difference. Formally, one writes

$$
\begin{aligned}
& \beta^{\prime}=0 \quad \text { if } \quad T B>T B_{\mathbf{d s}} \\
& \beta^{\prime}=1-\frac{T B-T B_{\mathbf{w s}}}{T B_{\mathbf{d s}}-T B_{\mathbf{w s}}} \text { if } T B \leq T B_{\mathbf{d s}}
\end{aligned}
$$

500 with $T B_{\mathrm{ds}}$ and $T B_{\mathrm{ws}}$ being the "dry soil" and "wet soil" 501 brightness temperatures, respectively, both being estimated for $502 f_{\mathrm{sv}}=0$. Since green vegetation is partially transparent to mi503 crowaves, the "dry soil" brightness temperature is computed as 504 a weighted sum of the brightness temperature over dry bare soil 505 (noted as $\mathbf{T} \mathbf{B}_{\mathrm{b}, \mathrm{ds}}$ ) and the brightness temperature over full506 cover green vegetation with dry soil (noted as $\mathbf{T} \mathbf{B}_{\mathrm{fcgv}, \mathrm{ds}}$ )

$$
T B_{\mathrm{ds}}=f_{\mathrm{gv}} \mathbf{T B}_{\mathrm{fcgv}, \mathrm{ds}}+\left(1-f_{\mathrm{gv}}\right) \mathbf{T B}_{\mathbf{b}, \mathbf{d s}} .
$$

507 Similarly, the "wet soil" brightness temperature is computed as 508 a weighted sum of the brightness temperature over wet bare soil 509 (noted as $\mathbf{T B}_{\mathbf{b}, \mathbf{w s}}$ ) and the brightness temperature over full510 cover green vegetation with wet soil (noted as $\mathbf{T} \mathbf{B}_{\mathrm{fcgv}, \mathbf{w s}}$ )

$$
T B_{\mathrm{ws}}=f_{\mathrm{gv}} \mathbf{T B}_{\mathrm{fcgv}, \mathrm{ws}}+\left(1-f_{\mathrm{gv}}\right) \mathbf{T B}_{\mathbf{b}, \mathbf{w s}} .
$$

511 The spatial variation of $\beta^{\prime}$ over the study area is shown in Fig. 2.

\section{2 \\ V. Estimating End-Members}

513 A key step in the disaggregation procedure is estimating 514 the 14 end-members from ASTER and PLMR data. They 515 are composed of the following: $\mathbf{N D V I}_{\mathbf{b s}}, \mathbf{N D V I}_{\mathbf{f c g v}}, \alpha_{\mathbf{b s}}$, $516 \alpha_{\mathrm{fcgv}}, \alpha_{\mathrm{fcsv}}, \mathbf{T}_{\mathbf{b}, \mathrm{ws}}, \mathbf{T}_{\mathrm{b}, \mathrm{ds}}, \mathbf{T}_{\mathrm{fcgv}}, \mathbf{T}_{\mathrm{fcsv}}, \mathbf{T B}_{\mathrm{b}, \mathrm{ws}}, \mathbf{T B}_{\mathrm{b}, \mathrm{ds}}$, $517 \mathbf{T B}_{\mathrm{fcgv}, \mathrm{ws}}, \mathbf{T B}_{\mathrm{fcgv}, \mathrm{ds}}$, and $\mathbf{T B}_{\mathrm{fcsv}, \mathrm{ds}}$. For the convenience 518 of the reader, the unit is degree Celsius for radiometric temper519 ature and kelvin for brightness temperature.

\section{A. NDVI}

521 NDVI end-members are estimated as the minimum and maxi522 mum values of NDVI observed over the $5 \mathrm{~km}$ by $32 \mathrm{~km}$ area for 523 bare soil and full-cover green vegetation, respectively. Values 524 for $\mathbf{N D V I}_{\mathrm{bs}}$ and $\mathbf{N D V I}_{\mathbf{f c g v}}$ are reported in Table II.

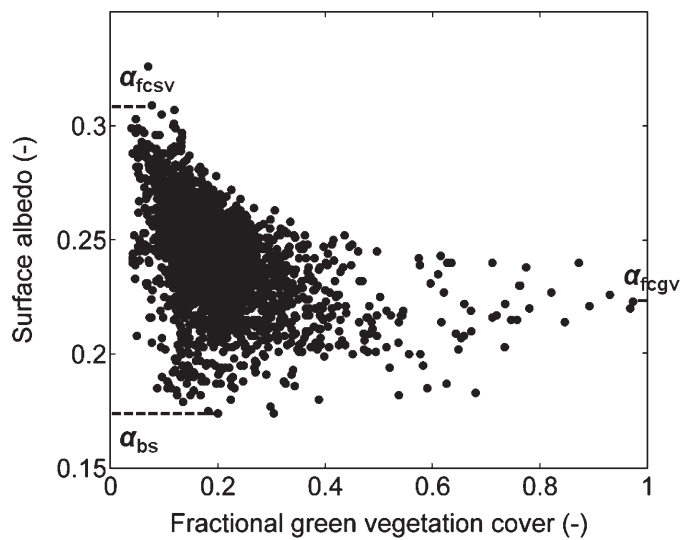

Fig. 3. ASTER surface albedo $\alpha$ plotted against ASTER fractional green vegetation cover $f_{\mathrm{gv}}$. Three particular values of $\alpha$ are identified: the soil albedo $\alpha_{\mathrm{bs}}$ estimated as the minimum surface albedo, the green vegetation albedo $\alpha_{\mathrm{fcgv}}$ estimated as the albedo corresponding to the largest $f_{\mathrm{gv}}$, and the senescent vegetation albedo $\alpha_{\mathrm{fcsv}}$ estimated as the maximum surface albedo.

In this paper, the study domain included extreme conditions 525 in terms of vegetation cover so that NDVI end-members could 526 be estimated from the red and near-infrared reflectances ac- 527 quired over the area on a single date. In the case where extreme 528 conditions are not encountered in the application domain, a 529 different approach should be adopted, such as the use of a time 530 series of NDVI data (instead of a single snapshot image) that 531 would capture the phenological stages of agricultural crops. 532 Also, the determination of reflectance end-members could 533 be further constrained by the use of ancillary spectral data 534 sets [47].

\section{B. Albedo}

Fig. 3 shows the space defined by surface albedo $\alpha$ and 537 fractional green vegetation cover $f_{\mathrm{gv}}$. Pixels including open 538 water are removed from the scatterplot. The soil albedo $\alpha_{\mathbf{b s}} 539$ is defined as the minimum ASTER surface albedo observed 540 within the study area by assuming that the dependence of 541 $\alpha_{\mathrm{bs}}$ on soil moisture is small compared to the dependence of 542 $\alpha$ on vegetation cover. The green vegetation albedo $\alpha_{\mathbf{f c g v}}$ is 543 estimated as the surface albedo corresponding to maximum 544 fractional green vegetation cover. The senescent vegetation 545 albedo $\alpha_{\mathbf{f c s v}}$ is estimated as the maximum surface albedo 546 observed within the study area. Values for $\alpha_{\mathbf{b s}}, \alpha_{\mathbf{f c g v}}$, and 547 $\alpha_{\mathrm{fcsv}}$ are reported in Table II.

\section{Land Surface Temperature}

As the range of surface conditions varies with spatial res- 550 olution, two different procedures are developed to estimate 551 temperature end-members.

552

1) When estimating temperature end-members from 250 -m 553 resolution data, one pixel is identified as fully covered 554 green vegetation, one pixel as fully covered senescent 555 vegetation, one pixel as bare dry soil, and one pixel as 556 bare wet soil. In this case, it is assumed that all extreme 557 conditions are included at high resolution within the study 558 domain. 
TABLE III

LAND SURFACE TEMPERATURE AND L-BAND BRIGHTNESS Temperature End-Members That ARe Estimated From High-Resolution ASTER Temperature Data, Extrapolated From AGgREGATED ASTER TEMPERATURE DATA, AND EXTRAPOLATED From MODIS TEMPERATURE DATA. For THE CONVENIENCE OF THE READER, THE UNIT IS DEgREE CELSIUSFOR RADIOMETRIC TEMPERATURE AND KELVIN FOR BRIGHTNESS TEMPERATURE

\begin{tabular}{|c||c|c|c|c|}
\hline & High-resolution & Aggregated ASTER & MODIS & \\
End-member & $T$ & $T_{\mathrm{km}}$ & $T_{\mathrm{km}}$ & Unit \\
\hline $\mathbf{T}_{\mathbf{b}, \mathbf{d s}}$ & 38 & 40.2 & 38.9 & ${ }^{\circ} \mathrm{C}$ \\
$\mathbf{T}_{\mathbf{b}, \mathbf{w s}}$ & 25 & 27.6 & 26.2 & ${ }^{\circ} \mathrm{C}$ \\
$\mathbf{T}_{\text {fcgv }}$ & 21 & 21.0 & 21.0 & ${ }^{\circ} \mathrm{C}$ \\
$\mathbf{T}_{\text {fcsv }}$ & 34 & 32.0 & 28.7 & ${ }^{\circ} \mathrm{C}$ \\
$\mathbf{T B}_{\mathbf{b}, \mathbf{d s}}$ & 240 & 246 & 241 & $\mathrm{~K}$ \\
$\mathbf{T B}_{\mathbf{b}, \mathbf{w s}}$ & 190 & 193 & 193 & $\mathrm{~K}$ \\
$\mathbf{T B}_{\text {fcgv,ws }}$ & 205 & 205 & 205 & $\mathrm{~K}$ \\
$\mathbf{T B}_{\text {fcgv,ds }}$ & 240 & 240 & 240 & $\mathrm{~K}$ \\
$\mathbf{T B}_{\text {fcsv,ds }}$ & 280 & 280 & 280 & $\mathrm{~K}$ \\
\hline
\end{tabular}

560

561

562

563

564

565

566

567

568 569 mined by analyzing the consistency of the diagrams in Fig. 4. 570 Fig. 4(a) shows the space defined by ASTER land surface 571 temperature and ASTER fractional green vegetation cover. The 572 three edges of the triangle $T-f_{\mathrm{gv}}$ are interpreted [27] as "bare 573 soil" between $\mathbf{A}$ and $\mathbf{B}$, "wet surface" between $\mathbf{B}$ and $\mathbf{C}$, and 574 "dry soil" between C and A. Fig. 4(b) shows the space de575 fined by ASTER land surface temperature and ASTER surface 576 albedo. An interpretation of the polygon $T-\alpha$ is provided 577 in [5], which is consistent with the triangle method. The four 578 edges are interpreted as "bare soil" between $\mathbf{A}$ and B, "wet 579 surface" between B and C, "full cover" between C and D, 580 and "dry surface" between $\mathbf{D}$ and $\mathbf{A}$. The notation system for 581 polygon vertices $\mathbf{A}, \mathbf{B}, \mathbf{C}$, and $\mathbf{D}$ is summarized in Table $\mathrm{I}$, and 582 the corresponding temperature values $\mathbf{T}_{\mathbf{b}, \mathbf{d s}}, \mathbf{T}_{\mathbf{b}, \mathbf{w s}}, \mathbf{T}_{\mathbf{f c g v}}$, 583 and $\mathbf{T}_{\mathbf{f c s v}}$ are reported in Table III.

584 In this paper, high-resolution temperature $T$ is assumed to 585 be unavailable. Consequently, the extreme temperatures $\mathbf{T}_{\mathbf{b}, \mathbf{d s}}$, $586 \mathbf{T}_{\mathbf{b}, \mathbf{w s}}, \mathbf{T}_{\mathbf{f c g v}}$, and $\mathbf{T}_{\mathbf{f c s v}}$ are extrapoled from the spaces $T_{\mathrm{km}}-$ $587\left\langle f_{\mathrm{gv}}\right\rangle_{\mathrm{km}}$ and $T_{\mathrm{km}}-\langle\alpha\rangle_{\mathrm{km}}$ defined at kilometric resolution 588 (see Fig. 4(c) and (d) for aggregated ASTER temperature and 589 Fig. 4(e) and (f) for MODIS temperature). An approach similar 590 to [5] is used as follows.

1) Vertex $\mathbf{C}$ corresponds to full-cover green vegetation and is located at $\left(1, \mathbf{T}_{\text {fcgv }}\right)$ in Fig. 4(c) (Fig. 4(e) for MODIS temperature) and at $\left(\alpha_{\mathbf{f c g v}}, \mathbf{T}_{\mathbf{f c g v}}\right)$ in Fig. $4(\mathrm{~d})$ [Fig. 4(f)]. In this paper, $\mathbf{T}_{\mathbf{f c g v}}$ is set to the air temperature $\mathbf{T}_{\mathbf{a}}$ measured at the time of ASTER overpass. Vertex $\mathbf{C}$ is thus placed at $\left(1, \mathbf{T}_{\mathbf{a}}\right)$ in Fig. 4(c) [Fig. 4(e)] and at $\left(\alpha_{\text {fcgv }}, \mathbf{T}_{\mathbf{a}}\right)$ in Fig. 4(d) [Fig. 4(f)].
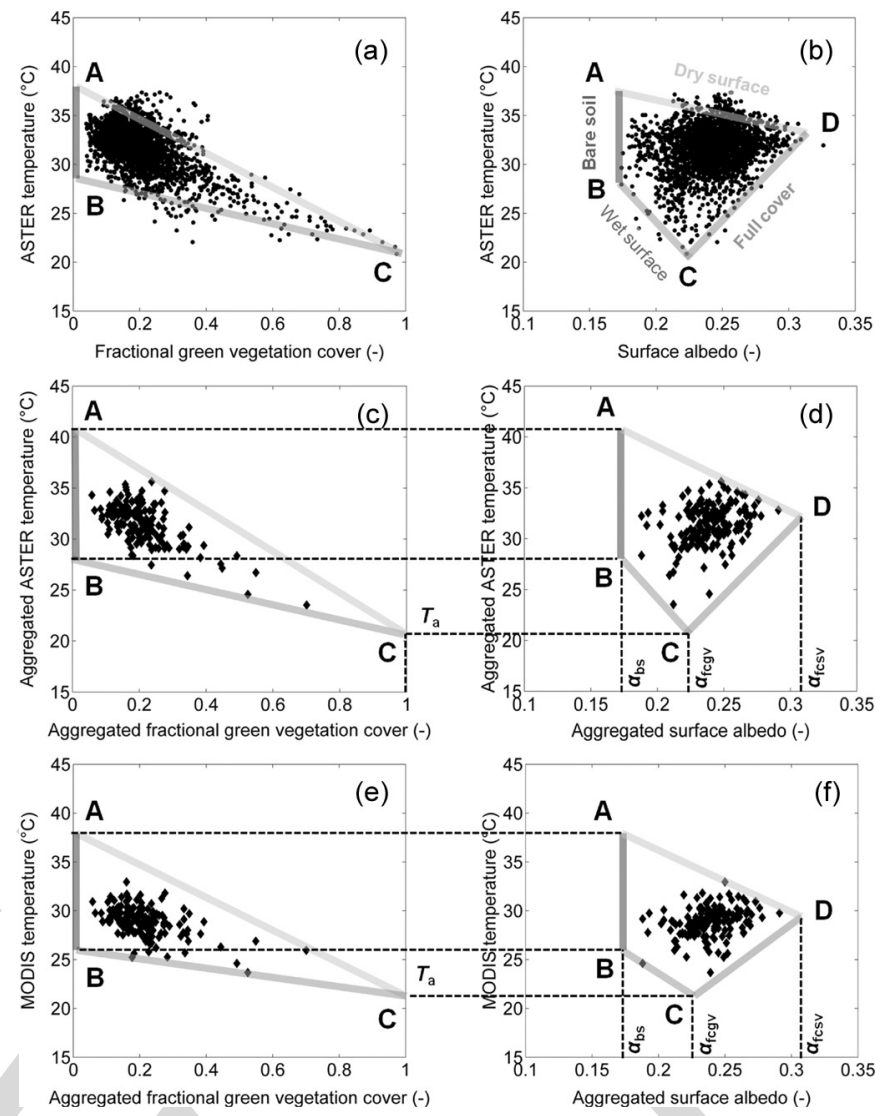

Fig. 4. (a) Scatterplot of ASTER temperature versus fractional green vegetation cover and (b) versus surface albedo, (c) scatterplot of aggregated ASTER temperature versus aggregated fractional green vegetation cover and (d) versus aggregated surface albedo, and (e) scatterplot of MODIS temperature versus aggregated fractional green vegetation cover and (f) versus aggregated surface albedo. The vertices $\mathbf{A}, \mathbf{B}, \mathbf{C}$, and $\mathbf{D}$ obtained using high-resolution data in (a) and (b) are extrapolated using low-resolution data in (c), (d), (e), and (f) from ancillary data composed of air temperature $\mathbf{T}_{\mathbf{a}}$, soil albedo $\alpha_{\mathbf{b s}}$, green vegetation albedo $\alpha_{\mathbf{f c g v}}$, and senescent vegetation albedo $\alpha_{\mathbf{f c s v}}$.

2) Vertex $\mathbf{B}$ corresponds to wet bare soil and is located at 598 $\left(0, \mathbf{T}_{\mathbf{b}, \mathbf{w s}}\right)$ in Fig. 4(c) [Fig. 4(e)] and at $\left(\alpha_{\mathbf{b s}}, \mathbf{T}_{\mathbf{b}, \mathbf{w s}}\right)$ in 599 Fig. 4(d) [Fig. 4(f)]. It is placed in Fig. 4(c) [Fig. 4(e)] 600 at the intersection between (BC) and the vertical line 601 $\left\langle f_{\mathrm{gv}}\right\rangle_{\mathrm{km}}=0$. The slope of $(\mathbf{B C})$ is computed as the slope 602 of the linear regression of the data points corresponding 603 to the "wet surface" edge of the triangle $T_{\mathrm{km}}-\left\langle f_{\mathrm{gv}}\right\rangle_{\mathrm{km}} .604$ The off-set of $(\mathbf{B C})$ is determined from $\mathbf{C}$.

605

3) Vertex $\mathbf{A}$ corresponds to dry bare soil and is located at 606 $\left(0, \mathbf{T}_{\mathbf{b}, \mathbf{d s}}\right)$ in Fig. 4(c) [Fig. 4(e)] and at $\left(\alpha_{\mathbf{b s}}, \mathbf{T}_{\mathbf{b}, \mathbf{d s}}\right)$ in 607 Fig. 4(d) [Fig. 4(f)]. It is placed in Fig. 4(c) [Fig. 4(e)] 608 at the intersection between $(\mathbf{A C})$ and the vertical line 609 $\left\langle f_{\mathrm{gv}}\right\rangle_{\mathrm{km}}=0$. The slope of $(\mathbf{A C})$ is computed as the slope 610 of the linear regression of the data points corresponding 611 to the "dry soil" edge of the triangle $T_{\mathrm{km}}-\left\langle f_{\mathrm{gv}}\right\rangle_{\mathrm{km}}$. The 612 off-set of $(\mathbf{A C})$ is determined from $\mathbf{C}$.

4) Vertex $\mathbf{D}$ corresponds to full-cover senescent vegetation 614 and is located at $\left(\alpha_{\mathbf{f c s v}}, \mathbf{T}_{\mathbf{f c s v}}\right)$ in Fig. $4(\mathrm{~d})$ [Fig. 4(f)]. 615 It is placed in Fig. 4(d) [Fig. 4(f)] at the intersection 616 between $(\mathbf{A D})$ and the vertical line $\langle\alpha\rangle_{\mathrm{km}}=\alpha_{\mathrm{fcsv}}$. The 617 line $(\mathbf{A D})$ is considered as being parallel to (BC)[5]. 618 Consequently, the slope of (AD) is determined from 619 

from $\mathbf{A}$. Note that the lines (AD) and (BC) might not be strictly parallel. This may be due to a lack of representativeness of the surface conditions captured at 250-m resolution within the study area. In that case, one or several data points may be located above (AD). To circumvent this artifact, the slope of (AD) in Fig. 4(d) [Fig. 4(f)] is increased so that all data points will be located below the "dry surface" edge. 630 mated from Fig. 4(a) and (b) using high-resolution ASTER 631 data; 2) extrapolated from Fig. 4(c) and (d) using aggregated 632 ASTER temperature data; and 3) extrapolated from Fig. 4(e) 633 and (f) using MODIS temperature data. The values extrapo634 lated from aggregated ASTER and MODIS temperatures are 635 rather close to those estimated from high-resolution ASTER 636 temperature data, with the maximum difference in extrapolated 637 temperatures being $2.6{ }^{\circ} \mathrm{C}$, except for $\mathbf{T}_{\text {fcsv }}$ using MODIS 638 data. In the latter case, the significant underestimation $\left(5.3{ }^{\circ} \mathrm{C}\right)$ 639 of $\mathbf{T}_{\text {fcsv }}$ can be explained by the following: 1) the negative 640 mean difference $\left(-2.3{ }^{\circ} \mathrm{C}\right)$ between MODIS and ASTER data $641 \mathrm{and} /$ or 2) the smaller range of (spatial dynamics) of 1-km 642 resolution MODIS data in relation to 1-km aggregated ASTER 643 data [please compare Fig. 4(c) with Fig. 4(e), and Fig. 4(d) with 644 Fig. 4(f)].

\section{D. Brightness Temperature}

646 To estimate soil evaporative efficiency $\beta$ in (20) and $\beta^{\prime}$ 647 in (22), five brightness temperature values corresponding to 648 extreme surface conditions are required: $\mathbf{T B}_{\mathbf{b}, \mathbf{d s}}, \mathbf{T} \mathbf{B}_{\mathbf{b}, \mathbf{w s}}$, $649 \mathbf{T B}_{\text {fcgv,ws }}, \mathbf{T B}_{\text {fcgv,ds }}$, and $\mathbf{T B}_{\text {fcsv,ds. In this paper, those }}$ 650 five values are estimated from a generalized version [5], [9] of 651 the classical "triangle method" [27].

652 Fig. 5(a) shows the space defined by PLMR brightness 653 temperature and ASTER land surface temperature. In the fol654 lowing, an original interpretation of the five vertices visible 655 in Fig. 5(a) is provided, which is consistent with both the 656 classical "triangle method" and the state-of-the-art L-band ra657 diative transfer models. Vertices are presented successively in 658 the counterclockwise direction, and the correspondence with 659 vegetation and soil conditions is summarized in Table I.

1) Vertex at minimum brightness temperature: L-band radiative transfer models predict an increase of brightness temperature with biomass and a decrease of brightness temperature with surface soil moisture (e.g., [48] and [49]). Therefore, the point at minimum brightness temperature corresponds to wet bare soil. This vertex is noted as B in Fig. 5(a), which is consistent with Fig. 4.

2) Vertex at maximum land surface temperature: the triangle method predicts a decrease of land surface temperature with both vegetation cover and surface soil moisture. Therefore, the point at maximum land surface temperature corresponds to dry bare soil. This vertex is noted as A in Fig. 5(a), which is consistent with Fig. 4.

3) Vertex at maximum brightness temperature: being consistent with an increase of vegetation emission with biomass and a decrease of soil emission with surface soil moisture, the point at maximum brightness temperature 676 corresponds to full-cover vegetation with dry soil. It 677 could correspond to full-cover green vegetation. How- 678 ever, the associated land surface temperature in Fig. 5(a) 679 is much larger than that over full-cover green vegetation 680 $\left(21{ }^{\circ} \mathrm{C}\right)$ and rather close to the temperature over full- 681 cover senescent vegetation $\left(34^{\circ} \mathrm{C}\right)$. Therefore, the point 682 at maximum brightness temperature corresponds to full- 683 cover senescent vegetation with dry soil. This vertex 684 is noted as $\mathbf{D}^{\prime}$ in Fig. 5(a), which is consistent with 685 Fig. 4. A prime mark indicates that $\mathbf{D}^{\prime}$ corresponds to a 686 dry soil, whereas D does not specify soil hydric status. 687 Note that $\mathbf{D}^{\prime}$ does not necessarily correspond to dry 688 senescent vegetation since wet senescent vegetation can 689 lead to large values of brightness temperature [50]. In 690 our case study, however, no rainfall occurred during the 691 four days preceding the ASTER overpass, which means 692 that senescent vegetation was completely dry. In terms of 693 radiative transfer modeling, the effect of dry biomass on 694 brightness temperature can be represented by large values 695 of roughness parameter [51].

696

4) Vertices at minimum land surface temperature: two more 697 vertices are apparent in the counterclockwise direction. 698 Being consistent with a decrease of land surface tem- 699 perature with green vegetation, both points correspond 700 to full-cover green vegetation. As vegetation is partially 701 transparent to the L-band emission from the soil, each 702 point corresponds to a different soil hydric status. The 703 vertex with a larger $T B$ [noted as $\mathbf{C}^{\prime \prime}$ in Fig. 5(a)] 704 corresponds to full-cover green vegetation with dry soil, 705 and the point with a lower $T B$ [noted as $\mathbf{C}^{\prime}$ in Fig. 5(a)] 706 corresponds to full-cover green vegetation with wet soil. 707

As high-resolution temperature is assumed to be unavailable 708 in this paper, brightness temperature end-members are not 709 estimated from the polygon $T B-T$ in Fig. 5(a) but from 710 the polygon $T B-f_{\mathrm{gv}}$ shown in Fig. 5(b). The following is 711 an interpretation of the polygon in Fig. 5(b), based on the 712 consistency with the polygon in Fig. 5(a). In particular, the five 713 vertices in Fig. 5(a) can be located in Fig. 5(b) as follows.

714

1) Vertex B corresponds to wet bare soil. It is located at 715 the minimum value of brightness temperature such that 716 $f_{\mathrm{gv}}=0$.

2) Vertex $\mathbf{A}$ corresponds to bare dry soil. It is not apparent 718 in Fig. 5(b) because fractional green vegetation is not 719 sufficient information to distinguish between bare soil 720 and senescent vegetation.

3) Vertex $D^{\prime}$ corresponds to full-cover senescent vegetation 722 with dry soil. It is located at the maximum value of 723 brightness temperature.

4) Vertex $\mathbf{C}^{\prime \prime}$ corresponds to full-cover green vegetation 725 with dry soil. It is located at the maximum value of 726 brightness temperature such that $f_{\mathrm{gv}}=1$.

5) Vertex $\mathbf{C}^{\prime}$ corresponds to full-cover green vegetation with 728 wet soil. It is located at the minimum value of brightness 729 temperature such that $f_{\mathrm{gv}}=1$.

Based on the aforementioned interpretation of the polygon 731 $T B-f_{\mathrm{gv}}$ in Fig. 5(b), the methodology used for estimating 732 

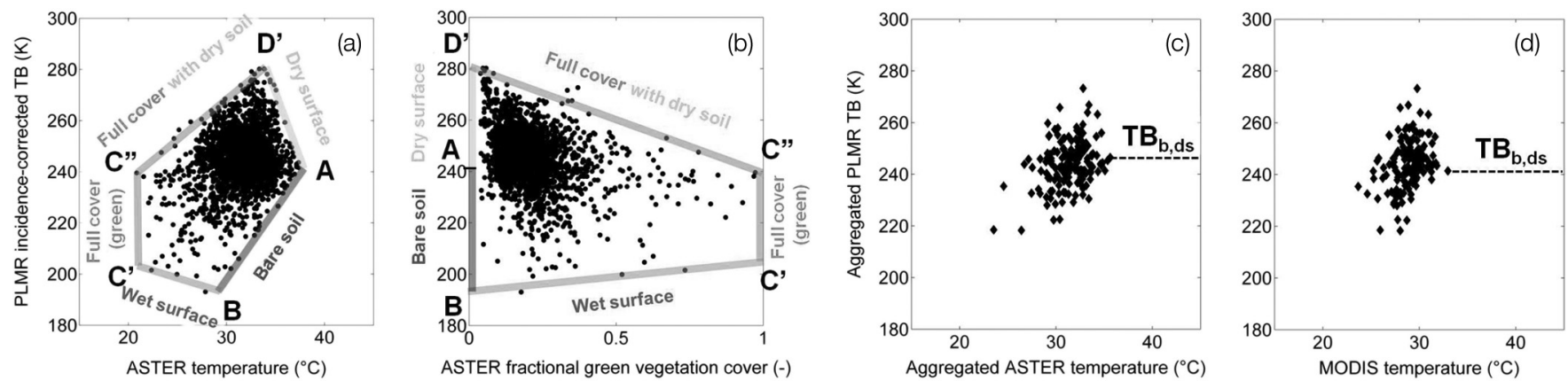

Fig. 5. (a) Scatterplot of PLMR incidence-corrected brightness temperature $T B$ versus ASTER land surface temperature and (b) versus ASTER fractional green vegetation cover, and (c) scatterplot of aggregated $T B$ versus aggregated ASTER temperature and (d) versus MODIS temperature. Extreme brightness temperatures $\mathbf{T} \mathbf{B}_{\mathrm{b}, \mathbf{w s}}, \mathbf{T} \mathbf{B}_{\mathrm{fcgv}, \mathrm{ws}}, \mathbf{T} \mathbf{B}_{\mathrm{fcgv}, \mathrm{ds}}$, and $\mathbf{T} \mathbf{B}_{\mathrm{fcsv}, \mathrm{ds}}$ are estimated by interpreting the bare soil, dry surface, full-cover vegetation, and wet surface edges of the polygon in (b). The estimation of $\mathbf{T} \mathbf{B}_{\mathbf{b}, \mathbf{d s}}$ using low-resolution temperature data is illustrated with aggregated ASTER temperature in (c) and MODIS temperature in $(\mathrm{d})$.

$733 \mathbf{T B}_{\mathrm{b}, \mathrm{ds}}, \mathbf{T B}_{\mathrm{b}, \mathrm{ws}}, \mathbf{T B}_{\mathrm{fcgv}, \mathrm{ws}}, \mathbf{T B}_{\mathrm{fcgv}, \mathrm{ds}}$, and $\mathbf{T B}_{\mathrm{fcsv}, \mathrm{ds}}$ is 734 detailed in the following.

754 1) estimated from Fig. 5(a) using high-resolution ASTER data; 755 2) estimated from Fig. 5(b) and (c) using high-resolution 756 fractional green vegetation cover and aggregated ASTER tem757 perature data; and 3) estimated from Fig. 5(b) and (d) using 758 high-resolution fractional green vegetation cover and MODIS 759 temperature data. Values estimated from low-resolution tem760 perature are remarkably close to those estimated from high761 resolution ASTER temperature data (Table III), except for $762 \mathbf{T B}_{\mathrm{b}, \mathrm{ds}}$ with a difference of $6 \mathrm{~K}$. This difference is apparently 763 due to the lack of representativeness of kilometric aggregated 764 brightness temperature and the method for estimating $\mathbf{T B}_{\mathbf{b}, \mathbf{d s}}$ 765 at kilometric scale. Note, however, that a 6-K difference is still 766 relatively low compared to the range (190 K-280 K) covered 767 by brightness temperature values.

\section{APPLICATION}

769 The disaggregation algorithms presented here are applied 770 to the NAFE'06 data set. ASTER land surface temperature is 771 aggregated at $1-\mathrm{km}$ resolution, and kilometric temperature is 772 used as input to D0, D1, D1', D2, D2 ', D3', D4', and D4 ${ }^{\prime \prime}$. As shown in Fig. 1, the verification strategy consists in comparing 773 disaggregation results at 250-m resolution with ASTER land 774 surface temperature. An application to MODIS data is also 775 presented.

\section{A. Application to Aggregated ASTER Data}

1) End-Members Derived From High-Resolution Data: The 778 approach is first implemented using the end-members estimated 779 from high-resolution ASTER temperature data. This allows 780 testing the robustness of the model in (15) and (16) inde- 781 pendently of the methodology used for extrapolating the nine 782 end-members $\mathbf{T}_{\mathbf{b}, \mathbf{d s}}, \mathbf{T}_{\mathbf{b}, \mathbf{w s}}, \mathbf{T}_{\mathrm{fcgv}}, \mathbf{T}_{\mathrm{fcsv}}, \mathbf{T B}_{\mathbf{b}, \mathbf{d s}}, \mathbf{T B}_{\mathrm{b}, \mathbf{w s}}, 783$ $\mathbf{T B}_{\text {fcgv, ws }}, \mathbf{T B}_{\text {fcgv,ds }}$, and $\mathbf{T B}_{\mathrm{fcsv}, \mathrm{ds}}$.

Fig. 6 shows the output images of the eight disaggregation 785 algorithms, which are to be compared with the reference image 786 derived from ASTER land surface temperature. One observes 787 that the disaggregated temperature is successively improved 788 by including additional factors in the disaggregation, which 789 indicates that the methodology is able to take into account 790 several independent factors. Although the boxy artifact at 1-km 791 resolution is successively reduced from $T^{(0)}$ to $T^{\left(4^{\prime \prime}\right)}$, it is still 792 apparent for $T^{\left(4^{\prime \prime}\right)}$. This effect may be due to the following: 1) 793 other factors that are not taken into account in the procedure, 794 such as green vegetation water stress, wind speed, surface 795 emissivity, surface albedo, etc.; 2 ) errors in estimated $f_{\mathrm{gv}}, f_{\mathrm{sv}}, 796$ $f_{\text {ow }}$, and $\beta$; and/or 3) resampling errors at 250-m resolution. 797

Table IV lists the RMSD, correlation coefficient, and slope 798 between the disaggregated and ASTER temperatures for each 799 of the eight disaggregation algorithms. The error is successively 800 decreased from $1.65{ }^{\circ} \mathrm{C}$ to $1.16{ }^{\circ} \mathrm{C}$, while the correlation coef- 801 ficient and slope are successively increased from 0.79 and 0.63802 to 0.89 and 0.88 , respectively. When comparing D1, D2, D1', 803 and D2', no significant differences are observed between all 804 four algorithms in terms of root-mean-square error, correlation 805 coefficient, and slope. Note that, in this paper, $f_{\text {tv }}$ was estimated 806 in a different way than in [5] because only one visible and 807 near-infrared image was available and a FORMOSAT-like time 808 series would be required to derive $f_{\mathrm{tv}}$ more accurately on a 809 pixel-by-pixel basis. Nevertheless, this comparison suggests 810 that $\mathrm{D} 1^{\prime}$ seems to be equivalent to D1 and D2' equivalent to 811 D2, which justifies the use of the $T_{\bmod }$ model. 

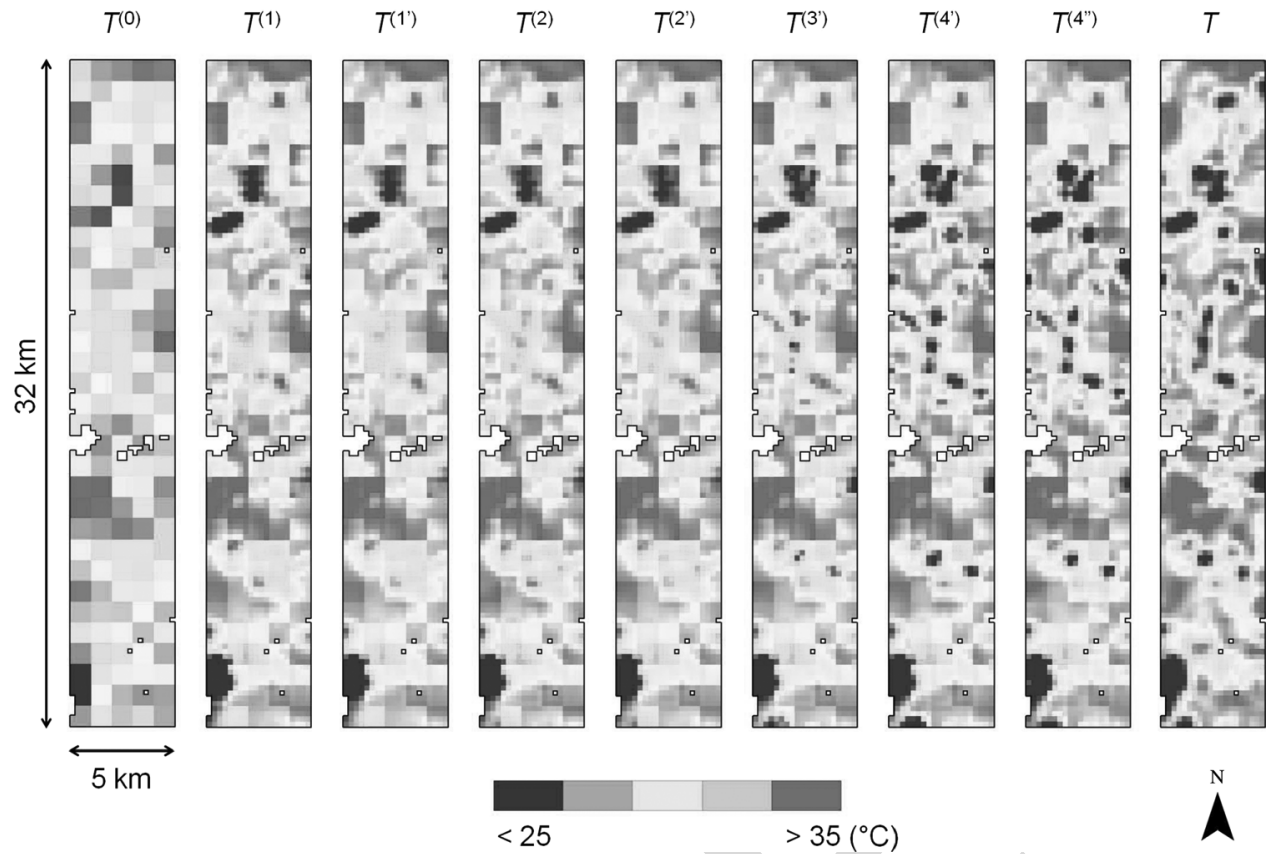

Fig. 6. Maps of the temperature disaggregated by the eight algorithms as compared with the map (right) of high-resolution ASTER temperature.

TABLE IV

RMSD, CorRelation COEFFicient $(R)$, AND SLOPE BETWEen THE DisAGgREGATED AND ASTER TEMPERATURES. THE RESUlTS CORRESPOND TO THE END-MEMBERS ESTIMATED USING High-RESOLUTION ASTER TEMPERATURE DATA (TO THE END-MEMBERS EXTRAPOLATED USING Aggregated ASTER Temperature Data)

\begin{tabular}{|c||c|c|c|}
\hline Algorithm & $\begin{array}{c}\text { RMSD } \\
{ }^{\circ} \mathrm{C}\end{array}$ & $\begin{array}{c}\mathrm{R} \\
-\end{array}$ & $\begin{array}{c}\text { Slope } \\
-\end{array}$ \\
\hline $\mathrm{D} 0$ & 1.65 & 0.79 & 0.63 \\
$\mathrm{D} 1$ & 1.39 & 0.86 & 0.76 \\
$\mathrm{D} 2$ & $1.35(1.35)$ & $0.87(0.87)$ & $0.76(0.76)$ \\
$\mathrm{D}^{\prime}$ & $1.38(1.39)$ & $0.86(0.86)$ & $0.74(0.72)$ \\
$\mathrm{D}^{\prime}$ & $1.30(1.40)$ & $0.88(0.86)$ & $0.75(0.73)$ \\
$\mathrm{D}^{\prime}$ & $1.22(1.27)$ & $0.89(0.88)$ & $0.78(0.76)$ \\
D4 $^{\prime}$ & $1.15(1.15)$ & $0.91(0.91)$ & $0.86(0.84)$ \\
D4 $^{\prime \prime}$ & $1.16(1.24)$ & $0.89(0.80)$ & $0.88(0.86)$ \\
\hline
\end{tabular}

813 The main advantage of the new approach is to take into 814 account a number of additional factors, including fractional 815 open water and soil evaporative efficiency. When comparing the 816 results obtained for D $3^{\prime}, \mathrm{D} 4^{\prime}$, and D4 $4^{\prime \prime}$ in Table IV, it is observed 817 that the disaggregated temperature is significantly improved 818 against the classical approaches D1 and D2. Moreover, the 819 statistical results are successively improved by including $f_{\text {ow }}$, $820 \beta$, and $\beta^{\prime}$. Fig. 7 shows the improvement, especially in the 821 slope between the disaggregated and ASTER temperatures. The 822 good results obtained for D4" indicate that the performance of 823 disaggregation algorithms is intimately related to the following: 8241 ) the capability of separating the independent factors that 825 impact on surface temperature and 2) the ability to integrate 826 them consistently into the procedure.

827 2) End-Members Derived From Aggregated ASTER Data: 828 As disaggregation procedures $\mathrm{D} 1^{\prime}, \mathrm{D} 2^{\prime}, \mathrm{D} 3^{\prime}, \mathrm{D} 4^{\prime}$, and $\mathrm{D} 4^{\prime \prime}$
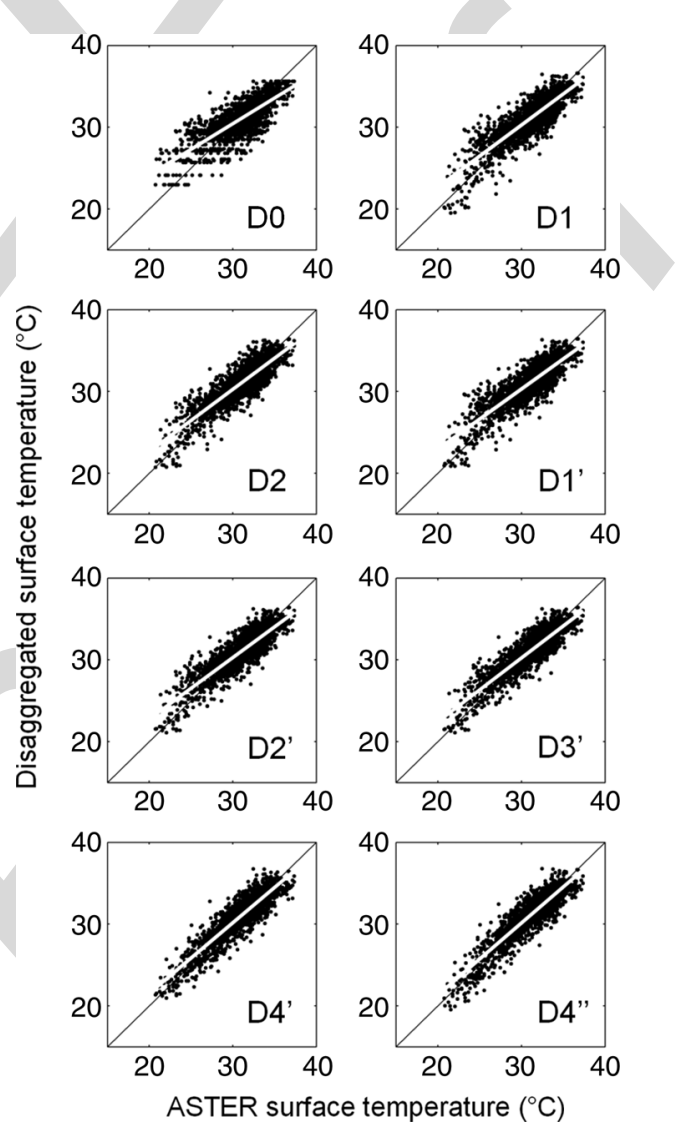

Fig. 7. Aggregated ASTER temperature $(1 \mathrm{~km})$ is disaggregated by each of the eight algorithms and is plotted against high-resolution ASTER temperature.

are subjected to uncertainties in land surface temperature and 829 brightness temperature end-members, the five algorithms are 830 next tested using the end-members estimated from kilomet- 831 ric temperature data, as presented in Section V. Aggregated 832 ASTER (instead of MODIS) data are used to evaluate the 833 

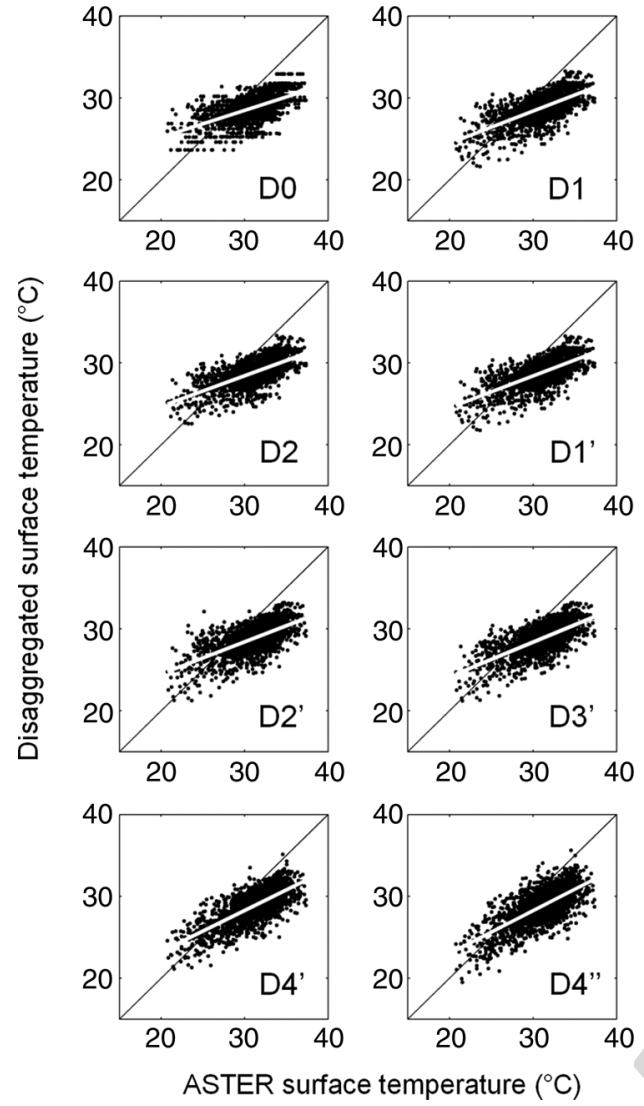

Fig. 8. MODIS temperature $(1 \mathrm{~km})$ is disaggregated by each of the eigh algorithms and is plotted against high-resolution ASTER temperature.

834 impact of end-members regardless of the discrepancy between 835 MODIS and ASTER temperatures.

836 Table IV lists the RMSD, correlation coefficient, and slope 837 between the disaggregated and ASTER temperatures for each 838 of the five algorithms. Results are compared with those ob839 tained using the end-members estimated from high-resolution 840 ASTER temperature. In general, the error is slightly larger, 841 and the correlation coefficient and slope are slightly lower us842 ing extrapolated end-members. Nevertheless, the disaggregated 843 temperature is still much improved by applying D4" instead of $844 \mathrm{D}^{\prime}$, with the correlation coefficient and slope increasing from 8450.74 to 0.88 and from 0.72 to 0.86 , respectively. Consequently, 846 the extrapolation of end-members from kilometric data is not 847 found to be a limiting factor in the methodology.

\section{B. Application to MODIS Data}

849 Disaggregation algorithms D0, D1, D1', D2, D2', D3', D4', 850 and D4" are then applied to MODIS data. In this case, end851 members are derived from MODIS data. Fig. 8 shows the scat852 terplot of disaggregated MODIS versus ASTER temperature for 853 each algorithm separately. One observes that the new methodol854 ogy improves the correlation and slope of the linear regression 855 between the disaggregated and ASTER temperatures. However, 856 a systematic negative bias is apparent in the disaggregated 857 temperature. Table V lists the RMSD, correlation coefficient, 858 and slope between the disaggregated and ASTER temperatures 859 for each of the eight algorithms. The error slightly decreases
TABLE $\mathrm{V}$

RMSD, Correlation CoefFicient $(R)$, AND SLope Between the Dis AGgREgated AND ASTER TEMPERATURES. THE RESUltS CORRESPOND TO THE END-MEMBERS EXTRAPOLATED USING MODIS TEMPERATURE DATA

\begin{tabular}{|c||c|c|c|}
\hline Algorithm & $\begin{array}{c}\text { RMSD } \\
{ }^{\circ} \mathrm{C}\end{array}$ & $\begin{array}{c}\mathrm{R} \\
-\end{array}$ & $\begin{array}{c}\text { Slope } \\
-\end{array}$ \\
\hline D0 & 3.19 & 0.60 & 0.33 \\
D1 & 3.08 & 0.67 & 0.39 \\
D2 & 3.11 & 0.66 & 0.37 \\
D1' & 3.09 & 0.67 & 0.39 \\
D2' $^{\prime}$ & 3.12 & 0.65 & 0.39 \\
D3' $^{\prime}$ & 3.06 & 0.69 & 0.42 \\
D4 $^{\prime}$ & 2.98 & 0.73 & 0.50 \\
D4 $^{\prime \prime}$ & 3.03 & 0.70 & 0.52 \\
\hline
\end{tabular}

from $3.2{ }^{\circ} \mathrm{C}$ to $3.0{ }^{\circ} \mathrm{C}$, while the correlation coefficient and 860 slope increase from 0.6 and 0.3 to 0.7 and 0.5 , respectively. 861 The results obtained for $\mathrm{D} 3^{\prime}$ and $\mathrm{D} 4^{\prime}$ in Table $\mathrm{V}$ indicate that 862 the disaggregated temperature is improved against the classical 863 approaches D1 and D2. As for the application to aggregated 864 ASTER data, the statistical results are successively improved 865 by including $f_{\text {ow }}, \beta$, and $\beta^{\prime}$. However, the improvement with 866 MODIS data is not as visible as with aggregated ASTER 867 data because the difference between MODIS and ASTER data 868 (please refer to Section II-C) has the same order of magnitude 869 as the subpixel variability at 250-m resolution (see RMSD for 870 D0 in Table V). In particular, the mean bias and the relatively 871 low slope of the linear regression between the disaggregrated 872 and ASTER data are associated with the discrepancy at 1-km 873 resolution between the MODIS and ASTER temperature data. 874

\section{SENSITIVITY ANALYSIS}

To further assess the stability of the new $\mathrm{D}^{\prime}$ algorithms based 876 on radiative transfer, two sensitivity analyses are conducted 877 by the following: 1) adding a Gaussian noise on kilometric 878 temperatures and high-resolution brightness temperatures and 879 2) estimating the contribution of each factor on the variability 880 of modeled land surface temperature.

\section{A. Uncertainty in End-Members}

To test the stability of the method for estimating the nine 883 end-members $\left(\mathbf{T}_{\mathbf{b}, \mathbf{d s}}, \mathbf{T}_{\mathbf{b}, \mathbf{w s}}, \mathbf{T}_{\mathbf{f c g v}}, \mathbf{T}_{\mathbf{f c s v}}, \mathbf{T B}_{\mathbf{b}, \mathbf{d s}}, \mathbf{T B}_{\mathbf{b}, \mathbf{w s}}, 884\right.$ $\mathbf{T B}_{\text {fcgv }, \mathbf{w s}}, \mathbf{T B}_{\text {fcgv }, \mathbf{d s}}$, and $\mathbf{T B}_{\text {fcsv }, \mathbf{d s}}$ ) from low-resolution 885 temperature data, a Gaussian noise with a standard deviation 886 of $1{ }^{\circ} \mathrm{C}$ is added to the kilometric (aggregated ASTER) land 887 surface temperature data set, and a Gaussian noise with a stan- 888 dard deviation of $2 \mathrm{~K}$ is added to the high-resolution brightness 889 temperature data set. An ensemble of 100 data sets is generated 890 and used as input to the disaggregation algorithms.

891

Table VI reports the average and standard deviation of ex- 892 trapolated end-members computed within the ensemble of 100893 artificially perturbed data sets. Results indicate that the method 894 for extrapolating end-members is stable for all end-members. 895 
TABLE VI

Mean and Standard Deviation of Land Surface Temperature AND L-BAND BRIGHTNESS TEMPERATURE END-MEMBERS Extrapolated Using Kilometric TEMPerature Data. For the CONVENIENCE OF THE READER, THE UNIT IS DEgREE CELSIUS FOR RADIOMETRIC TEMPERATURE AND KELVIN FOR BRIGHTNESS TEMPERATURE

\begin{tabular}{|c||c|c|c|}
\hline End-member & Mean & St. dev. & Unit \\
\hline $\mathbf{T}_{\mathbf{b}, \mathbf{d s}}$ & 40.8 & 0.8 & ${ }^{\circ} \mathrm{C}$ \\
$\mathbf{T}_{\mathbf{b}, \mathbf{w s}}$ & 25.7 & 1.5 & ${ }^{\circ} \mathrm{C}$ \\
$\mathbf{T}_{\text {fcgv }}$ & 21.0 & 0 & ${ }^{\circ} \mathrm{C}$ \\
$\mathbf{T}_{\text {fcsv }}$ & 33.1 & 1.3 & ${ }^{\circ} \mathrm{C}$ \\
$\mathbf{T B}_{\mathbf{b}, \mathbf{d s}}$ & 246 & 3.2 & $\mathrm{~K}$ \\
$\mathbf{T B}_{\mathbf{b}, \mathbf{w s}}$ & 193 & 1.4 & $\mathrm{~K}$ \\
$\mathbf{T B}_{\text {fcgv,ws }}$ & 204 & 2.3 & $\mathrm{~K}$ \\
$\mathbf{T B}_{\text {fcgv,ds }}$ & 240 & 1.5 & $\mathrm{~K}$ \\
$\mathbf{T B}_{\text {fcsv,ds }}$ & 281 & 1.0 & $\mathrm{~K}$ \\
\hline
\end{tabular}

TABLE VII

RMSD, Correlation CoefFicient $(R)$, ANd Slope Between the DISAGGREGATED AND ASTER TEMPERATURES FOR THE DATA InCLUding All the 100 ARTificially Noised Data SETS

\begin{tabular}{|c||c|c|c|}
\hline Algorithm & $\begin{array}{c}\text { RMSD } \\
{ }^{\circ} \mathrm{C}\end{array}$ & $\begin{array}{c}\mathrm{R} \\
-\end{array}$ & $\begin{array}{c}\text { Slope } \\
-\end{array}$ \\
\hline D0 & 1.81 & 0.75 & 0.63 \\
D1 & 1.58 & 0.82 & 0.76 \\
D2 & 1.54 & 0.83 & 0.76 \\
D1' & 1.57 & 0.82 & 0.73 \\
D2' $^{\prime}$ & 1.54 & 0.83 & 0.74 \\
D3 $^{\prime}$ & 1.44 & 0.85 & 0.78 \\
D4 $^{\prime}$ & 1.39 & 0.87 & 0.87 \\
D4 $^{\prime \prime}$ & 1.48 & 0.86 & 0.89 \\
\hline
\end{tabular}

896 Table VII lists the RMSD, correlation coefficient, and slope 897 between the disaggregated and ASTER temperatures for all 100 898 data sets. Although the results are generally degraded by using 899 noisy input data sets, D4" is still superior to all other algorithms 900 (see Fig. 9). Therefore, the integration of fractional open water 901 and soil evaporative efficiency into the disaggregation is able to 902 improve the representation of land surface temperature variabil903 ity despite the uncertainties in $f_{\text {ow }}$ and $\beta^{\prime}$, and the uncertainties 904 in extrapolated end-members.

\section{B. Weighting Variability Factors}

906 Results with the NAFE'06 data set have indicated that the 907 new $\mathrm{D}^{\prime}$ algorithms based on radiative transfer significantly 908 improve (in relation to D1 and D2 methods) the representation 909 of disaggregated temperature by directly integrating the various 910 input parameters of the radiative transfer equation. Another ad911 vantage of the proposed methodology is to quantify the weight 912 of these input parameters. Here, the relative weights of $f_{\mathrm{gv}}$, $913 f_{\mathrm{sv}}, f_{\mathrm{ow}}$, and $\beta^{\prime}$ are compared, and the relative improvement in 914 disaggregated temperature when including these factors in the 915 disaggregation is assessed. The weight of $f_{\mathrm{gv}}$ on the variability
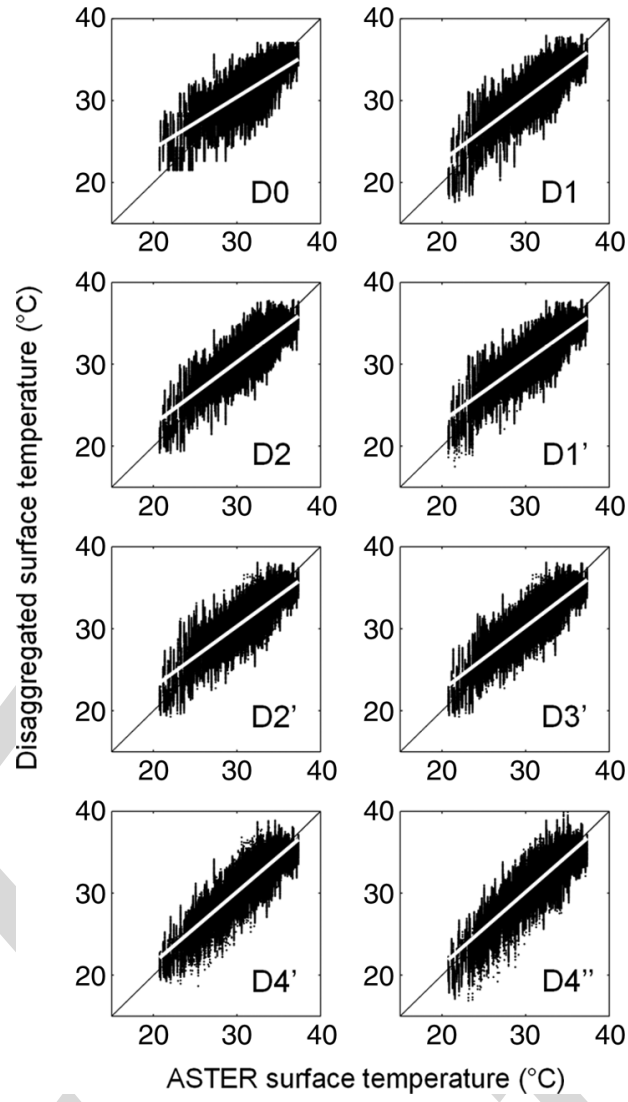

Fig. 9. As for Fig. 7 but using all the 100 artificially noised input data sets.

in land surface temperature is derived by computing the first 916 partial derivative of $T_{\bmod }$ from (15) and (16)

$$
\frac{\partial T_{\text {mod }}}{\partial f_{\mathrm{gv}}}=-\left(1-f_{\mathrm{ow}}\right)\left(\mathbf{T}_{\mathrm{fcsv}}-\mathbf{T}_{\mathrm{fcgv}}\right) .
$$

Similarly, the first partial derivative of $T_{\bmod }$ is computed with 918 respect to $f_{\mathrm{Sv}}$

$$
\frac{\partial T_{\mathrm{mod}}}{\partial f_{\mathrm{sv}}}=-\left(1-f_{\mathrm{ow}}\right)\left[\beta^{\prime} \mathbf{T}_{\mathbf{b}, \mathbf{w s}}+\left(1-\beta^{\prime}\right) \mathbf{T}_{\mathbf{b}, \mathbf{d s}}-\mathbf{T}_{\mathbf{f c s v}}\right]
$$

with respect to $f_{\text {ow }}$

$$
\begin{aligned}
& \frac{\partial T_{\mathrm{mod}}}{\partial f_{\mathrm{ow}}}=-\left[f_{\mathrm{gv}} \mathbf{T}_{\mathbf{f c g v}}+\left(f_{\mathrm{tv}}-f_{\mathrm{gv}}\right) \mathbf{T}_{\mathbf{f c s v}}\right. \\
& \left.\quad+\left(1-f_{\mathrm{tv}}\right)\left(\beta^{\prime} \mathbf{T}_{\mathbf{b}, \mathbf{w s}}+\left(1-\beta^{\prime}\right) \mathbf{T}_{\mathbf{b}, \mathbf{d s}}\right)-\mathbf{T}_{\mathbf{f c g v}}\right]
\end{aligned}
$$

and with respect to $\beta^{\prime}$

$$
\frac{\partial T_{\text {mod }}}{\partial \beta^{\prime}}=-\left(1-f_{\text {ow }}\right)\left(1-f_{\text {tv }}\right)\left(\mathbf{T}_{\mathbf{b}, \mathbf{d s}}-\mathbf{T}_{\mathbf{b}, \mathbf{w s}}\right) .
$$

Table VIII lists the standard deviation of each parameter 922 within the study area, the average of partial derivatives, and the 923 relative weight of each parameter on the variability of modeled 924 land surface temperature. The relative weights of $f_{\mathrm{gv}}, f_{\mathrm{sv}}, f_{\mathrm{ow}}, 925$ and $\beta^{\prime}$ are estimated as the mean partial derivative times the 926 standard deviation. Results indicate that all parameters have a 927 negative impact on $T$. More interestingly, $f_{\mathrm{gv}}$ appears to be 928 the most significant variability factor, with a relative weight 929 of $42 \%$, which is consistent with NDVI-based approaches [4]. 930 
TABLE VIII

Standard Deviation, Mean Partial Derivative, and Impact on High-Resolution Modeled Temperature of Each of the Four Parameters: Fractional Green Vegetation Cover, Fractional Senescent Vegetation Cover, FRACTIONAL OPEN WATER, AND SOIL EVAPORATIVE EFFICIENCY

\begin{tabular}{|c||c|c|c|}
\hline $\begin{array}{c}\text { Factor } \\
-\end{array}$ & $\begin{array}{c}\text { Standard deviation } \\
-\end{array}$ & $\begin{array}{c}\text { Mean partial derivative } \\
{ }^{\circ} \mathrm{C}\end{array}$ & $\begin{array}{c}\text { Impact on } T_{\text {mod }} \text { (percentage of total) } \\
{ }^{\circ} \mathrm{C}(\%)\end{array}$ \\
\hline$f_{\mathrm{gv}}$ & 0.11 & -13 & $0.97(42)$ \\
$f_{\mathrm{sv}}$ & 0.19 & -2.0 & $0.26(11)$ \\
$f_{\text {ow }}$ & 0.06 & -11 & $0.45(20)$ \\
$\beta^{\prime}$ & 0.19 & -4.8 & $0.17(27)$ \\
\hline
\end{tabular}

931 The second and third most significant variability factors are soil 932 evaporative efficiency and fractional open water, with relative 933 weights of $27 \%$ and $20 \%$, respectively. Finally, fractional senes934 cent vegetation cover represents only $11 \%$ of the variability 935 in land surface temperature. The low impact of $f_{\mathrm{Sv}}$ can be 936 associated with the low mean partial derivative. In particular, $937 \partial T_{\bmod } / \partial f_{\mathrm{sv}}$ is low because the temperature difference be938 tween dry bare soil $\left(\mathbf{T}_{\mathbf{b}, \mathbf{d s}}\right)$ and full-cover senescent vegetation $939\left(\mathbf{T}_{\mathbf{f c s v}}\right)$ is also low in our case study.

940 The relative weights in Table VIII are now related with 941 the disaggregation results in Table III. Consequently, the poor 942 improvement of D2 against D1 (and D2' against D1') can be 943 attributed to the relatively low weight of $f_{\mathrm{Sv}}$ in the variability of 944 land surface temperature. Conversely, the significant improve945 ments of D4" against D3', D3' against D2', and D1 (and D1') 946 against D0 are attributed to the large weights of $\beta^{\prime}, f_{\text {ow }}$, and $947 f_{\mathrm{gv}}$, respectively.

948 In summary, the variability of land surface temperature is rea949 sonably represented by model $T_{\bmod }$. Moreover, the approach 950 allows the relative weight of each variability factor to be taken 951 into account in the disaggregation procedure.

\section{SUMmARY AND CONCLUSION}

953 A new disaggregation methodology for land surface tem954 perature has been developed to integrate the main surface 955 parameters involved in the surface energy budget. It is based 956 on a linearized radiative transfer equation, which distinguishes 957 between soil, vegetation, and water temperature, and uses soil 958 evaporative efficiency and fractional senescent vegetation cover 959 to parameterize/estimate soil and vegetation hydric status, re960 spectively. The approach is implemented using four parame961 ters: the fraction of green vegetation cover derived from red 962 and near-infrared bands, the fraction of senescent vegetation 963 cover derived from red and near-infrared bands, the fraction 964 of open water derived from shortwave-infrared band, and the 965 soil evaporative efficiency derived from microwave-L band. 966 It is tested over a $5 \mathrm{~km}$ by $32 \mathrm{~km}$ area of irrigated land in 967 Australia, including flooded rice crops, using ASTER and L968 band airborne data. Low-resolution land surface temperature 969 is simulated by aggregating ASTER land surface tempera970 ture at $1-\mathrm{km}$ resolution, and the disaggregated temperature is 971 compared to high-resolution ASTER temperature. The results 972 indicate that the methodology is able to separate efficiently the 973 independent factors that impact surface temperature and to inte974 grate them consistently into the disaggregation procedure. The error in disaggregated temperature is successively reduced from 975 $1.65{ }^{\circ} \mathrm{C}$ to $1.16{ }^{\circ} \mathrm{C}$ by including each of the four parameters. 976 The correlation coefficient and slope between the disaggregated 977 and ASTER temperatures are improved from 0.79 to 0.89 and 978 from 0.63 to 0.88 , respectively. Moreover, the radiative transfer 979 equation allows quantifying the impact at high resolution of 980 each parameter on land surface temperature. In this case study, 981 fractional green vegetation cover is responsible for $42 \%$ of the 982 variability in disaggregated land surface temperature, fractional 983 senescent vegetation cover for $11 \%$, fractional open water for 984 $20 \%$, and soil evaporative efficiency for $27 \%$.

985

Note that the approach presented in this paper did not take 986 into account the water stress of green vegetation because none 987 of the considered parameters (fractional green vegetation cover, 988 fractional senescent vegetation cover, fractional open water, and 989 soil evaporative efficiency) could describe the hydric status of 990 photosynthetically active (green) vegetation. The analysis was 991 conducted solely in a highly irrigated environment in which 992 vegetation water stress was small. However, in most cases, 993 the vegetation water stress might not be negligible for natural 994 areas. In the presence of water-stressed green vegetation, the 995 scatterplot (temperature versus green vegetation cover) would 996 be transformed into a trapezoidal shape with four vertices 997 rather than a triangle. In such conditions, the disaggregation 998 problem would be partly undetermined since the partitioning 999 between unstressed and stressed green vegetations would not 1000 be represented. Consequently, the approaches shown here are 1001 not expected to be representative of other less extreme environ- 1002 ments than the present irrigated area. Nevertheless, one should 1003 keep in mind that improving the spatial resolution of land 1004 surface temperature data via disaggregation is only relevant in 1005 the conditions where the spatial variability of temperature is 1006 large.

Although the approach was successfully applied to airborne 1008 and satellite data collected during NAFE'06, further research is 1009 needed to test the disaggregation approach on a routine basis. 1010 One may anticipate that fractional green and senescent vege- 1011 tation covers could be derived accurately using FORMOSAT- 1012 like data. The FORMOSAT-2 instrument [52] provides short- 1013 wave data at high spatial resolution $(8 \mathrm{~m})$ and high temporal 1014 frequency (potentially one image per day), which allow a fine 1015 analysis of the seasonality of canopies during the crop cycle 1016 [5], [53], [54]. Fractional open water could be derived from 1017 Landsat-5 data (e.g., [20]). Although the repeat cycle of Landsat 1018 (16 days) is longer than the temporal resolution needed for land 1019 surface temperature, the seasonal variations of water bodies 1020 
1021 such as irrigation canals and flooded fields are expected to 1022 be low. Soil evaporative efficiency could be derived at high 1023 resolution from active microwave sensors, such as the Phased 1024 Array L-band SAR (PALSAR) [55]. Soil evaporative efficiency 1025 formulas express evaporation as a function of normalized sur1026 face soil moisture. Therefore, soil evaporative efficiency is 1027 equivalent to a soil moisture index, which could be replaced 1028 in (20) by the radar-derived soil wetness index computed as 1029 the observed to minimal backscattering coefficient difference 1030 divided by the maximal to minimal backscattering coefficient 1031 difference [56], [57]. Note, however, that the temporal coverage 1032 of the PALSAR fine beam dual polarization mode is relatively 1033 low, with a revisit cycle of 46 days. Consequently, accurate 1034 disaggregation of land surface temperature would still rely on 1035 the availability of high-resolution radar data.

\section{6 \\ ACKNOWLEDGMENT}

1037 The authors would like to thank the NAFE'06 participants 1038 for their participation in collecting this extensive data set.

1039

1040

1041

1042

1043

1044

1045

1046

1047

1048

1049

1050

1051

1052

1053

1054

1055

1056

1057

1058

1059

1060

1061

1062

1063

1064

1065

1066

1067

1068

1069

1070

1071

1072

1073

1074

1075

1076

1077

1078

1079

1080

1081

1082

1083
1084

1085

1086

\section{REFERENCES}

[1] S. Stisen, I. Sandholt, A. Nørgaard, R. Fensholt, and K. H. Jensen, "Combining the triangle method with thermal inertia to estimate regional evapotranspiration-Applied to MSG-SEVERI data in the Senegal River basin," Remote Sens. Environ., vol. 112, no. 3, pp. 1242-1255, Mar. 2008.

2] R. Tang, Z.-L. Li, and B. Tang, "An application of the Ts-VI method with enhanced edges determination for evapotranspiration estimation from MODIS data in arid and semi-arid regions: Implementation and validation," Remote Sens. Environ., vol. 114, no. 3, pp. 540-551, Mar. 2010. doi:DOI:10.1016/j.rse.2009.10.012.

[3] B. Seguin, F. Becker, T. Phulpin, X. F. Gu, G. Guyot, Y. Kerr, C. King, J. P. Lagouarde, C. Ottlé, M. P. Stoll, A. Tabbagh, and A. Vidal, "IRSUTE: A minisatellite project for land surface heat flux estimation from field to regional scale," Remote Sens. Environ., vol. 68, no. 3, pp. 357-369, Jun. 1999.

[4] N. Agam, W. P. Kustas, M. C. Anderson, F. Li, and C. M. U. Neale, "A vegetation index based technique for spatial sharpening of thermal imagery," Remote Sens. Environ., vol. 107, no. 4, pp. 545-558, Apr. 2007.

[5] O. Merlin, B. Duchemin, O. Hagolle, F. Jacob, B. Coudert, G. Chehbouni, G. Dedieu, J. Garatuza, and Y. Kerr, "Disaggregation of MODIS surface temperature over an agricultural area using a time series of FORMOSAT-2 images," Remote Sens. Environ., vol. 114, no. 11, pp. 2500-2512, Nov. 2010. doi:DOI:10.1016/j.rse.2010.05.025.

[6] S. B. Idso, R. D. Jackson, P. J. Pinter, R. J. Reginato, and J. L. Hatfield, "Normalizing the stress-degree-day parameter for environmental variability," Agric. Meteorol., vol. 24, no. 1, pp. 45-55, 1981.

7] R. D. Jackson, S. B. Idso, R. J. Reginato, and P. J. Pinter, "Canopy temperature as a crop water stress indicator," Water Resour. Res., vol. 17, no. 4, pp. 1133-1138, 1981 .

[8] M. S. Moran, T. R. Clarke, Y. Inoue, and A. Vidal, "Estimating crop water deficit using the relation between surface-air temperature and spectral vegetation index," Remote Sens. Environ., vol. 49, no. 3, pp. 246-263, Sep. 1994

[9] O. Merlin, J. P. Walker, J. D. Kalma, E. J. Kim, J. Hacker, R. Panciera, R. Young, G. Summerell, J. Hornbuckle, M. Hafeez, and T. J. Jackson, "The NAFE'06 data set: Towards soil moisture retrieval at intermediate resolution," Adv. Water Resour., vol. 31, no. 11, pp. 1444-1455, Nov. 2008. doi:DOI:10.1016/j.advwatres.2008.01.018.

0] R. Panciera, J. P. Walker, J. D. Kalma, E. J. Kim, J. Hacker, O. Merlin, M. Berger, and N. Skou, "The NAFE'05/CoSMOS data set: Toward SMOS calibration, downscaling and assimilation," IEEE Trans. Geosci. Remote Sens., vol. 46, no. 3, pp. 736-745, Mar. 2008. doi:DOI:10.1109/TGRS.2007.915403.

1] T. Schmugge, T. J. Jackson, W. P. Kustas, R. Roberts, R. Parry, D. C. Goodrich, S. A. Amer, and M. A. Weltz, "Push broom microwave radiometer observations of surface soil moisture in Monsoon '90,' Water Resour. Res., vol. 30, no. 5, pp. 1321-1328, 1994.
[12] M. Abrams, "The Advanced Spaceborne Thermal Emission and 1087 Reflection radiometer (ASTER): Data products for the high spatial res- 1088 olution imager on NASA's Terra platform," Int. J. Remote Sens., vol. 21, 1089 pp. 847-859, 2000.

1090

[13] K. Thome, K. Arai, S. Hook, H. Kieer, H. Lang, T. Matsunaga, A. Ono, 1091 F. Palluconi, H. Sakuma, P. Slater, T. Takashima, H. Tonooka, S. Tsuchida, 1092 R. M. Welch, and E. Zalewski, "ASTER preflight and inflight calibration 1093 and the validation of level 2 products," IEEE Trans. Geosci. Remote Sens., 1094 vol. 36, no. 4, pp. 1161-1172, Jul. 1998.

1095

[14] F. Jacob, F. Petitcolin, T. Schmugge, E. Vermote, A. French, and 1096 K. Ogawa, "Comparison of land surface emissivity and radiometric 1097 temperature derived from MODIS and ASTER sensors," Remote Sens. 1098 Environ., vol. 90, no. 2, pp. 137-152, Mar. 2004.

1099

[15] J. A. Sobrino, J. C. Jiménez-Muñoz, L. Balick, A. R. Gillespie, 1100 D. A. Sabol, and W. T. Gustafson, "Accuracy of ASTER level-2 1101 thermal-infrared standard products of an agricultural area in Spain," 1102 Remote Sens. Environ., vol. 106, no. 2, pp. 146-153, Jan. 2007. 1103 doi:DOI:10.1016/j.rse.2006.08.010.

1104

[16] C. Coll, V. Caselles, E. Valor, R. Niclòs, J. M. Sánchez, J. M. Galve, and 1105 M. Mira, "Temperature and emissivity separation from ASTER data for 1106 low spectral contrast surfaces," Remote Sens. Environ., vol. 110, no. 2, 1107 pp. 162-175, Sep. 2007. doi:DOI:10.1016/j.rse.2007.02.008. 1108

[17] A. French, T. Schmugge, J. Ritchie, A. Hsu, F. Jacob, and K. Ogawa, 1109 "Detecting land cover change at the Jornada Experimental Range, New 1110 Mexico with ASTER emissivities," Remote Sens. Environ., vol. 112, no. 4, 111 pp. 1730-1748, Apr. 2008. doi:DOI:10.1016/j.rse.2007.08.020.

[18] F. Jacob, T. Schmugge, A. Olioso, D. Courault, A. French, K. Ogawa, 1113 F. Petitcolin, G. Chehbouni, A. Pinheiro, and J. Privette, Modeling and 1114 Inversion in Thermal Infrared Remote Sensing Over Vegetated Land Sur- 1115 faces. Advances in Land Remote Sensing, vol. 10, S. Liang, Ed. New 1116 York: Springer-Verlag, 2008.

[19] D. E. Sabol, A. R. Gillespie, E. Abbott, and G. Yamada, "Field val- 1118 idation of the ASTER temperature-emissivity separation algorithm," 1119 Remote Sens. Environ., vol. 113, no. 11, pp. 2328-2344, Nov. 2009. 1120 doi:DOI:10.1016/j.rse.2009.06.008.

[20] T. G. Van Niel, T. R. McVicar, H. Fang, and S. Liang, "Calculating 1122 environmental moisture for per-field discrimination of rice crops," Int. J. 1123 Remote Sens., vol. 24, no. 4, pp. 885-890, 2003.

[21] Y. Liu, T. Hiyama, and Y. Yamaguchi, "Scaling of land surface tempera- 1125 ture using satellite data: A case examination on ASTER and MODIS prod- 1126 ucts over a heterogeneous terrain area," Remote Sens. Environ., vol. 105, 1127 no. 2 , pp. $115-128$, Nov. 2006

[22] Z. Wan and J. Dozier, "A generalized split-window algorithm for retriev- 1129 ing land-surface temperature from space," IEEE Trans. Geosci. Remote 1130 Sens., vol. 34, no. 4, pp. 892-905, Jul. 1996.

[23] G. C. Hulley and S. J. Hook, "Generating consistent land surface tem- 1132 perature and emissivity products between ASTER and MODIS data for 1133 Earth science research," IEEE Trans. Geosci. Remote Sens., vol. 49, no. 9, 1134 pp. 1304-1315, Apr. 2011. doi:DOI:10.1109/TGRS.2010.2063034. 1135

[24] M. Atitar and J. A. Sobrino, "A split-window algorithm for estimating 1136 LST from Meteosat 9 data: Test and comparison with in situ data and 1137 MODIS LSTs," IEEE Geosci. Remote Sens. Lett., vol. 6, no. 1, pp. 122- 1138 126, Jan. 2009. doi:DOI:10.1109/LGRS.2008.2006410.

[25] Y. Liu, Y. Yamaguchi, and C. Ke, "Reducing the discrepancy between 1140 ASTER and MODIS land surface temperature products," Sensors, vol. 7, 1141 pp. 3043-3057, 2007.

[26] O. Merlin, G. Chehbouni, Y. Kerr, E. G. Njoku, and D. Entekhabi, "A 1143 combined modeling and multi-spectral/multi-resolution remote sensing 1144 approach for disaggregation of surface soil moisture: Application to 1145 SMOS configuration," IEEE Trans. Geosci. Remote Sens., vol. 43, no. 9, 1146 pp. 2036-2050, Sep. 2005.

[27] T. Carlson, "An overview of the 'triangle method' for estimating surface 1148 evapotranspiration and soil moisture from satellite imagery," Sensors, 1149 vol. 7, pp. 1612-1629, 2007.

[28] M. C. Anderson, J. M. Norman, G. R. Diak, W. P. Kustas, and J. R. 1151 Mecikalski, "A two-source time-integrated model for estimating surface 1152 fluxes using thermal infrared remote sensing," Remote Sens. Environ., 1153 vol. 60, no. 2, pp. 195-216, May 1997.

[29] O. Merlin and G. Chehbouni, "Different approaches in estimating heat 1155 flux using dual angle observations of radiative surface temperature," 1156 Int. J. Remote Sens., vol. 25, no. 1, pp. 275-289, 2004.

[30] K. Nishida, R. R. Nemani, J. M. Glassy, and S. W. Running, "Develop- 1158 ment of an evapotranspiration index from Aqua/MODIS for monitoring 1159 surface moisture status," IEEE Trans. Geosci. Remote Sens., vol. 41, no. 2, 1160 pp. 493-501, Feb. 2003.

[31] G. Gutman and A. Ignatov, "The derivation of the green vegeta- 1162 tion fraction from NOAA/AVHRR data for use in numerical weather 1163 
prediction models," Int. J. Remote Sens., vol. 19, no. 8, pp. 1533-1543, 1998.

2] J. Noilhan and S. Planton, "A simple parameterization of land surface processes for meteorological models," Monthly Weather Rev., vol. 117, no. 3, pp. 536-549, 1989.

33] D. A. Roberts, M. O. Smith, and J. B. Adams, "Green vegetation, nonphotosynthetic vegetation, and soils in AVIRIS data," Remote Sens. Environ. vol. 44, no. 2/3, pp. 255-269, May 1993.

4] M. Weiss, F. Baret, M. Leroy, A. Begué, O. Hautecoeur, and R. Santer, "Hemispherical reflectance and albedo estimates from the accumulation of across track sun synchronous satellite data," J. Geophys. Res., vol. 104, no. D18, pp. 221-232, 1999.

5] F. Jacob, A. Olioso, M. Weiss, F. Baret, and O. Hautecoeur, "Mapping short-wave albedo of agricultural surfaces using airborne PolDER data," Remote Sens. Environ., vol. 80, no. 1, pp. 36-46, Apr. 2002.

6] F. Jacob, M. Weiss, A. Olioso, and A. French, "Assessing the narrowband to broadband conversion to estimate visible, near infrared and shortwave apparent albedo from airborne PolDER data," Agronomie, vol. 22, no. 6, pp. 537-546, Sep./Oct. 2002.

37] F. Jacob and A. Olioso, "Derivation of diurnal courses of albedo and reflected solar irradiance from airborne PolDER data acquired near solar noon," J. Geophys. Res., vol. 110, no. D10, p. D10 104, May 2005.

38] A. Bsaibes, D. Courault, F. Baret, M. Weiss, A. Olioso, F. Jacob, O. Hagolle, O. Marloie, N. Bertrand, V. Desfond, and F. Kzemipour, "Albedo and LAI estimates from FORMOSAT-2 data for crop monitoring," Remote Sens. Environ., vol. 113, no. 4, pp. 716-729, Apr. 2009. doi:DOI:10.1016/j.rse.2008.11.014.

39] P. M. Barbosa, M. A. Casterad, and J. Herrero, "Performance of several Landsat 5 Thematic Mapper (TM) image classification methods for crop extent estimates in an irrigation district," Int. J. Remote Sens., vol. 17, no. 18, pp. 3665-3674, Dec. 1996.

[40] H. Xu, "Modification of normalized difference water index (NDWI) to enhance open water features in remotely sensed imagery," Int. J. Remote Sens., vol. 27, no. 14, pp. 3025-3033, Jul. 2006.

1] W. P. Kustas, T. J. Schmugge, K. S. Humes, T. J. Jackson, R. Parry, M. A. Weltz, and M. S. Moran, "Relationships between evaporative fraction and remotely sensed vegetation index and microwave brightness temperature for semiarid rangelands," J. Appl. Meteor., vol. 32, no. 12, pp. 1781-1790, Dec. 1993.

42] J. W. Deardorff, "Efficient prediction of ground temperature and moisture with inclusion of a layer of vegetation," J. Geophys. Res., vol. 83, no. C4, pp. 1889-1903, Apr. 1978.

43] P. J. Camillo and R. J. Gurney, "A resistance parameter for bare soil evaporation models," Soil Sci., vol. 141, no. 2, pp. 95-105, Feb. 1986.

4] F. T. Ulaby, R. K. Moore, and A. K. Fung, Microwave Remote Sensing. Active and Passive, vol. 2. Norwood, MA: Artech House, 1982.

5] T. J. Schmugge, "Applications of passive microwave observations of surface soil moisture," J. Hydrol., vol. 212/213, pp. 188-197, Dec. 1998.

6] M. C. Anderson, J. M. Norman, W. P. Kustas, R. Houborg, P. J. Starks, and N. Agam, "A thermal-based remote sensing technique for routine mapping of land-surface carbon, water and energy fluxes from field to regional scales," Remote Sens. Environ., vol. 112, no. 12, pp. 4227-4241, Dec. 2008. doi:DOI:10.1016/j.rse.2008.07.009.

7] L. M. Montandon and E. E. Small, "The impact of soil reflectance on the quantification of the green vegetation fraction from NDVI," Remote Sens. Environ., vol. 112, no. 4, pp. 1835-1845, Apr. 2008. doi:DOI:10.1016/j.rse.2007.09.007.

8] E. G. Njoku and D. Entekhabi, "Passive microwave remote sensing of soil moisture," J. Hydrol., vol. 184, no. 1/2, pp. 101-129, Oct. 1996.

9] J.-P. Wigneron, Y. Kerr, P. Waldteufel, K. Saleh, M.-J. Escorihuela, P. Richaume, P. Ferrazzoli, P. de Rosnay, R. Gurneye, J.-C. Calvet, J. P. Grant, M. Guglielmettih, B. Hornbuckle, C. Matzler, T. Pellarin, and M. Schwank, "L-band Microwave Emission of the Biosphere (L-MEB) model: Description and calibration against experimental data sets over crop fields," Remote Sens. Environ., vol. 107, no. 4, pp. 639-655, Apr. 2007. doi:DOI:10.1016/j.rse.2008.10.014.
[50] K. Saleh, J.-P. Wigneron, P. de Rosnay, J.-C. Calvet, M. J. Escorihuela, 1230 Y. Kerr, and P. Waldteufel, "Impact of rain interception by vegetation and 1231 mulch on the L-band emission of natural grass," Remote Sens. Environ., 1232 vol. 101, no. 1, pp. 127-139, Mar. 2006.

[51] K. Saleh, J.-P. Wigneron, P. Waldteufel, P. deRosnay, M. Schwank, 1234 J.-C. Calvet, and Y. H. Kerr, "Estimates of surface soil moisture under 1235 grass covers using L-band radiometry," Remote Sens. Environ., vol. 109, 1236 no. 1, pp. 42-53, Jul. 2007.

[52] J.-S. Chern, J. Ling, and S.-L. Weng, "Taiwan's second remote sensing 1238 satellite," Acta Astronaut., vol. 63, no. 11/12, pp. 1305-1311, Dec. 2008. 1239 doi:DOI:10.1016/j.actaastro.2008.05.022.

[53] B. Duchemin, O. Hagolle, B. Mougenot, I. Benhadj, R. Hadria, 1241 V. Simonneaux, J. Ezzahar, J. Hoedjes, S. Khabba, M. H. Kharrou, 1242 G. Boulet, G. Dedieu, S. Er-Raki, R. Escadafal, A. Olioso, and 1243 A. G. Chehbouni, "Agrometeorological study of semi-arid areas: An 1244 experiment for analysing the potential of time series of FORMOSAT-2 1245 images (Tensift-Marrakech plain)," Int. J. Remote Sens., vol. 29, no. 17, 1246 pp. 5291-5299, 2008. doi:DOI:10.1080/01431160802036482. 1247

[54] R. Hadria, B. Duchemin, L. Jarlan, G. Dedieu, F. Baup, S. Khabba, 1248 A. Olioso, and T. Le Toan, "Potentiality of optical and radar satellite data 1249 at high spatio-temporal resolutions for the monitoring of irrigated wheat 1250 crops in Morocco," Int. J. Appl. Earth Obs. Geoinf., vol. 12, pp. S32-S37, 1251 Feb. 2010. doi:DOI:10.1016/j.jag.2009.09.003.

[55] A. Rosenqvist, M. Shimada, N. Ito, and M. Watanabe, "ALOS PALSAR: 1253 A pathfinder mission for global-scale monitoring of the environment," 1254 IEEE Trans. Geosci. Remote Sens., vol. 45, no. 11, pp. 3307-3316, 1255 Nov. 2007.

[56] W. Wagner, G. Lemoine, M. Borgeaud, and H. Rott, "A study of vegetation 1257 cover effects on ERS scatterometer data," IEEE Trans. Geosci. Remote 1258 Sens., vol. 37, no. 2, pp. 938-948, Mar. 1999.

[57] R. Fieuzal, B. Duchemin, L. Jarlan, M. Zribi, F. Baup, O. Merlin, 1260 O. Hagolle, and J. Garatuza-Payan, "Combined use of optical and radar 1261 satellite data for the monitoring of irrigation and soil moisture of wheat 1262 crops," Hydrol. Earth Syst. Sci., vol. 15, no. 4, pp. 1117-1129, 2011. 1263 doi:DOI:10.5194/hess-15-117-2011.

Olivier Merlin, photograph and biography not available at the time of 1265 AQ4 publication.

Frédéric Jacob, photograph and biography not available at the time of 1267 publication.

Jean-Pierre Wigneron, photograph and biography not available at the time of 1269 publication.

Jeffrey Walker, photograph and biography not available at the time of 1271 publication.

Ghani Chehbouni, photograph and biography not available at the time of 1273 publication. 


\section{AUTHOR QUERIES}

\section{AUTHOR PLEASE ANSWER ALL QUERIES}

Please be aware that the authors are required to pay overlength page charges ( $\$ 200$ per page) if the paper is longer than 6 pages. If you cannot pay any or all of these charges please let us know.

AQ1 = Please provide the current affiliation (name and specific address of the company) of authors "Frederic Jacob," "Jean-Pierre Wigneron," "Jeffrey Walker," and "Ghani Chehbouni."

AQ2 = The sentence that starts with "It is a three-step procedure..." was modified to properly introduce the list. Please check if the thought is preserved, and correct if necessary.

AQ3 = The caption for Table III was modified. Please check if the thought is preserved, and correct if necessary.

AQ4 = Please provide photo and biography of all authors.

END OF ALL QUERIES 